\title{
Fructosamine : possibilities and limitations in pregnant and non-pregnant subjects
}

Citation for published version (APA):

Salemans, T. H. B. (1990). Fructosamine : possibilities and limitations in pregnant and non-pregnant subjects. [Doctoral Thesis, Maastricht University]. Rijksuniversiteit Limburg. https://doi.org/10.26481/dis.19900216ts

Document status and date:

Published: 01/01/1990

DOI:

10.26481/dis.19900216ts

Document Version:

Publisher's PDF, also known as Version of record

\section{Please check the document version of this publication:}

- A submitted manuscript is the version of the article upon submission and before peer-review. There can be important differences between the submitted version and the official published version of record.

People interested in the research are advised to contact the author for the final version of the publication, or visit the DOI to the publisher's website.

- The final author version and the galley proof are versions of the publication after peer review.

- The final published version features the final layout of the paper including the volume, issue and page numbers.

Link to publication

\footnotetext{
General rights rights.

- You may freely distribute the URL identifying the publication in the public portal. please follow below link for the End User Agreement:

www.umlib.nl/taverne-license

Take down policy

If you believe that this document breaches copyright please contact us at:

repository@maastrichtuniversity.nl

providing details and we will investigate your claim.
}

Copyright and moral rights for the publications made accessible in the public portal are retained by the authors and/or other copyright owners and it is a condition of accessing publications that users recognise and abide by the legal requirements associated with these

- Users may download and print one copy of any publication from the public portal for the purpose of private study or research.

- You may not further distribute the material or use it for any profit-making activity or commercial gain

If the publication is distributed under the terms of Article $25 \mathrm{fa}$ of the Dutch Copyright Act, indicated by the "Taverne" license above, 


\section{Fructosamine}

Possibilities and limitations

in pregnant and non-pregnant subjects 


\title{
Fructosamine
}

\section{Possibilities and limitations in pregnant and non-pregnant subjects}

\author{
Proefschrift
}

ter verkrijging van de graad van doctor aan de Rijksuniversiteit Limburg te Maastricht, op gezag van de Rector Magnificus, Prof.Dr.F.I.M. Bonke, volgens het besluit van het College van Dekanen, in het openbaar te verdedigen op vrijdag 16 februari 1990 om 14.00 uur

door

Thomas Hubertus Bartholomeus Salemans geboren te Maastricht in 1953 
Promotores:

Prof.Dr.P.J. Brombacher

Prof.Dr.J. de Haan

Co-promotores: $\quad$ Dr.M.P. van Dieijen-Visser

Dr.L.L.H. Peeters

Beoordelingscommissie: Prof.Dr.J.A. Flendrig (voorzitter)

Prof.Dr.H.C. Hemker

Prof.Dr.M.J.N.C. Keirse

Prof.Dr.R.H. Kuijten

Prof.Dr.E.A. van der Veen 
Ter nagedachtenis aan mijn vader 


\section{Contents}

Voorwoord

$\begin{array}{ll}\text { Abbreviations } & 11\end{array}$

CHAPTER 1

Introduction

CHAPTER 2

Non-enzymatic glycation of proteins; a review 21

$\begin{array}{ll}2.1 \text { The glycation reaction } & 21\end{array}$

2.2 Non-enzymatic glycation of haemoglobin 23

1 History 23

2 Methods for quantitation of glycated haemoglobin 25

3 Effect of glycation on the haemoglobin function 25

4 Clinical applications of the measurement of glycated haemoglobin 25

1 Glycated haemoglobin and glycaemic control 26

2 Glycated haemoglobin measurement as a screening test for impaired glucose tolerance and diabetes mellitus 28

3 Glycated haemoglobin and pregnancy 30

2.3 Non-enzymatic glycation of serum proteins 33

1 History 33

2 Methods for quantitation of glycated serum proteins 34

3 Effect of glycation on function and metabolism of serum albumin 34

4 Interferences in the measurement of glycated serum proteins 35

1 Effect of protein concentration and protein composition on the measurement of glycated serum proteins 35

2 The influence of protein half-life on the concentration of glycated serum proteins 36

3 Influence of age and sex on the concentration of glycated serum proteins 36

5 Clinical applications of glycated serum protein measurements 37

1 Glycated serum proteins and glycaemic control 38

2 Glycated serum protein measurement as screening test for impaired glucose tolerance and diabetes mellitus 40

3 Glycated serum proteins and pregnancy 42

2.4 Non-enzymatic glycation of other proteins 44 


\section{CHAPTER 3}

The fructosamine assay $\quad 59$

3.1 Principle of the fructosamine assay 59

3.2 Measurement of the serum fructosamine concentration 59

3.3 Evaluation of the assay 60

1 Linearity of the assay; effect of dilution of the sample 60

2 Assay precision 61

3 Effect of freezing, thawing, and long-term storage on the fructosamine concentration $\quad 62$

3.4 Sensitivity to rapid glycaemic change 62

3.5 The influence of variations in the albumin or total protein concentration on the serum fructosamine concentration 63

\section{CHAPTER 4}

Comparison of fructosamine, glycated haemoglobin and postprandial blood glucose concentrations as measures of glycaemic control in noninsulin dependent diabetics

\section{CHAPTER 5}

The value of fructosamine and haemoglobin $A_{1}$ measurements for screening and diagnosis of impaired glucose tolerance, diabetes mellitus and gestational diabetes

\section{CHAPTER 6}

Fructosamine and glycated haemoglobin in normal pregnancy

\section{CHAPTER 7}

The value of fructosamine measurement for the prediction of hyperglycaemia-related adverse neonatal outcome and large-for-gestationalage births

\section{CHAPTER 8}

Summary and conclusions

Samenvatting en conclusies 


\section{Voorwoord}

Het in dit proefschrift beschreven onderzoek is uitgevoerd binnen de afdeling Obstetrie van het De Wever Ziekenhuis te Heerlen in samenwerking met het Klinisch Chemisch Laboratorium en de afdeling Interne Geneeskunde van dit ziekenhuis.

Bij het tot stand komen van dit proefschrift was de hulp van velen onontbeerlijk. Zonder anderen tekort te willen doen, wil ik met name bedanken:

Prof.Dr.P.J. Brombacher en Dr.M.P. Van Dieijen-Visser die de initiators en katalysators waren van de studie. De realisatie van dit proefschrift is voor een belangrijk deel aan hen te danken.

Dr.L.L.H. Peeters die een essentiële bijdrage leverde aan de verwerking en analyse van de onderzoeksgegevens van de zwangeren en het manuscript tevens enkele malen heeft "gescreend", zoals hij placht te zeggen. Zijn uitzonderlijke inzet waardeer ik ten zeerste.

Dr.L.A. Schellekens en Prof.Dr.J. de Haan die beiden op een eigenzinnige manier een belangrijke bijdrage geleverd hebben aan mijn opleiding tot gynaecoloog, mij hebben gestimuleerd tot het doen van onderzoek en mij bovendien de mogelijkheid hebben gegeven om dit proefschrift te schrijven.

De leden van de beoordelingscommissie (Prof.Dr.J.A. Flendrig, Prof.Dr.H.C. Hemker, Prof.Dr.M.J.N.C. Keirse, Prof.Dr.R.H. Kuijten en Prof.Dr.E.A. van der Veen) voor de kritische beschouwing van het manuscript en hun waardevolle adviezen.

De verpleegkundigen van de verloskamer en afdeling obstetrie die te allen tijde bereid waren bij patienten bloed af te nemen en tevens noodzakelijke gegevens verzamelden.

Het personeel van de polikliniek wist steeds weer de zwangeren te motiveren hun medewerking te verlenen aan het onderzoek.

De medewerkers van het klinisch chemisch en haematologisch laboratorium, in het bijzonder mevrouw S.H.C.M. Joosten-Deckers en de heer G.J. Marell voor het nauwgezet coördineren van de analyse van de vele bloedmonsters.

Dr.J. van Pelt, mevrouw M.L.F. Poetschlack-Sieler en mevrouw C.M. Lamine voor het verzorgen van de opmaak van diverse figuren en tabellen.

Dr.J.W.J. Van Wersch onder wiens leiding de bepalingen van geglyceerd haemoglobine werden uitgevoerd.

Dr.B.I. Davies die het manuscript taalkundig corrigeerde.

De patiënten die hun medewerking aan het onderzoek verleenden.

Tenslotte de leden van de maatschap (Dr.J.M.H. Ubachs, Dr.J.E.G.M. Stoot, J.A. Zandvoort, J.E.M. Degen en Dr.M.J. Heineman), die mij in woord en daad steunden. 


\section{Abbreviations}

$\begin{array}{ll}\text { AGA } & \text { appropriate-for-gestational-age } \\ \text { BWR } & \text { birth weight ratio } \\ \text { CV } & \text { coefficient of variation } \\ \text { DM } & \text { diabetes mellitus } \\ \text { DMF } & \text { 1-desoxy-1-morpholinofructose } \\ \text { DNA } & \text { deoxyribonucleic acid } \\ \text { GDM } & \text { gestational diabetes mellitus } \\ \text { GIGT } & \text { gestational impaired glucose tolerance } \\ \text { GSP } & \text { glycated serum protein } \\ \text { HbA } & \text { haemoglobin A } \\ \text { IDDM } & \text { insulin dependent diabetes mellitus } \\ \text { Ig } & \text { immunoglobulin } \\ \text { IGT } & \text { impaired glucose tolerance } \\ \text { LDL } & \text { low-density lipoproteins } \\ \text { LGA } & \text { large-for-gestational-age } \\ \text { NBT } & \text { nitroblue tetrazolium } \\ \text { NIDDM } & \text { non-insulin dependent diabetes mellitus } \\ \text { OGTT } & \text { oral glucose tolerance test } \\ \text { RDS } & \text { respiratory distress syndrome } \\ \text { ROC } & \text { receiver operating characteristic } \\ \text { SD } & \text { standard deviation } \\ \text { SEM } & \text { standard error of the mean } \\ \text { SGA } & \text { small-for-gestational-age } \\ \text { WHO } & \text { world health organization } \\ \end{array}$




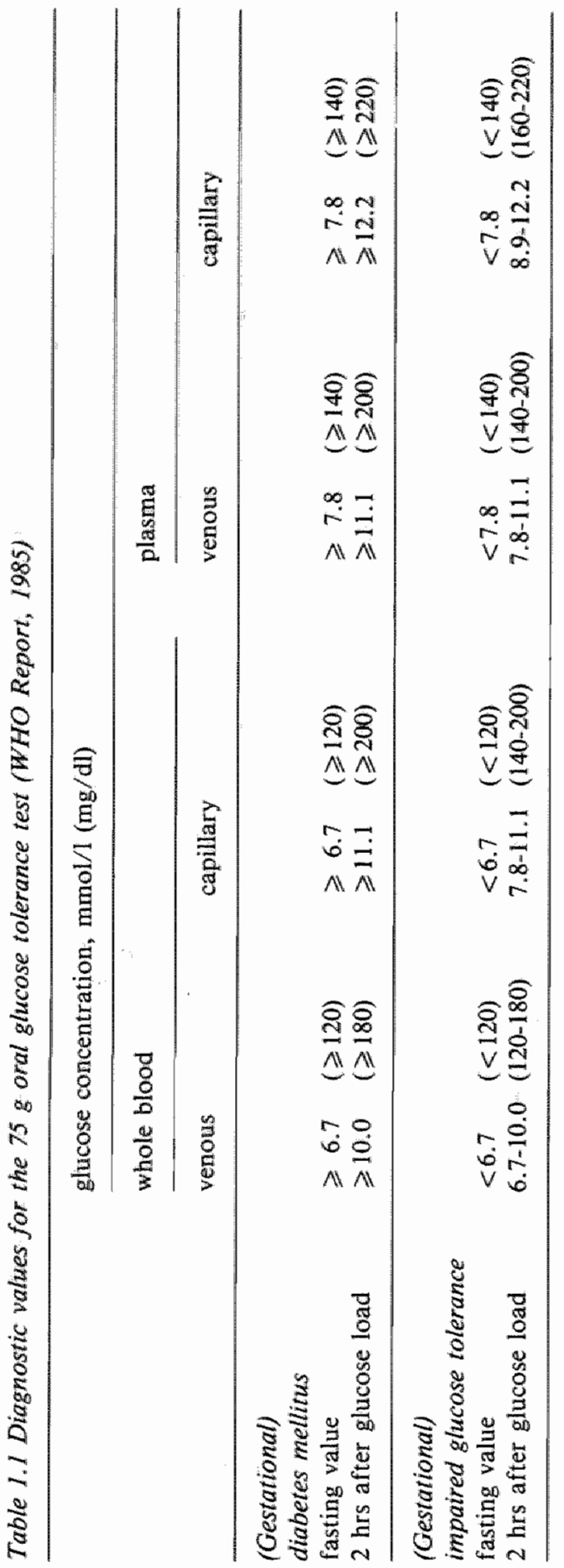


In order to prevent the development of diabetic complications, maintenance of normoglycaemia is crucial. Several controlled prospective trials have provided evidence that long-term near normoglycaemia appears to prevent both severity and progression of late diabetic complications (The Steno Study: Deckert et al., 1983; The Oxford Study: Holman et al., 1983; The Dallas Study: Raskin et al., 1983; The Oslo Study: Dahl-Jorgensen et al., 1986). In the treatment of non-pregnant diabetics it is recommended to aim for fasting venous plasma glucose concentrations between 3.9 and $6.6 \mathrm{mmol} / \mathrm{A}$, corresponding with the normal glucose range in non-diabetics. Furthermore, peaks after meals should not exceed $11.1 \mathrm{mmol} / 1$ (WHO Report, 1985).

Both in known diabetic patients who become pregnant (pregnant diabetics) and in gestational diabetics, maintenance of normoglycaemia improves foetal outcome (O'Sullivan et al., 1973; Gabbe et al., 1977; Coustan and Imarah, 1984). More spe cifically, normoglycaemia in the embryonic period of diabetic pregnancy decreases the incidence of congenital anomalies (Chung and Myrianthopoulos, 1975; Miller et al., 1981; Fuhrmann, 1984), whereas in the second and third trimesters it diminishes the risk of perinatal morbidity and mortality (Karlsson and Kjellmer, 1972; Landon et al., 1987). Optimal treatment of gestational diabetics and pregnant diabetics is best served by maintenance of fasting blood glucose levels between 3.3 and $5.6 \mathrm{mmol} / \mathrm{l}$ with two-hour post-prandial values of less than $7.8 \mathrm{mmol} / \mathrm{l}$ (WHO, 1985; Gillmer et al., 1975).

From the above, it follows that, in order to minimize the risk of typical complications, both early detection and adequate treatment of hyperglycaemia is important. For both purposes the measurement of urinary glucose, blood glucose and glycated proteins has been proposed. However, it has been demonstrated that the measurement of glucose in the urine provides unreliable information about the glycaemic status (Service et al., 1972) and its value as a screening test is also limited (Lind and Hytten, 1972).

The measurement of the blood glucose concentration is commonly used for screen= ing and diagnostic purposes. The information obtained provides a relliable estimate of the actual glycaemic state at the time of blood sampling. Measurements performed in the fasting individual or obtained at random can be used to screen for diabetes mellitus, whereas the outcome of the OGTT is principally used to confirm the diagnosis. However, one should keep in mind that the moderate reproducibility of the OGTT limits its diagnostic value (O'Sullivan and Mahan, 1966; Siperstein, 751975; Kobberling et al., 1980). Besides, the OGTT is expensive and timeconsuming and unpleasant to the patient, who may experience nausea, vomiting, abdominal bloating, and even headache.

With the detection of haemoglobin $\mathrm{A}_{\mathrm{ic}}\left(\mathrm{HbA}_{\mathrm{lc}}\right)$, a non-enzymatically glycated derivate of haemoglobin, a method became available for evaluating the quality of longterm glycaemic control. $\mathrm{HbA}_{\mathrm{ic}}$ is identical in structure to the major component haemoglobin $\mathrm{A}$, except that glucose is attached to the $\mathrm{NH}_{2}$-terminus of the 
$\beta$-chain. Nowadays the measurement of $\mathrm{HbA}_{1}$ is widely accepted as a quantitative index of the average blood glucose concentration over the preceding 6-10 weeks (Koenig et al., 1976; Gonen et al., 1977; Gabbay et al., 1977; Bunn et al., 1978). On the other hand, the value of $\mathrm{HbA}_{1}$ to screen a population for diabetes mellitus. and/or gestational diabetes is still disputed (Lester et al., 1985; Cousins et al., 1984; Morris et al., 1986). Most laboratory techniques for measuring $\mathrm{HbA}_{\mathrm{i}}$ are hampered by the fact that they have shortcomings in the measurement procedure, which may be time-consuming, laborious, expensive, or unsuitable for routine purposes in a clinical laboratory setting.

It has become clear that non-enzymatic glycation is not unique for haemoglobin. In fact, this phenomenon is a common post-translational reaction of all proteins in vivo and in vitro. Next to haemoglobin, non-enzymatic glycation has been observed in serum proteins and in a large number of other body proteins such as eye lens crystallins (Stevens et al., 1978), collagen (Kohn and Schnider, 1982), peripheral nerve proteins (Vlassara et al., 1981), and glomerular basement membrane (Sasser and Poffenbarger, 1983). As non-enzymatic glycation increases as a function of the blood glucose concentration, it has often been speculated that this phenomenon plays an important role in the pathogenesis of chronic complications of diabetes mellitus (Brownlee et al., 1984, 1988; Raskin and Rosenstock, 1986).

The observation that also the glycation of serum albumin and other serum proteins is accelerated in poorly controlled diabetics, led to the introduction of glycated serum protein (GSP) measurement as a new diagnostic tool for glycaemic control (McFarland et al., 1979; Dolhofer and Wieland, 1979, 1980; Yue et al, 1980). GSPs differ from $\mathrm{HbA}_{1}$ in that they reflect glycaemia over a shorter period, i.e. 1-3 weeks (Dolhofer and Wieland, 1980; Hindle et al., 1986; Baker et al., 1984). Therefore, the GSP concentration forms an index of intermediate-term glycaemic control. A number of methods have been developed to quantitate GSPs. Most of these are as laborious, time-consuming, and expensive as is the measurement of $\mathrm{HbA}_{1}$. However, in 1982, Johnson and co-workers described a new colorimetric assay for the measurement of the GSP concentration. This so-called 'fructosamine test', has the advantage of technical simplicity, low cost, and ease of automation using standard laboratory equipment. Therefore, the fructosamine test is the method of choice for measurement of the GSP concentration.

\section{Aim of this study}

The present study was designed to evaluate the possibilities and limitations of fructosamine measurement: 
1. as a screening test to identify patients with impaired glucose tolerance, diabetes mellitus, or gestational diabetes,

2. as a diagnostic test for glycaemic control in diabetics,

3. as a test during pregnancy for the prediction of hyperglycaemia-related adverse neonatal outcome and large-for-gestational-age (LGA) births.

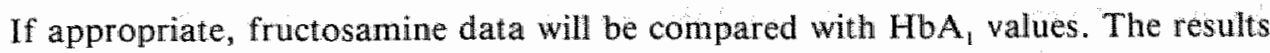
of the study will be preceded by an extensive review of the literature on nonenzymatic glycation of proteins.

\section{References}

Baker JR, Johnson RN, Scott DJ. Serum fructosamine concentrations in patients with type II (noninsulin-dependent) diabetes mellitus during changes in management.

Br Med J 288: 1484-1486, 1984.

Banting FG, Best CH, Collip JB, Campbell WR, Fletcher AA. Pancreatic extracts in the treatment of diabetes mellitus.

Can Med Assoc J 12: 141-146, 1922.

Brownlee M, Vlassara H, Cerami A. Nonenzymatic glycosylation and the pathogenesis of diabetic conplications.

Amn Intern Med 101: 527-537, 1984.

Brownlee M, Cerami A, Vlassara H. Advanced glycosylation end products in tissue and the biochemical basis of diabetic complications.

N Engl J Med 318: 1315-1321, 1988.

Bunn HF, Gabbay KH, Gallop PM. The glycosylation of hemoglobin: relevance to diabetes mellitus. Science 200: 21-27, 1978 .

Chung $\mathrm{CS}$, Myrianthopoulos $\mathrm{NC}$. Effect of maternal diabetes on congenital malformations. Birth Defects vol XI, no 10: 23-37, 1975.

Cousins L, Dattel BJ, Hollingsworth DR, Zettner AZ. Glycosylated hemoglobin as a screening test for" carbohydrate intolerance in pregnancy.

Am J Obsiet Gynecol 150: 455-460, 1984.

Coustan DR, Imarah J. Prophylactic insulin treatment of gestational diabetes reduces the incidence of macrosomia, operative delivery, and birth trama.

Am J Obster Gynecol 150: 836-842, 1984.

Dahl-Jorgensen $\mathrm{K}$. Brinchmann-Hansen $\mathrm{O}$, Hanssen KF, et all. Effect of near normoglycaemla for two years on progression of early diabetic retinopathy, nephropathy, and neuropathy: the Oslo study. Br Med J 293: 1195-1199, 1986. 
Decker T, Caminen I, Parving H, Christensen 35, Steno Study Group. Effect of two years of strict metabolic control on kidney function ir long-term insulin-dependent diabetics.

Diabetch Nephropathy 2:6*10,1983.

Dolhofer $\mathbf{R}$; Wielland OH. Olycosylation of serum abumin: elevated glycosylalbumin in diabetic palientils.

FEBS Let 103: 282:286, 1979

Dollhofer $\mathrm{I}_{\text {. Wheland }}$ OH. Increased glycosylation of serum albumin in diabetes mellitus. Diabetes 29: $417-422,1980$.

Fuhrmaini $\mathbf{K}$. Tight metabolic control during early pregnancy prevents malformation in offspring of insisulin-dependent diabetic women.

In: Peringtal medicine. MTP Press Itd. USA, Clinch J (ed): 259-267, 1984.

Grallowil KH, Masty K, Breslow JL, WLison RC, Bunn MF, Gallop PM. Glycosylated hemoglobins and long-term glucose control in diabetes mellitus.

J Clin Endocrinol Metab 44: 859-864, 1977.

Gabbe SG, Mestman JH, Freeman RK, Anderson GV, Iowensohn RL. Management and outcone of class A diabetes mellitus..

An I Obstet Gynecoll 127:465-69, 1977.

Gillmer MDC, Beard RW, Brooke FM, Oakley NW. Carbohydrate metabolism in pregnancy. Part I Diurnal plasma glucose protile in normal and diabetic pregnancy.

Bur Med J 3: 399-404, 1975 .

Gonen B, Rubenstein AH, Rochman H, Tanega SF, Horwitz DL" Haternoglobin $A_{\text {, }}$, an indicator of the metabolic control of diabetic patients.

Larteet ii: 7344377,1977 .

Hindle EJ, Ripstron GM, Clark SA, Gatt JA. Serum fructosamine and glycated haemoglobin measurements in diabetic control.

Arch Dis Childhood 61: 113-117, 1986.

Holnan RR, Dornan TL, Mayon-White $V$, et al. Prevertion of deterioration of renal and sensoryanerve function by more intensive management of insulin-dependent diabetic patients: a wo-year randomised prospective study.

Lancet: $204-208,1983$.

Johnson RN, Motcalf PA, Bulker JR. fructosamine: a new approach to the estination of serum glycosyl protein. Aru index of dibabetic contuol.

Clin Chim Acta 127: 87-95, 1982.

Karlssion K, Kjellmer 1 . The outcome of diabetic pregnancies in relation to the mother's blood sugar level.

Anf J Obstet Gynecol 112: 213-220, 1972 .

Kobberling $J$, Kerlin $A_{n}$ Creutafeld $W$. The reproducibility of the aral glucose tolerance test over long ( $\$$ years) and short periods (I week).

Klin Wochenschr 58: $527-530,1980$.

Koenig RJ, Peterson CM, Jones RL, Saudek C, Lehrman M, Cerami A, Correlation of glucose regula. tion and hemoglobin $A_{1 c}$ in diabetes mallitus.

N Engl J Mad 295: $417-420,1976$.

Kohn RR, Schnider SL. Olucosylation of human collagen.

Diabetes 31 (suppl 3): 47-51, 1982. 
Landon MB, Gabbe SG, Piana R, Mennuti MT, Main EK. Neonatal morbidity in pregnancy complicated by diabetes mellitus: Predictive value of maternal glycemic profiles:

Am J Obstet Gynec 156: 1089-1095, 1987.

Lester E, Frazer AD, Shephard CA, Woodroffe FJ. Glycosylated haemoglobin as an alternative to the glucose tolerance test for diagnosis of diabetes mellius.

Ann Clin Biochem 22: 7478,1985 .

Lind T, Hytten FE. The excretion of glucose during normal pregnancy.

J Obstet Gynaecol Br Commonw 79: 961-965, 1972.

McFarland KF, Catalano EW, Day JF, Thorpe SR, Baynes JW. Nonenzymatic glucosylation of serum proteins in diabetes mellitus.

Diabetes 28: 1011-1014, 1979.

Miller E, Hare JW, Cloherty JP, et al. Elevated maternal hemoglobin $\mathrm{A}_{1 \mathrm{c}}$ in early pregnancy and major: congenital anomalies in infants of diabetic mothers.

N Engl J Med 304: 1331-1334, 1981.

Morris MA, Grandis AS, Litton J. Glycosylated hemoglobin: a sensitive indicator of gestational diabetes.

Obstet Gynecol 68: 357-361, 1986.

O'Sullivan JB, Mahan CM. Ghucose tolerance test. Variability in pregnant and nonpregnant women. Am $\mathrm{J}$ Clin Nutr 19: 345-351, 1966.

O'Sullivan JB, Charles D, Mahan CM, Dandrow RV. Gestational diabetes and perinatal mortality rate. Am J Obstet Gynecol 116: 901-904, 1973.

Raskin P, Pietra A, Unger R, Shannon WA Jr. The effect of diabetic control on the width of skeletalmuscle capillary basement membrane in patients with type $\mathbb{I}$ diabetes mellitus.

N Engl J Med 309: 1546-1550, 1983.

Raskin P, Rosenstock J. Blood glucose control and diabetic conplications.

Ann Intern Med 105: 254-263, 1986.

Sasser BW, Poffenbarger PL. Nonenzymatic glycosylation of renal tubular basement membrane.

Diabetes 32 (suppl 1): 123, 1983.

Second International Workshop-Conference on Gestational Diabetes Mellitus.

Diabetes, 34 (suppll 2): 123-126, 1985.

Service FJ, Molnar GD "Taylor WF. Urine glucose analyses during contimuous blood glucose monitor. ing.

JAMA 222: 294-298, 1972.

Siperstein MD. The glucose tolerance test: a pitfall in the diagnosis of diabetes mellitus.

Adv Intern Med 20: 297-323, 1975.

Stevens VS, Rouzer CA, Monnier VM, Cerami A. Diabetic cataract formation; potential role of glycosy. lation of lens crystallins.

Proc Natl Acad Sci USA 75: 2918-2922, 1978.

Vlassara H, Browniee $\mathbf{M}$, Cerami A. Nonenzymatic glycosylation of peripheral nerve protein in diabetes mellitus.

Proc Natl Acad Sci USA 78: 5190-5192, 1981. 
WHO. Diabetes mellitus. Report of a WHO study group.

World Health Organization, Geneva. Technical report series $727,1985$.

Yue DK, Morris $K_{*}$ MCLennan S, Turtle JR. Glycosylation of plasma protein and its relation to glycosylated hemoglobin in diabetes.

Diabetes 29: 296-300, 1980. 


\section{Chapter 2}

\section{Non-enzymatic glycation of proteins; a review}

\section{Protein-sugar compounds}

Linkage of a sugar to a protein can be achieved either by enzymatic or nonenzymatic reactions. Because of improper use of the terms glycation, glycosylation and glucosylation in the literature, the IUPAC-IUB Joint Commission on Biochemial Nomenclature decided to define the term 'glycation' as any reaction that links a sugar to a protein, whether catalyzed by an enzyme or not (Roth, 1983).

An example of enzymatic coupling of glucose to proteins is seen in the synthesis of biologically important glycoproteins such as fibrinogen and haptoglobin, in which molecules glucose is linked at a specific site. On the other hand, in the nonenzymatic process, glucose may react with several $\mathrm{NH}_{2}$-groups along any available peptide chain. The non-enzymatic process often has an adverse effect on the structure and thus on the function of the protein. For example, lens crystallins may change through non-enzymatic glycation, resulting in cataract.

\subsection{The glycation reaction}

In 1912 Maillard, a food chemist, was the first to describe the non-enzymatic reaction between glucose and protein. This so-called 'Maillard reaction' is responsible for the browning phenomenon that occurs when milk and other foods are heated; the non-enzymatic reaction between glucose and proteins results in poorly soluble brown products. Until recently, only few biologists recognized that the same reaction is likely to take place in vivo as well, particularly in long-lived proteins (Monnier et al., 1984).

\section{Early glycation products}

The glycation starts with the formation of a Schiff's base by the reaction of the active hydroxyl group of an aldohexose with an available free primary amino group in the protein molecule. The $\mathrm{k}-\mathrm{NH}_{2}$ groups in lysine moieties are often involved in this reaction, leading to formation of relatively unstable Schiff's bases. The kinetics and equilibrium constants of the latter have been studied for human serum albumin (Baynes et al., 1984) and haemoglobin (Higgins and Bunn, 1981) and a remarkable similarity was found. The equilibrium constants were proportional to both the rela- 
tive lysine content and glucose concentration. Steady-state concentrations of Schiff's base are reached within hours.

The formation of the relatively unstable Schiff's base is followed by its decomposition through Amadori rearrangement, giving rise to the formation of the more stable Amadori-type product. The primary 1-imino-1-deoxy-glucose derivate is transformed into a more stable 1-amino-1-deoxy-fructose group which is covalently bound to the protein molecule. The formation of the latter complex has led to the expression 'fructosamines' (figure 2.1).
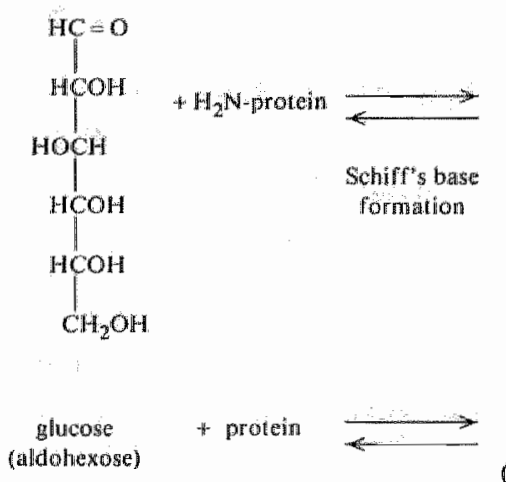

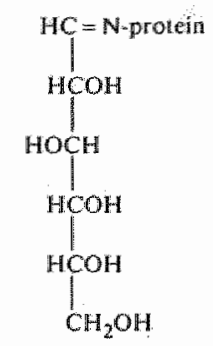

1-(iminoprotein)-1deoxygh hucose (aldimine, Schilr's bage)
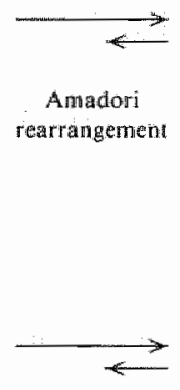

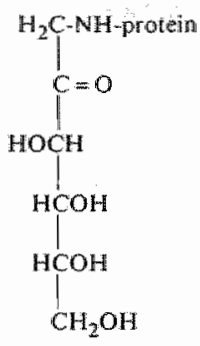

1-(arinoprotein $)-1$ deoxyfructiose (ketoamine. Amadori product)

Figure 2.1 Keroanine formation

Although the kinetics and equilibrium constants for the formation of Schiff's base are similar for albumin and haemoglobin, the rate of formation of the Amadori products is about 4-5 times more rapid for human serum albumin than for haemoglobin (Higgins and Bunn, 1981; Baynes et al., 1984). Therefore, in response to a prolonged elevation in blood glucose, the increase in glycated albumin will precede that in glycated haemoglobin.

Both the Schiff's base formation and the Amadori rearrangement are reversible equilibrium reactions. It follows that the formation of these so-called "early glycation products' reaches a steady-state plateau within a given period of time. The concentration of the early glycation products increases when blood glucose concentrations are high, but returns to normal when blood glucose levels normalize. The early glycation products do not accumulate.

\section{Advanced glycation end products}

Some of the Amadori products on proteins with long half-lives such as lens crystallins, collagen, elastin and myelin do not easily dissociate. Instead, they undergo a further series of slow, complex, irreversible chemical rearrangements and dehydra- 
tions, resulting in formation of so-called 'advanced glycation end products' (Brownlee et al., 1984(a); Cerami et al., 1987). These products can be identified qualitatively by their characteristic brown pigment and fluorescence. The irreversibility of the chemical reaction that leads to the formation of advanced glycation end products implies that the concentration of the latter does not return to normal when hyperglycaemia is corrected. Instead, the products accumulate over the lifetime of proteins, such as for instance on collagen. The rate of this accumulation is proportional to the average blood glucose concentration over an extended period.

In non-diabetics, a linear increase with age in the amount of advanced glycation end products has been demonstrated in dura collagen. In diabetics, these products have been found to accumulate to a larger extent than in non-diabetics (Monnier et al., 1984). In addition, a strong correlation has been reported between accumulated levels of advanced glycation end products in collagen and the severity of diabetic retinopathy (Monnier et al., 1986).

Later in this chapter the probable role of excessive accumulation of advanced glycated end products on biologically important proteins in the pathogenesis of various diabetic complications will be discussed in more detail.

\subsection{Non-enzymatic glycation of haemoglobin}

\subsubsection{History}

Already in 1958 it was demonstrated that 3 minor components could be discerned in human haemoglobin: $\mathrm{HbA}_{\mathrm{la}}, \mathrm{HbA}_{1 b}$ and $\mathrm{HbA}_{\mathrm{lc}}$ (Allen et al., 1958). About 10 years later it was demonstrated that the concentration of one of these components, $\mathrm{HbA}_{1 \mathrm{c}}$, was about 2-3 times higher in diabetics than in non-diabetic controls (Rahbar et al., 1969; Trivelli et al., 1971). Bunn and co-workers (1976) reported that the cause of the increased $\mathrm{HbA}_{\mathrm{Ic}}$ concentration in diabetics was related to abnormal carbohydrate metabolism. The latter workers demonstrated that $\mathbf{H b A}_{\mathrm{fi}}$ was formed by a post-translational reaction between glucose and haemoglobin $\mathrm{A}$. They also presented evidence that glucose was attached to the $\mathrm{N}$-terminal amino group of the $\beta$-chain of haemoglobin A.

Also $\mathrm{HbA}_{1 \mathrm{a}}$ and $\mathrm{HbA}_{1 b}$ are post-translational modifications of $\mathrm{HbA}$ (Bunn et al., 1976). $\mathrm{HbA}_{1 \mathrm{a}}$ and $\mathrm{HbA}_{\mathrm{lb}}$ differ from $\mathrm{HbA}_{1 \mathrm{c}}$ in that either fructose-1-6-phosphate or glucose-6-phosphate is attached to the $\mathrm{NH}_{2}$-terminus of the $\beta$-chain $\left(\mathrm{HbA}_{1 \mathrm{H}}\right)$, or the compound is a deamination product of $\mathrm{HbA}\left(\mathrm{HbA}_{\| \mathrm{b}}\right)$ (table 2.1).

In 1976, Koenig and co-workers made mention of the relation between $\mathrm{HbA}_{1}$ and blood glucose in diabetics. They demonstrated that $\mathrm{HbA}_{1}$ correlated positively with both the daily average blood glucose concentration and the daily urinary glucose loss. The $\mathrm{HbA}_{1}$ concentration was found to correlate better with the mean blood glucose concentration over the preceding 1-3 months than with the actual glu- 
Table 2.1 Haemoghobins and their glycated derivatives in blood of healhy hwan adults

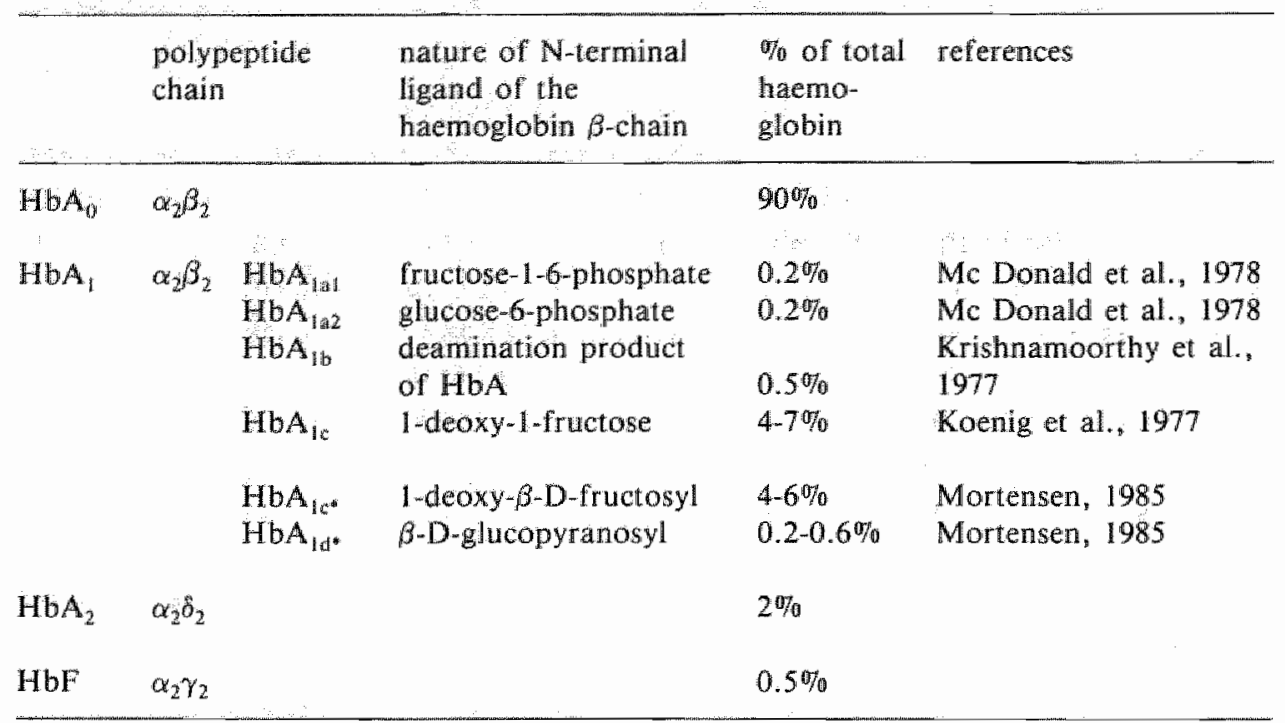

* Classification by Mortensen.

cose level at a single point in time. The authors also noted that accurate metabolic control in diabetics reduced the $\mathrm{HbA}_{1}$ fraction.

Nowadays the measurement of $\mathrm{HbA}_{1}$ in diabetics is widely accepted as an objective and quantitative tool for assessing the time-averaged blood glucose concentration and thus the quality of treatment over the preceding 6-10 weeks (Koenig et al., 1976; Gonen et al., 1977; Gabbay et al., 1977; Bunn et al., 1978).

One of the major controversies among specialists in diabetes mellitus has been the relation between the accuracy of blood glucose control and the risk of developing longterm complications of diabetes mellitus. Although it is obvious to assume that maintenance of nomoglycaemia in diabetics ought to diminish the risk of secondary complications, it has been difficult to obtain conclusive evidence. A reason for the latter may be the lack of adequate means of measuring the accuracy of glycaemic control. Nevertheless, some recent prospective studies have provided evidence that the occurrence of long-term diabetic complications is closely correlated with the quality of glycaemic control based upon the $\mathrm{HbA}_{1}$ value (Holman et al., 1983; Raskin et al., 1983; The Kroc collaborative study group, 1985; Dahl-Jorgensen et al. 1986). 


\subsubsection{Methods for quantitation of glycated haemoglobin}

For the determination of the glycated haemoglobin derivatives, especially $\mathrm{HbA}_{\mathrm{c}}$, various chromatographic, electrophoretic, immunochemical, and photometric methods have been developed. Recently, these methods have been reviewed by Miedema and Casparie (1984).

The development of a whole variety of quantitative methods not only underlines the interest in $\mathrm{HbA}_{1}$, it also demonstrates the lack of superiority of one single method. A major problem of most methods is that they are time-consuming, laborious, and expensive. Some methods are unsuitable for routine use in a clinical chemistry laboratory because automation is not possible. In other methods the presence of Schiff's bases or free glucose influences the final result. Differences in methodology and reference values also complicate the comparison of studies on $\mathrm{HbA}_{1}$. None of the measurement techniques for $\mathrm{HbA}_{1}$ is clearly superior. Usually $\mathrm{HbA}_{1}$ is isolated by either electrophoresis or column chromatography, followed by quantitative photometric measurement.

\subsubsection{Effect of glycation on the haemoglobin function}

In $\mathrm{HbA}_{1 c}$ glucose is covalently bound to the $\mathrm{N}$-terminal valine group of the $\beta$-chain. This site is normally involved in the binding of organic phosphates. 2,3-diphosphoglycerate (2,3-DPG) is an important regulator of intracellular haemoglobin function. Binding of 2,3-DPG to haemoglobin reduces the affinity of haemoglobin for oxygen. Blockage of the $\mathrm{N}$-terminal site of haemoglobin by glycation interferes with the binding of 2,3-DPG. This action leads to a higher oxygen affinity of $\mathrm{HbA}_{\mathrm{tc}}$ as compared to that of $\mathrm{HbA}_{0}$ (Bunn and Briehl, 1970). In compensation, the concentration of 2,3-DPG in the erythrocytes is increased in diabetics, resulting in a decreased affinity of non-glycated haemoglobin $\left(\mathrm{HbA}_{0}\right)$ for oxygen (Ditzel et al., 1975). It is unlikely that the marginal abnormality of the oxygen dissociation curve in diabetics interferes with tissue oxygen transport, as suggested by the small effect on tissue oxygenation observed in patients with mutant haemoglobins, in whom much greater shifts in the oxygen dissociation curve have been demonstrated (Bunn et al., 1978).

\subsubsection{Clinical applications of the measurement of glycated haemoglobin}

The first data on $\mathrm{HbA}_{1 c}$ concentrations in diabetic patients were reported in the early seventies (Trivelli et al., 1971) and a 3-fold higher concentration of $\mathrm{HbA}_{\mathrm{lc}}$ was found in diabetics as compared to a non-diabetic reference group. In 1976, Kocnig and co-workers studied the effects of quality of glycaemic control on the levels of $\mathrm{HbA}_{\mathrm{yc}}$ in diabetic patients. During optimal glycaemic control, the $\mathrm{HbA}$ con- 
centration was clearly lower than in conditions of poor control.

Leslie and associates (1978) reported that 3 of 5 diabetics with an elevated $\mathrm{HbA}_{\text {. }}$ concentration in pregnancy gave birth to children with fatal congenital anomalies, whereas no abnormalities were noted in 20 children born to diabetic mothers with normal $\mathrm{HbA}_{1}$ coneentrations during pregnancy.

The measurement of $\mathrm{HbA}_{1}$ concentration has also been suggested as an alternative to the oral glucose tolerance test for detection of diabetes mellitus (Dods and Bolney, 1979).

These and other results initiated a series of studies to evaluate the clinical usefulness of $\mathrm{HbA}_{4}$ measurements for screening and diagnostic purposes.

\subsubsection{Glycated haemoglobin and glycaemic control}

Since the mid-seventies, measurement of $\mathrm{HbA}_{1}$ has been proposed as an index of diabetic control. For this reason the relation between the $\mathrm{HbA}_{1}$ concentration and a number of other commonly used parameters of diabetic control will be discussed.

\section{Glycated haemoglobin and glucosuria}

The daily urinary glucose loss has been used as an approximation of blood glucose control. This variable correlated with the $\mathrm{HbA}_{1}$ concentration determined 2 months later in insulin-dependent juvenile diabetics (Gabbay et al., 1977; Dunn et al., 1979).

\section{Glycated haemoglobin and the 'clinical impression' of glycaemic control}

The 'clinical impression' of the quality of glycaemic control was also found to correlate with the concentration of $\mathrm{HbA}_{1}$ (Gonen et al., 1977). However, the lack of firm criteria for classifying clinically the quality of metabolic control in the latter study, as well as the inability to confirm these findings in a subsequent study using a well-defined scoring system (Van Heyningen et al., 1986), raises some doubts about the reported correlation.

\section{Glycated haemoglobin and the fasting blood glucose concentration}

It has been suggested that the fasting blood glucose concentration could serve as a reliable index of glycaemic control in patients with non-insulin-dependent diabetes mellitus (NIDDM). Holman and Turner (1979) demonstrated that the pattern in overnight plasma glucose concentrations in lean, diet-treated subjects with NIDDM varied little with time. In addition, they showed that the fasting blood glucose concentration in these patients after an overnight fast correlated closely with diurnal plasma glucose values. Therefore, this so-called 'basal glucose level' was said to provide a convenient estimate of the quality of glucose control in NIDDM (Holman and Turner, 1980).

By comparing the value of $\mathrm{HbA}_{1}$ with that of the fasting blood glucose in the qual- 
ity assessment of glycaemic control, a difference was found between NIDDM and IDDM patients. In NIDDM patients the $\mathrm{HbA}_{1}$ concentration was found to be as reliable as the fasting blood glucose concentration, whereas in IDDM patients the concentration of $\mathrm{HbA}_{1}$ was superior to the fasting blood glucose concentration (Pecoraro et al., 1986; Mosca et al., 1987). The difference is likely to be a result of less stable blood glucose concentrations in IDDM than in NIDDM patients. This instability has a greater impact on the fasting blood glucose concentration than on the $\mathrm{HbA}_{1}$ concentration.

\section{Glycated haemoglobin and the mean blood glucose concentration}

The repeated measurement of blood glucose concentration over one day is a method frequently employed for evaluating glycaemic control in diabetics. A majority of patients with diabetes mellitus measure their own blood glucose concentrations at home by fingerprick and subsequently adjust their insulin dose. This approach has led to a better overall metabolic control. In more or less stable home-controlled IDDM patients, $\mathrm{HbA}_{1}$ was found to correlate well with the mean blood glucose concentration during each of the three preceding months (Paisey et al., 1980). It should be stressed that patient compliance is a prerequisite for obtaining such results in this type of management of diabetes. In fact, discrepancies between homemeasured and hospital-measured blood glucose concentrations do occur and could reflect inadequate patient compliance (Miedema, 1981; Langer and Mazze, 1986). As nowadays home glucose monitoring is a well-accepted way of achieving diabetic control, insight into patient compliance has become important. Occasional $\mathrm{HbA}_{1}$ measurement may provide a satisfactory check on patients" reliability (Miedema and Casparie, 1984).

Although there is general agreement about the fact that a normal $\mathrm{HbA}_{1}$ concentration in diabetics indicates adequate blood glucose control during the preceding 6-8 weeks, one should keep in mind that $\mathrm{HbA}_{1}$ has limited value for the monitoring of short-term changes in glycaemic control. This limitation is due to the kinetic properties of $\mathrm{HbA}_{1}$ with respect to formation and disappearance. The long half-life of $\mathrm{HbA}_{1}$ ( 60 to 90 days) implies that it takes several weeks before an improvement in glucose control will be reflected in a lower concentration of $H \mathrm{Hb} \mathrm{A}_{1}$. On the other hand, since the rate of $\mathrm{HbA}_{1}$ formation exceeds that of its clearance (Higgins and Bunn, 1981), recurrent brief periods of hyperglycaemia may increase the concentration of $\mathrm{HbA}_{1}$ disproportionately. It follows that an elevated concentration of $\mathrm{HbA}_{1}$ does not necessarily reflect continuous poor glycaemic control, but may also be the result of brief periods of poor glycaemic control in the preceding weeks. Inasmuch as glucose control is more stable in NIDDM than in IDDM, measurement of $\mathrm{HbA}_{1}$ in the former group correlates better to other parameters of glucose control than in the latter group. 
2.2.4.2 Glycated haemoglobin measurement as a screening test for impaired glucose tolerance and diabetes mellitus

The relationship between $\mathrm{HbA}_{1}$ and the glycaemic state thas led various investigators to evaluate the possibilities of $\mathrm{HbA}_{\mathrm{t}}$ measurement as a screen for diabetes mellitus in an entire population. Comparison of earlier studies on the relation between $\mathrm{HbA}_{1}$ and OGTT is hampered by the lack of standardization in performance and classification of the OGTT. However, the increasing acceptance of WHO recommendations on this matter has improved the comparability of more recent studies.

Lester and co-workers (1985) compared the results of the OGTT (WHO criteria) and the $\mathrm{HbA}_{1}$ concentration in 168 subjects suspected of diabetes mellitus. The value of $\mathrm{HbA}_{1}$ for screening purposes was determined from their data by calculating the sensitivity, specificity, and positive and negative predictive values (table 2.2 and table 2.3). The sensitivity and specificity of the $\mathrm{HbA}_{i}$ concentration for identifying patients with diabetes mellitus were good $(96 \%$ and $97 \%$ respectively).

Table 2.2 Evaluation of a screening test

\begin{tabular}{|c|c|c|}
\hline & Subjects with disease & Subjects without disease \\
\hline Positive (abnormal) tesi & True positives (TP) & False positives (FP) \\
\hline Negative (normal) test & False negatives (FN) & True negatives (TN) \\
\hline Sensitivity & $=\frac{\mathrm{TP}}{\mathrm{TP}+\mathrm{FN}} \times 100 \%$ & \\
\hline Specificity & $=\frac{\mathrm{TN}}{\mathrm{TN}+\mathrm{FP}} \times 100 \%$ & \\
\hline Positive predictive value & $=\frac{\mathrm{TP}}{\mathrm{TP}+\mathrm{FP}} \times 100 \%$ & \\
\hline Negative predictive value & $=\frac{\mathrm{TN}}{\mathrm{TN}+\mathrm{FN}} \times 100 \%$ & \\
\hline Prevalence & $=\frac{T P+F N}{T P+F N+F P+T N} \times 100 \%$ & \\
\hline
\end{tabular}

Recently, Little and co-workers (1988) evaluated the value of $\mathrm{HbA}_{4}$ as a screening test for diabetes mellitus in 381 Pima indians. An OGTT on the base of WHO standards was performed in all subjects. Table 2.3 shows that the results differed from the results of Lester and co-workers (1985) as well as from our own results (Salemans et al., 1987). The differences between the sensitivity and specificity may be 
the result of different, arbitrarily chosen, cut-off values (upper limit of normal range) and of a different incidence and/or degree of abnormal glucose tolerance in the population studied. Optimal cut-off values can be obtained by constructing a receiver operating characteristic curve ( $R O C)$. This curve is a graphical presentation of sensitivity plotted against specificity for different cut-off values. In chapter 5 we will report on this method and its application for assessment of the cut-off value of $\mathrm{HbA}_{1}$ in screening for diabetes mellitus.

Table 2.3 Value of HbA, measurement as screening test for diabetes mellitus (DM) and impaired glucose tolerance (IGT)

\begin{tabular}{|c|c|c|c|}
\hline & $\begin{array}{l}\text { Lester } \\
1985\end{array}$ & $\begin{array}{l}\text { Little } \\
1988\end{array}$ & $\begin{array}{l}\text { Salemans } \\
1987\end{array}$ \\
\hline 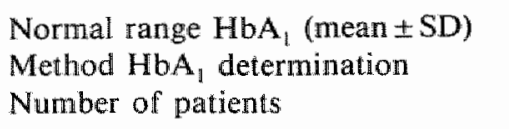 & $\begin{array}{l}5.92 \pm 1.05 \\
\text { Electrophoresis } \\
168\end{array}$ & $\begin{array}{l}5.05 \pm 0.50 \\
\text { HPLC } \\
381\end{array}$ & $\begin{array}{l}6.7 \pm 0.95 \\
\text { Microcolumn } \\
183\end{array}$ \\
\hline $\begin{array}{ll}\text { Sensitivity }(\%) & \text { for DM } \\
& \text { for DM and IGT }\end{array}$ & $\begin{array}{l}96 \\
82\end{array}$ & $\begin{array}{l}85 \\
63\end{array}$ & $\begin{array}{l}67 \\
44\end{array}$ \\
\hline Specificity $(\%)$ & 97 & 91 & 97 \\
\hline $\begin{aligned} \text { Positive PV }(\%) & \text { for DM } \\
& \text { for DM and IGT }\end{aligned}$ & $\begin{array}{l}96 \\
94\end{array}$ & $\begin{array}{l}73 \\
91\end{array}$ & $\begin{array}{l}82 \\
88\end{array}$ \\
\hline $\begin{array}{l}\text { Negative PV }(\%) \text { for DM } \\
\text { for DM and. IGT }\end{array}$ & $\begin{array}{l}98 \\
91\end{array}$ & $\begin{array}{l}92 \\
64\end{array}$ & $\begin{array}{l}97 \\
82\end{array}$ \\
\hline
\end{tabular}

- The upper limit of a normal $\mathrm{HbA}_{1}$ concentration was defined as $2 \mathrm{SD}$ above the mean of the reference popullation.

- The OGTTs were performed and classified according to WHO criteria (1985).

- PV: predictive value.

- HPLC: high pressure liquid chromatography.

From the results of several studies (as listed in table 2.3) it can be concluded that the $\mathrm{HbA}_{\mathrm{i}}$ measurement has little value when used to detect IGT, whereas its value for detecting DM is better, but also not conclusive.

It is not surprising that $\mathbb{G T}$ can not be detected by $\mathrm{HbA}_{1}$ measurement since the two parameters measure quite different aspects of glucose metabolism. An abnormal OGTT, especially IGT, reflects a temporary elevation of the blood glucose concentration after a non-physiological glucose load. These patients may be normoglycaemic on their own dietary regimen and therefore the $\mathrm{HbA}_{1}$ concentration may remain within the normal range. Moreover, one should keep in mind that the OGTT may also be occasionally abnormal due to transient conditions such as medication, illness or stress. Because of the latter and many other factors, the OGTT has a moderate reproducibility (O'Sullivan and Mahan, 1966; Siperstein, 1975; 
Kobberling et al., 1980; Cummings and Fraser, 1988). It is concluded that HbA, measurement is an imperfect method for identifying IGT or DM.

The most important reason to identify diabetics as early as possible is to start early with treatment, thus diminishing the risk of long-term sequelae (Brownlee et al., 1984(a), 1988; Raskin and Rosenstock, 1986). Only hyperglycaemic patients need treatment, irrespective of the outcome of an OGTT. The fact that a patient with an elevated $\mathrm{HbA}_{1}$ concentration will generally be hyperglycaenic and a patient with an abnormal OGTT may be normoglycaemic, suggests that measurement of $\mathrm{HbA}_{1}$ may be more appropriate than the OGTT for selecting the target population.

\subsubsection{Glycated haemoglobin and pregnancy}

Measurement of $\mathrm{HbA}_{1}$ may be useful in several conditions during pregnancy. The $\mathrm{HbA}_{1}$ concentration has been recommended for use in screening for gestational diabetes and for identifying patients with hyperglycaemia-related increased risk of major congenital anomalies, macrosomia, perinatal morbidity and perinatal mortality.

\section{Glycated haemoglobin in normal pregnancy}

In order to evaluate the usefulness of $\mathrm{HbA}_{1}$ measurement during pregnancy it is necessary to be informed about the normal pattern throughout pregnancy. The pattern of the $\mathrm{HbA}_{1}$ concentration in pregnancy has been studied cross-sectionally (Lind and Cheyne, 1979; Phelps et al., 1983) and longitudinally (Hanson et al, 1983; Worth et al., 1985; Griffiths et al., 1987). The results of these studies indicate that the $\mathrm{HbA}_{1}$ concentration decreases slightly in the first half of pregnancy, to reach its lowest value between 17 and 24 weeks. Towards term, the $\mathrm{HbA}_{1}$ concentration has been reported either to remain low (Lind and Cheyne, 1979; Hanson et al., 1983) or to increase again gradually (Phelps et al., 1983). Our own data on this subject will be presented in chapter 6 .

The slight decrease of the $\mathrm{HbA}_{1}$ concentration in the first half of pregnancy, reported in most studies, may be related to a small reduction in the mean blood glucose concentration during normal early pregnancy (Lind et al., 1973; Gillmer et al., 1975). It may also be related to the increase of the total erythrocyte volume after the 10th week of pregnancy (Hytten and Lind, 1973). The rise in red cell volume in early pregnancy is associated with a rise in the proportion of young cells. These young cells contain less $\mathrm{HbA}_{1}$ than the older cells because of shorter exposure time to glycation. Because of this phenomenon the $\mathrm{HbA}_{\mathrm{L}}$ concentration may also
decrease.

The observations on the trend of the $\mathrm{HbA}_{1}$ concentration in the second half of pregnancy are less uniform. Nevertheless, it seems that the $\mathrm{HbA}_{4}$ concentration changes together with the fasting blood glucose concentration. The differences in the $\mathrm{HbA}$, pattern in late pregnancy are probably related to the fact that different 
populations have been investigated, as indicated by the concomitant differences in fasting glucose concentrations.

\section{Glycated haemoglobin as a screening test for gestational diabetes}

It is generally accepted that early identification and treatment of gestational diabetes is important for preventing the development of the well-known complications, particularly macrosomia (Gabbe et al., 1977(a); Coustan and Imarah, 1984; Widness et all, 1985). The lack of agreement about which screening procedure should be employed led to a number of studies to determine the screening value of $\mathrm{HbA}_{1}$ with respect to gestational diabetes. In several studies the ability of $\mathbf{H b A}_{1}$ to identify the gestational diabetics, defined according to O'Sullivan's criteria, was found to be disappointing, as indicated by a low sensitivity and specificity (Cousins et al., 1984; Artal et al., 1984). To our knownledge, in only one study (Morris et al., 1986(a)) were these particular patients indeed identified satisfactory on the basis of an elevated $\mathrm{HbA}_{1}$ concentration between the 10 th and 15 th weeks of gestation. However, in this study the authors did not evaluate a general population but a population selected on the base of an abnormal OGTT. The results of a study from our group (Salemans et al., 1987; chapter 5) are in agreement with those reported by most investigators on this matter, namely that $\mathrm{HbA}_{1}$ routinely measured in a pregnant population is an inadequate screening test for gestational diabetes.

\section{Glycated haemoglobin and congenital anomalies}

The incidence of spinal anomalies (including the caudal regression syndrome), situs viscerum inversus, skeletal malformations, pseudohermaphroditism, urological anomalies, and heart anomalies has been found to be significantly higher in foetuses of diabetics than in those of a reference non-diabetic population (Kucera, 1971; Chung and Myrianthopoulos, 1975; Milunsky et al., 1982).

Developmental morphological dating shows that the malformations which occur more frequently in the offspring of diabetic women are related to a developmental disturbance which occurs before the seventh week of gestation (Mills et al., 1979). Although the pathogenetic mechanisms responsible for the high incidence of congenital anomalies among the infants of diabetic mothers are still poorly understood at this moment, there is growing evidence that poor glycaemic control in early pregnancy plays a crucial role in this respect. This does not exclude the contribution of hereditary factors to diabetic teratogenesis. In rat experiments, congenital anomalies were found to result from a teratogenic insult in a genetically predisposed organism (Eriksson, 1986). The relation between the higher incidence of spontaneous abortion in patients with an elevated $\mathrm{HbA}_{1}$ concentration during early pregnancy, provides additional support for the concept that poor glycaemic control is associated with a teratogenic effect (Key et al., 1987).

Leslie and associates (1978) observed in a small population sample that the earlypregnancy $\mathrm{HbA}_{1}$ concentrations had been elevated in diabetic women giving birth 
to babies with congenital anomalies. These observations have been confirmed in various studies (Miller et al., 1981; Fuhrmann, 1984; Key et al.; 1987; Lips, $1988(a))$, the results of which suggest that the incidence of malformations is proportional to the degree of elevation in $\mathrm{HbA}_{1}$ level during the first trimester of pregnancy (table 2.4).

Table 2.4 Relation between the glycated haemoglobin percentage in the first trimester of diabetic pregnancy and the malformation rate in the offspring
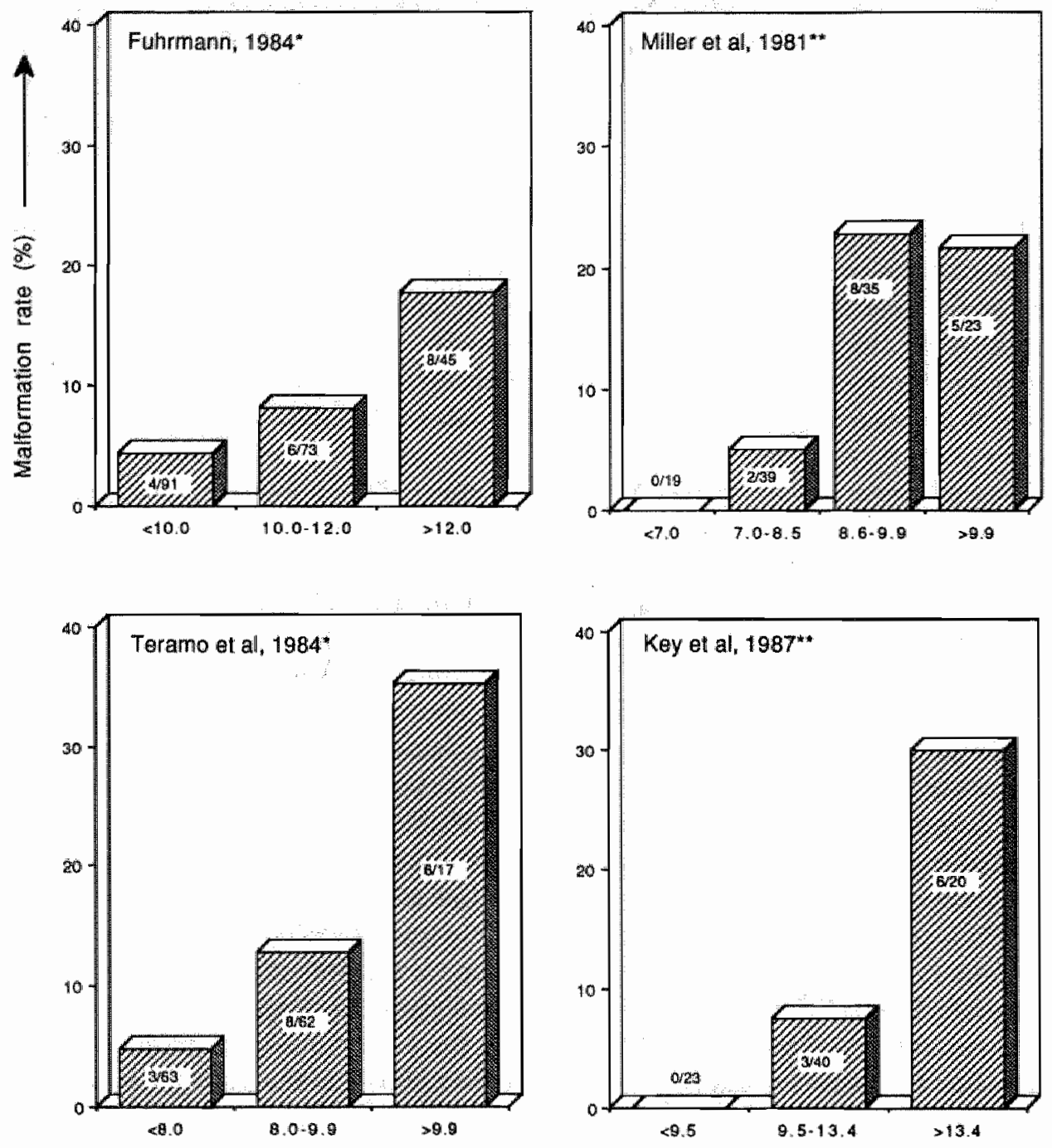

$\mathrm{HbA1}(\%)$ in first trimester of diabetic pregnancy

* Major and minor malformations

*** Major malformations 
The data stress the importance of meticulous control of the glycaemic state in diabetics already before conception in order to minimize the risk of congenital malformation and/or spontaneous abortion. In the first trimester of diabetic pregnancy, the measurement of $\mathrm{HbA}_{1}$ seems to provide information both on the average glucose level during the period of organogenesis and on the risk of malformation of the foetus.

\section{Glycated haemoglobin and birth weight}

Foetal macrosomia is a well-known feature of diabetic pregnancy (Gabbe et al., 1977 (b); Kitzmiller et al., 1978; Lips, 1988(b)). Pedersen (1977) and later Abell (1979) and Widness and co-workers (1978) suggested that maternal hyperglycaemia leads to foetal hyperglycaemia which, in turn, affects intra-uterine growth and development. While several authors have laid emphasis on the description of the relationship between maternal hyperglycaemia and foetal macrosomia, others described the effect of rigid glucose control in diabetic pregnancy on birtly weight (Gyves et al., 1977; Landon et al., 1987). However, since rigid maternal glucose control during diabetic pregnancy does not always prevent macrosomia, factors other than those in glucose handling may contribute to the development of foetal macrosomia (Kalkhof, 1985; Moore et al., 1987).

The relation between the quality of maternal glycaemic control and foetal growth led several investigators to study the relation between the $\mathrm{HbA}_{1}$ concentration and the infant's birth weight. Hanson and associates (1983) were unable to find a correlation in 19 non-diabetic pregnant women between the first trimester $\mathrm{HbA}_{1}$ concentration and relative birth weight (i.e. actual birth weight in percent of the anticipated 50th percentile weight, adapted for gestational age and sex). In contrast, Morris and associates (1985(a)) reported a higher incidence of large-for-gestational-age (LGA) infants in both non-diabetic and diabetic women when the $\mathrm{HbA}_{1}$ level in the first trimester of pregnancy had exceeded $7 \%$. In both pregnant diabetics and gestational diabetics, the third trimester $\mathrm{HbA}_{1}$ concentrations (Widness et al., 1978) and the $\mathrm{HbA}_{1}$ concentrations during labour (Faclel et al. „1986) were also found to correlate with birth weight. Such a relation was not found in a control group of women with normal glucose tolerance during pregnancy (Fadel et al., 1986; Bacigalupo et al., 1984).

In summary, in diabetics neonatal macrosomia seems to occur more often when the $\mathrm{HbA}_{1}$ concentration has been elevated during the preceding pregnancy.

\subsection{Non-enzymatic glycation of serum proteins}

\subsubsection{History}

Non-enzymatic glycation has been shown to occur in a large number of proteins including serum proteins. Glycation of albumin had already been observed in the 
horse in 1956 (Micheel and Klemer, 1956), but not until the mid-seventies was its clinical importance recognized. In 1979, glyeated rat and human albumin were prepared in-vitro, whereas the natural occurrence of glycated albumin was demonstrated for the human (Dolhofer and Wieland, 1979; Day et al., 1979). In the same period it was demonstrated that glycation of serum proteins was increased in diabetics (McFarland et al., 1979). In the latter study it was also demonstrated that the fractional glycation of albumin correlated closely with that of total serum proteins and that the concentration of these glycated proteins varied as a function of the fasting glucose concentration. Dolhofer and Wieland (1980) provided evidence that the level of glycated albumin was dependent upon the blood glucose concentration. The recognition of the potential clinical importance of the GSP measurement in the management of diabetes mellitus (Kennedy et al., 1981) and the introduction of a simple method for its measurement (Johnson et al., 1982) aroused interest in the determination of GSP in various clinical conditions.

\subsubsection{Methods for quantitation of glycated serum proteins}

Many different methods; recently reviewed by Armbruster (1987), have been developed to quantitate non-enzymatic GSPs.

A major disadvantage of the phenylhydrazine procedure (Ghiggeri et al., 1986) for use in a clinical chemistry laboratory is the interference of Schiff's base with the assay. The furosine procedure (Schleicher and Wieland, 1981; Schleicher et al., 1984) is claimed to be rapid, specific, sensitive and precise. However, the required 18-hours hydrolysis step is a major drawback for routine use in the laboratory. The measurement of GSPs by affinity chromatography (Brownlee et al., 1980; Yatscoff et al., 1984) is not widely used in the clinical laboratory. Routine use of this relatively simple method is obstructed by the time-consuming assay involved with little chance of automation. The thiobarbituric acid colorimetric procedure is precise and semi-automated (Moore et al., 1986), but analysis time and the number of steps make it cumbersome. In 1982 a new colorimetric assay was introduced for measurement of GSPs. This so-called 'Fructosamine test' is simple, cheap and automated (Johnson et al., 1982). Because of its precision and ease of performance, this method is now generally used for the measurement of GSPs in the clinical chemistry laboratory. In chapter 3 various aspects of this test will be discussed.

\subsubsection{Effect of glycation on function and metabolism of serum albumin}

The human serum proteins are continuously modified by glycation but this phenomenon occurs at a higher rate in diabetics than in non-diabetics. Also albumin, which is the most abundant protein in human serum, is subject to nonenzymatic glycation. Inherent in non-enzymatic glycation of a protein is often a 
change in its chemical, physical and biological properties. Using a fluorescence technique, Shaklai and co-workers (1984) demonstrated that non-enzymatic glycation of human albumin leads to a change in the configuration of the mollecule.

Glycation of albumin has been associated with a change in its affinity for drugs and for bilirubin. I $n$ vitro, it has been demonstrated that salicylate (Mereish et al., 1982) and bilirubin (Shaklai et al., 1984) binding is reduced in glycated albumin when compared to non-glycated albumin. However, this phenomenon appears to have little clinical impact since, in wivo, this effect has not yet been observed at the highest possible degree of glycation.

Glycation of proteins may also lead to an increased clearance rate of these proteins. However, data on the half-life of glycated albumin are conflicting and to our knowledge have only been obtained in laboratory animals. In rats, the half-life of glycated albumin was similar to that of non-glycated albumin (Day et al., 1979), whereas in dogs the half-life of glycated albumin was lower than that of non glycated albumin (Morris and Preddy, 1986(b)).

In animal studies several biological properties of albumin are found to be affected by glycation. However, for the time being, we do not have any evidence that in hu* mans (even in poorly controlled diabetics) non-enzymatic glycation of albumin interferes with its normal physiological function.

\subsubsection{Interferences in the measurement of glycated serum proteins}

Variables other than glucose may interfere with the measurement of GSPs. Several of these factors will be discussed in this paragraph.

2.3.4.1 Effect of protein concentration and protein composition on the measurement of glycated serum proteins

Several authors studied the effect of variations in albumin and total protein concentration on the fructosamine concentration. Under normal conditions, fructosamine varied independently of both the albumin and the total protein concentrations. However, in patients with uncompensated nephrotic syndrome, in whom serum albumin concentrations had decreased to below $30 \mathrm{~g} / 1$, the fructosamine concentrations were significantly lower than in normal subjects (Baker et al., 1983). Similar results have been reported in more recent studies (Lloyd and Marples, 1984; Hindle et al., 1985; Howey et al., 1987). Our own results on this subject will be presented in chapter 3. There is general agreement that correction of fructosamine is not needed when the albumin concentration exceeds $30 \mathrm{~g} / 1$ since the magnitude of the correction would be smaller than the intra-assay error of both the fructosamine and the protein measurements. 
Glycation of various serum proteins has been studied ever since the discovery of increased levels of glycated serum albumin in diabetics. It has become evident that, besides albumin, other serum proteins are also subject to non-enzymatic glycation. Incubation of freshly prepared serum with radioactive glucose resulted in binding of radioactivity not only to albumin but also to other serum proteins (Dolhofer and Wieland, 1979; Schleicher et al., 1984; Mosca et al., 1987). Per gram of protein, radioactivity was highest in the albumin and $\alpha_{i}$-globulin fraction, followed by the $\gamma$-globulin fraction. Approximately $78 \%$ of the serum-protein-bound radioactivity was recovered from the albumin fraction. On a molecular base, Mosca and co-workers (1987) observed the following fractional glycation for each protein: albumin $100 \%$, total immunoglobulins $76.2 \%$, transferrin $38.1 \%$ and $\alpha_{2}$-macroglobulin $14.3 \%$.

It can be concluded that many GSPs contribute to the total amount of ketoamine linkages. Glycated albumin contributes most to the total GSP concentration because of its large fractional contribution to the serum proteins. Moreover, albumin may comprise more ketoamine linkages per molecule than other much larger serum protein molecules. Therefore, a change in the albumin concentration may influence the GSP concentration, whereas increases or decreases in the concentrations of other serum proteins have little effect on the GSP concentration.

2.3.4.2 The influence of protein half-life on the concentration of glycated serum proteins

Proteins with short half-lives are generally less glycated than those with long halflives, due to shorter exposure to glucose. In patients with a normal protein metabolism, the influence of protein half-lives on the GSP concentration is constant unless serum protein turnover changes. For example, in thyrotoxic patients with accelerated protein turnover, the GSP concentration was lower than in euthyroid controls, whereas the opposite effect was observed in hypothyroid patients (Lloyd and Marples, 1986). Since the protein and glucose concentrations in these groups were comparable, these changes are likely to be related to differences in protein turnover. From the above it is concluded that GSP levels in patients with an abnormal serum protein turnover should be unterpreted with caution.

\subsubsection{Influence of age and sex on the concentration of glycated serum proteins}

Introduction of the GSP measurement for screening and diagnostic purposes should be preceded by an evaluation of the effect of age and sex on the concentration of GSP.

Sex-dependency could not be demonstrated either in 111 children aged between one and eighteen years (Krause et al., 1987) or in 145 non-diabetic adults (Lim and Staley, 1985). 
There are conflicting data concerning the relationship between the GSP concentration and age, with some investigators reporting similar values in children and in adults (Allgrove and Cockrill, 1988), whereas others have observed lower values in children (Hindle et al., 1986; Krause et al., 1987). In a study in 3664 non-pregnant volunteers, the GSP concentration was found to increase gradually during the first fifteen years of life (Roberts and Baker, 1986). There was no further change between twenty and and fifty years (figure 2.2). The lower GSP concentration in children can be caused by their higher protein turnover rate (James, 1978).

Figure 2.2 Relation between serwm fructosamine concentration and age in 3664 non-pregmant women. Hatched area is the reference interval (Roberts and Baker, 1986) (with permission)

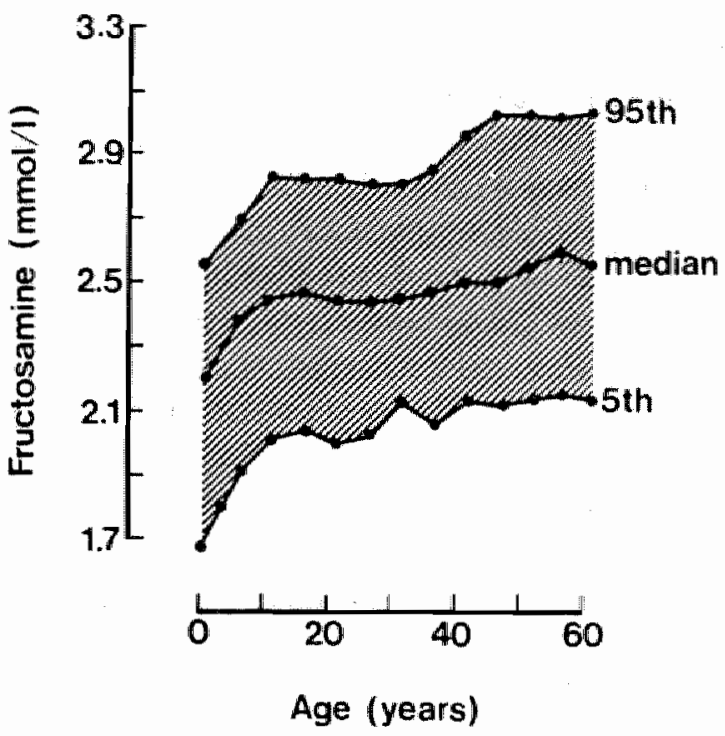

\subsubsection{Clinical applications of glycated serum protein measurements}

Chronic hyperglycaemia in diabetics results in a rise in the concentration of nonenzymatically glycated proteins. Because of this feature, $\mathrm{HbA}_{1}$ measurement has gained general acceptance in the management of diabetes. The HbA, concentration reflects the blood glucose levels during the preceding six to ten weeks and is thus an index of long-term blood glucose control. However, the long survival time of haemoglobin (120 days) implies that a high $\mathrm{HbA}_{1}$ level is likely to persist at least for several weeks after normoglycaemia has been achieved. Since most serum proteins have a much shorter half-life ( $t_{1 / 4}$ albumin $=18$ days) than haemoglobin, the GSP measurement may provide more reliable information on the recent glycaemic status. This feature may offer the advantage that fairly rapid information can be obtained about, for example, the efficacy of a change in treatment. 


\subsubsection{Glycated serum proteins and glycaemic control}

The GSP concentration is higher in diabetics than in non-diabetic controls, with wirtually no owerlap (Dolhofer and Wieland, 1979 and 1980; McFarland et al, 1979; Kennedy et al., 1981; Johnson et al., 1982). This feature has been the trigger to further analyse the clinical applicability of the relation between the GSP level and the glycaemic status.

\section{Glycated serum proteins and stable glycaemic control}

In elinical practice the 'clinical impression' is occasionally used to evaluate the quality of glycaemic control. In general, this 'clinical impression' is vague and subjective, due to the versatility of symptoms and laboratory tests on which it is based. Therefore, the good correlation reported between the fructosamine concentration and the 'clinical impression score of glycaemic control' (Kutter and Thoma, 1985; Buysschaert et al., 1986) should be interpreted with caution.

The fasting blood glucose concentration is frequently used to evaluate the quality of glycaemic control in diabetics (Holman and Turner, 1979 and 1980). It is generally agreed that the GSP concentration and the fasting blood glucose concentration are correlated (Johnson et al., 1982; Jones et al., 1983; Nelson et al., 1985; Baker et al., 1983; Kutter and Thoma, 1985; Koskinen et al., 1987; Poli et al., 1987; Jerntorp et al., 1988). This correlation is closer in NIDDM than in IDDM (Kennedy et al., 1981; Mosca et al., 1987), most probably due to the less stable glycaemic state in $\mathrm{IDDM}$.

The glucose concentration 2 hours after a meal provides additional information about the quality of glycaemic control in diabetics. Also this parameter was found to correlate with the GSP concentration. Again, the correlation in NIDDM patients was better than in IDDM patients (Smart et al., 1988). Our own results with respect to this relation will be presented in chapter 4 .

Glycaemic control can also be evaluated on the base of the average glucose concentration calculated from multiple blood glucose measurements throughout the day. This estimate, determined once weekly for a period of 4 weeks, was found to correlate well with the GSP concentration in a group of stable IDDM patients (Schleicher et al., 1984). Furthermore, a good correlation was found in pregnant diabetics between the GSP concentration and the average glicose concentration calculated from multiple postprandial glucose measurements determined in the previous week (Morris et al., 1985 (a)).

The correlations between various currently employed estimates of glycaemic status and fructosamine are summarized in table 4.4. From this table it can be concluded that, particularly in stable diabetics, the GSP (fructosamine) concentration appears: to provide reliable information on the quality of glycaemic control over a period of $1-3$ weeks. 
Glycated serum proteins and deterioration of glycaemic control

When the blood glucose concentration rises gradually, the rate of formation of ketoamines exceeds the rate of their dissociation and clearance until a new equilibrium level has been attained. This phenomenon results in a higher GSP concentration. In diabetic rats discontinuation of insulin administration led to a new steady-state concentration of GSPs after 4-5 clays (Day et al., 1979, 1980). To determine the clinical usefulness of fructosamine measurement in detecting loss of glycaemic control, the effect of discontinuing oral hypoglycaemic medication on the fructosamine concentration was studied in 7 NIDDM patients (Baker et al., 1984). There was a consistent increase in the fructosamine concentration during the first week after drug withdrawal, and a plateau was reached after $1-2$ weeks. In rats, steady-state GSP concentrations are reached within a shorter period than in humans, probably due to the short half-life of rat albumin ( 2 days) relative to that of human albumin ( 18 days). The number of reports on the effect of deterioration of the normoglycaemic status in the human are limited because of medical and ethical problems associated with such experiments. Nevertheless, there appears to be enough evidence to assume that deterioration of glycaemic control in diabetics will lead to a rapid increase in the GSP concentration. Therefore the GSP concentration is likely to provide useful information for the early detection of deterioration of glycaemic control in diabetics.

\section{Glycated serum proteins and improvement of glycaemic control}

When a state of poor glycaemic control is adequately treated and normoglycaemia is restored, dissociation and clearance of ketoamines exceed their formation, thus causing a fall in the GSP concentration. Since ketoamines are predominantly composed of glycated serum albumin, the half-life of GSP may theoretically approximate to that of glycated serum albumin, i.e. 18 days.

Improvement of the glycaemic status in poorly controlled diabetic patients decreased the GSP concentration by $37 \%$ within one week (Kennedy et al., 1981). A fall of the GSP concentration within 3 weeks after improvement in glycaemic status thas been confirmed by others (Dolhofer and Wieland, 1980; Baker et al., 1983; Jones et al., 1983; Cefalu et al., 1988; Krause et al., 1987).

In clinical practice it is often difficult to restore normoglycaemia in diabetics. Particularly in IDDM patients, the glucose concentration may fluctuate over a wide range in spite of an overall reduction in the mean daily blood concentration. In these patients, the accelerated removal of GSPs, associated with the lower mean glucose concentration, is counterbalanced by the enhanced formation of new GSPs during hyperglycaemic episodes. In newly diagnosed diabetics and diabetics with poor glycaemic control, the GSP concentration will only decrease to normal levels when stable normoglycaemia has been reached and few hyperglycaemic episodes occur. The GSP concentration therefore appears to provide valuable information to the clinician for evaluation of overall improvement in the glycaemic status. 
2.3.5.2 Glycated serum protein measurement as screening test for impaired glucose tolerance and diabetes mellitus

Screening for IGT and DM can be performed just for epidemiological reasons or to identify (symptom-free) patients in a population. For both purposes it would be convenient to have a simple method at hand with a good sensitivity and specificity which could replace the OGTT. Olycosuria has a poor specificity and sensitivity for DM (Service et al., 1972). Screening for DM by randomly measuring blood glucose during the day fails because of insufficient sensitivity (WHO, 1985). While the value of $\mathrm{HbA}_{1}$ measurement for detection of DM may be adequate, its value for detection of IGT appears to be insufficient (see 2.2.4.2).

Since the GSP concentration gives information on the glycaemic status over a shorter and more recent period, its measurement may be more reliable than the $\mathrm{HbA}_{1}$ concentration as an estimate of actual glucose tolerance. We calculated the sensitivity, specificity, and predictive value of the fructosamine test using data reported by Baker and co-workers (1983) (table 2.5). Although the sensitivity of the test for detection of DM was good, the test was weak with respect to identifying subjects with an IGT. In a larger population we reported comparable results (Salemans et al., 1987). Our clata are also listed in table 2.5 but will be discussed in more detail in chapter 5 .

Swai and co-workers (1988) reported that fructosamine measurement was a poor screening test for abnormal glucose tolerance. The sensitivity of the fructosamine test for DM was callculated to be only $45 \%$ and that for both DM and IGT only $12 \%$. However, their results may be influenced by the high prevalence of IGT and DM in the population studied $(33.4 \%)$.

Since glucose tolerance tests and average glycaemic ranges (fructosamine) give information on quite different aspects of carbohydrate metabolism, it is not surprising that IGT can not be detected by the measurement of fructosamine. The fructosa mine concentration reflects the mean blood glucose concentration during the preceding 1-3 weeks, whereas an IGT test implies a (temporary) abnormal elevation of the blood glucose concentration after a non-physiological glucose load. A subject with an IGT test, may be normoglycaemic under physiological conditions. In these subjects the fructosamine concentration will be normal.

Several stressful conditions such as surgery, trauma and disease may affect carbohydrate metabolism. In these situations it may be difficult to determine whether hyperglycaemia refleets the existence of DM or a temporary stress-related change in the carbohydrate metabolism. In these conditions the GSP concentration (which is less sensitive to acute disturbances in glycaemic control) may contribute to the diagnosis. Kyle and co-workers (1987) have studied the value of serum fructosamine measurement in screening for DM in a coronary care population. In these patients the incidence of hyperglycaemia is high (Oswald et all., 1986) and discrimination between 
Table 2.5 Value of fructosamine measuremen as screening test for dhabtes mellitws (DM) and impaired glucose tolerance (IGT)

\begin{tabular}{|c|c|c|c|c|}
\hline & $\begin{array}{l}\text { Baker } \\
1983\end{array}$ & $\begin{array}{l}\text { Salemans } \\
1987\end{array}$ & $\begin{array}{l}\text { Kyle } \\
1987\end{array}$ & $\begin{array}{l}\text { Swai } \\
1988\end{array}$ \\
\hline Classification OGTT & WHO & WHO & NDDO & WHO \\
\hline Number of patients & 74 & 183 & 107 & 573 \\
\hline \multirow[t]{2}{*}{ Sensitivity $(\%)$} & 88 & 67 & 78 & 45 \\
\hline & 53 & 52 & - & 12 \\
\hline Specificity $(00)$ & 91 & 98 & 95 & 99 \\
\hline Positive PV $(\%)$ for $\mathrm{DM}$ & 75 & 79 & 58 & 83 \\
\hline Positive PV $(\%)$ for DM and IGT & 80 & 93 & - & 93 \\
\hline Negative PV $(\%)$ for DM & 96 & 93 & 98 & 93 \\
\hline Negative PV (\%) for DM and IGT & 74 & 84 & - & 54 \\
\hline
\end{tabular}

- The OGTTs were performed and classified according to World Health Organization (WHO) criteria (1985) or to National Diabetes Data Group (NDDG) criteria (1979).

- PV: predictive value.

- The upper limit of a normal fructosamine concentration was defined as 2 SD above the mean of the reference population.

DM and stress hyperglycaemia is important from a therapeutic and diagnostic point of view (Jaffe et al., 1984). In 107 patients, the concentrations of fructosamine and glucose were measured at the time of admission to a coronary care unit. An OGTT was performed after 6-8 weeks. An abnormal fructosamine level yielded a positive predictive value of $58 \%$, a sensitivity of $78 \%$ and a specificity of $95 \%$ (table 2.5). These values for random plasma glucose (discrimination value $7.8 \mathrm{mmol} / \mathrm{l}$ ) were $17 \%, 100 \%$ and $52 \%$, respectively. Thus, in a population with a high incidence of acute stress-related hyperglycaemia, the fructosamine measurement provides a better method to screen for DM than the randomly measured glucose concentration.

In summary, fructosamine has little value when used to screen for $10 T$. When used to screen for DM and. IGT the test may be appropriate. For diagnosis of either DM or IGT the fructosiamine measurement is inadequate. However, as mentioned for $\mathrm{HbA}_{1}$, fructosamine measurement may be more sensitive than the OGT $\mathrm{T}$ for tacing patients at risk for long-term complications of diabetes mellitus. Finally, fructosamine measurement has an interesting potential for discriminating between stress-related hyperglycaemia and DM in a specific population such as that in a coronary care unit. 


\subsubsection{Glycated serum proteins and pregnancy}

\section{Glycated serum proteins in normal pregnancy}

In normal pregnancy the GSP concentration has been reported to be the same or slightly lower than in the non-pregnant state (Lim and Staley, 1985; Roberts and Baker, 1986). Using affinity chromatography for GSP measurement, Nelson and co-w orkers (1985) found the concentration to be stable between the $18 \mathrm{th}$ and $34 \mathrm{th}$ week of gestation. In constrast, Roberts and Baker (1986) reported a gradual decrease of the fructosamine concentration in the course of pregnancy. In pregnant patients with a normal OGTT, we also reported a slight but significant decrease of the fructosamine concentration in the course of normal pregnancy (Van DieijenVisser and Salemans, 1986(a)). Our data will be reported in chapter 6. Since the decrease is very small, there is no need to correct the fructosamine concentration for gestational age.

\section{Glycated serum protein measurement for screening of gestational diabetes}

Gestational diabetics are, by definition, those women in whom impaired glucose tolerance or diabetes mellitus is first detected during pregnancy. Gestational diabetes has been associated with increased perinatal morbidity and mortality, and it is claimed that carly diagnosis and treatment improves foetal outcome (O'Sullivan et al., 1973(a); Gabbe et al., 1977(a), Coustan and Imarah, 1984).

It is still common practice to subject pregnant women to an OGTT when there is 'clinical risk' of gestational diabetes. With this procedure, at best $50-60 \%$ of gestational diabetics will be detected (O'Sullivan et al., 1973(b)). Screening all pregnant women by blood glucose measurement 1 hour after a $50 \mathrm{~g}$ oral glucose load (cut-off value venous plasma glucose concentration $8.2 \mathrm{mmol} / 1$ ) will identify $79 \%$ of gestational diabetics (O'Sullivan et al., 1973(b)). However, this $50 \mathrm{~g}$ screening test is associated with an appreciable false positive rate and is inconvenient, time-consuming and cumbersome in a busy antenatal clinic. It follows that there is a need for a simple and reliable screening method for gestational diabetes.

This led various investigators to study the value of GSP measurement as a screening method for gestational diabetes. Roberts and co-workers (1983) measured the fructosamine concentration in 20 women with gestational diabetes and in 79 nondiabetic pregnant women. The fructosamine test discriminated well between the two groups as 17 out of 20 gestational diabetics were detected, with only 4 false positive subjects out of 79 controls. However, a major shortcoming of this study was that the results were obtained in patients selected on the basis of an abnormal OGTT. This selection implies that no conclusions can be drawn about the screening value of fructosamine measurement in an unselected population.

In another study the screening value of fructosamine measurement was studied in 1200 women at the time of intake, 28 weeks and 36 weeks gestation (Roberts and Baker, 1986). In only 167 of these patients was an OGTT performed because of clinical risk factors. No information was obtained about the glucose tolerance in the 
remaining 1033 patients. The authors' conclusion about the usefulness of fructosamine measurement as a screening test for gestational diabetes applies only to the selected OGTT population. Moreover, the degree of glucose intolerance in the gestational diabetics studied $(n=9)$ was much higher than in other studies (Al-Shawaf et al., 1988(a), 1988(b)), which may have improved the screening value of the fructosamine test in the former study.

Data on this subject from our clinic indicate that the fructosamine test is insensitive for use as a screen for gestational diabetes. Details of this study will be presented in chapter 5 .

\section{Glycated serum proteins and birth weight}

The most important reason why gestational diabetics need to be detected; is to prevent the sequelae of maternal hyperglycaemia in their offspring. Gestational diabetes has been related to foetal macrosomia which is associated with an increased risk of traumatic delivery, shoulder dystocia, and/or Caesarean section (Gabbe et al., 1977(a)). Since poor glycaemic control in diabetic pregnancy often results in macrosomia and strict glucose control yields lower rates of foetal macrosomia, the level of glycaemic control during diabetic pregnancy seems to influence foetal growth and subsequent newborn weight. As the GSP concentration is an index of glucose control over the preceding 1-3 weeks, this variable could theoretically have a predictive value with respect to the risk of macrosomia in (gestational) diabetic women.

In 30 pregnant diabetics, the relationship was determined between the fructosamine concentrations at different stages of gestation and birth weight (Roberts and Baker, 1987). Diabetic mothers giving birth to macrosomic children had a higher first trimester fructosamine concentration than those producing an infant with a normal birth weight. The reports on the correlation between second and third trimester fructosamine values and birth weight are rather conflicting for both non-diabetic and diabetic pregnancy (Roberts and Baker, 1987; Fadel et al., 1986; Roberts et al., 1988). Therefore, more studies are needed to determine the relation between the fructosamine concentrations during pregnancy and the birth weight.

\section{Glycated serum proteins in neonatal cord blood}

In non-diabetics, John and co-workers (1985) reported higher concentrations of glycated albumin in mothers relative to their babies while the foetal and maternal values were found to be correlated. Reports on the GSP concentration in neonatal cord blood are conflicting, with no conclusive data that the GSP concentration in cord blood of infants of (gestational) diabetic mothers differs consistently from that of non-diabetic controls (John et all, 1985; Roberts et al., 1983; Fadel et al., 1986; Roberts and Baker, 1987; Roberts et al., 1988).

It follows that the clinical relevance of cord GSP measurement is yet to be ascertained. 


\subsection{Non-enzymatic glycation of other proteins}

Retinopathy, neuropathy and proteinuria were already known to be associated with diabetes mellitus before the discovery of insulin. With the introduction of insulin therapy in diabetics the survival rate increased markedly. However, the increased life expectancy in diabetics allowed slow metabolic side effects of the disease to outgrow to health threatening complications such as nephropathy, microangiopathy and atherosclerosis. Since patients with prolonged poor glycaemic control experience more severe complications of diabetes mellitus more often, these complications are generally considered to be associated with hyperglycaemia. However, not all such patients develop complications. About 20-25\% of IDDM patients do not develop any complications at all, despite long-term disease and only moderate glycaemic control. On the other hand, about $5 \%$ of IDDM patients develop severe complications in spite of adequate glycaemic control and short duration of the disease. The exact cause of this discrepancy is not known.

A number of hypotheses have been proposed to explain the pathogenesis of the complications. A plausible explanation has been given recently on the basis of a combined genetic and metabolic factor (Raskin and Rosenstock, 1986). A concerted acthon of hyperglycaemia and some genetic predisposition triggers the development of the typical complications.

One mechanism by which hyperglycaemia can lead to tissue damage is by an increasing influx rate of glucose into various metabolic pathways. Intracellular hyperglycaemia, which occurs preferentially in insulin-independent tissues such as eye lens and nerves, may interfere with normal cell metabolism, which eventually leads to secondary cell damage. These processes have been reviewed by Brownlee and Cerami (1981).

Another mechanism by which hyperglycaemia leads to tissue damage is by nonenzymatic glycation. There is increasing evidence that non-enzymatic glycation of proteins, which is accelerated by hyperglycaemia, causes the central pathological features of diabetic complications (Brownlee et al., 1984(a), 1988).

\section{Alteration of physiological processes by non-enzymatic glycation}

The discovery of increased non-enzymatic glycation of haemoglobin and serum proteins in hyperglycaemic diabetics has raised interest in glycation of other body proteins. An important reason is the supposition that this phenomenon could play a crucial role in the pathogenesis of long-term diabetic complications. Non-enzymatic glycation of proteins seems to occur in most body tissues where it may interfere with the biological function of proteins, giving rise to alterations in physiological processes. Several of these processes, affected by non-enzymatic glycation, have been reviewed by Brownlee and associates (1984(a)). 


\section{Alteration of enzyme activity}

Although enzymes have relatively short half-lives, their catalytic properties may be altered by non-enzymatic glycation. Enzyme inactivation is often a result of glucose attachment to a functionally essential lysine $\epsilon$-amino group. This form of inactivation has been illustrated in the enzyme ribonuclease A (Eble et al., 1983). In vitro, loss of enzyme activity associated with glycation has also been described for cathepsine B (Coradello et al, , 1981), $\beta$ - $N$-acetyl-D-glucosaminidase (Dolhofer et al., 1982) and alkaline phosphatase (Pollak et al., 1983).

\section{Binding of regulatory molecules}

Binding of regulatory molecules can alter the functional activity of some proteins. When binding of regulatory molecules requires unsubstituted amino groups, nonenzymatic glycation can interfere with effector-molecule binding. This may impair the molecule's functional activity. The reversible binding of 2,3-diphosphoglycerate (2,3-DPG) to haemoglobin may serve as a model for regulatory molecule binding. As described in 2.2.3, binding of 2,3-DPG to the haemoglobin molecule reduces the affinity of haemoglobin for oxygen. Therefore, blockage of the binding site of 2,3-DPG by glycation increases oxygen affinity of the haemoglobin molecule (Bunn and Briehl, 1970).

The activity of the protein antithrombin III is also dependent on binding of regulatory molecules. After binding of heparin, antithrombin III becomes the major inhibitor of activated coagulation factors in plasma. In-vitro studies demonstrated that non-enzymatic glycation of antithrombin III diminishes this effect, which implies that the threshold of the coagulation cascade is reduced. This, in turn, may contribute to the accumulation of fibrin in various diabetic tissues (Brownlee et al., 1984(b)).

\section{Cross-linking of proteins}

Ketoamines on proteins with long half-lives may undergo a series of irreversible reactions, resulting in the formation of advanced glycation end products (Cerami et all., 1987). These products are involved in cross-linking of proteins. This process was first demonstrated in the lens protein $\alpha$-crystallin (Stevens et al., 1978). In crystallin solutions containing $50 \mathrm{mM}$ glucose, the development of opalescence was greatly accelerated. This opacification was found to be due to the formation of disulphide cross-links in glycated crystallins. The cross-linking resulted in the formation of high molecular weight, light-scattering protein aggregates. Besides nonenzymatic glycation, in vivo, also other processes associated with intracellular hyperglycaemia appear to be involved in the development of cataracts in diabetics (Cerami et al., 1979).

Studies of the dura mater of diabetics and non-diabetics has provided evidence that advanced glycation end products accumulate on collagen (Monnier et al., 1984). Some of the advanced glycated end products on collagen are capable of forming covalent bonds with amino groups on other proteins. In this way intercollagen 
bonds are formed, resulting in enhanced stiffening and loss of elasticity of tissue. The accumulated end products may also form covalent cross-links with other proteins such as albumin, $\operatorname{lgG}$ and low-density lipoproteins (LDL). Trapping of albumin in collagen of basement membranes has been associated with the thickening of these membranes in diabetics (Sensi et al., 1986), while trapping of $\mathrm{IgG}$ may result in complement activation and immune-complex formation in diabetics (Brownlee et al., 1984(a)). Finally, LDL trapping in collagen could contribute to the accelerated development of atherosclerosis in diabetics (Brownlee et al., 1985).

\section{Decreased suspectibility to proteolysis}

Several in-vitro experiments have shown that some glycated proteins are more resistant to physiological degradation. In viwo, this has been demonstrated for glycated glomerular basement membranes (Lubec and Pollak, 1980) and glycated fibrin (Brownlee et al. (1983). This phenomenon could explain why glycated fibrin accumulates in diabetics in retinal capillaries, glomerular basement membranes and several other tissues. The accumulation of fibrin may also contribute to capillary and arteriolar occlusion, resulting in loss of functional glomerules and development of diabetic retinopathy and neuropathy (Timperly et al., 1976; Cunha-Vaz, 1978).

\section{Function of nucleic acids}

In spite of the low reactivity of nucleic acids with reducing sugars, these acids are also subject to non-enzymatic glycation. Since nucleic acids are long-lived molecules in the resting cells, the accumulation of glycation products in these cells could play a role in biological aging (Bucala et al., 1984). Acceleration of this process by hyperglycaemia may be the cause of the decreased capacity of the fibroblast to replicate in diabetics (Vranko and Benditt, 1975). In an in-vitro study, Nanjou and coworkers (1986) provided evidence that oxygen radicals, generated during autooxidation of the ketoamines, induce site-specific damage in DNA. This observation supports the concept that the development of congenital anomalies in children of diabetic mothers may be caused by non-enzymatic glycation of DNA.

\section{Macromolecular recognition and endocytosis}

Most human cells have surface receptors. Each of these receptors recognizes a particular chemical structure. Binding of a chemical compound to its specific receptor on the cell membrane initiates a chain of events within the cell which cumulate in a specific response. Fibroblasts have low-density lipoprotein (LDL) receptors; binding to the receptor results in endocytosis of the cholesterol-rich LDL. This process is important in order to keep plasma LDL at a low level. When the LDL-receptor function is impaired or the LDL structure is changed, endocytosis is reduced. The LDL concentration in plasma and, with it, the cholesterol deposition in tissue will rise. In-vitro studies with non-glycated and glycated LDL have shown that the endocytotic activity of cultured human fibroblasts towards glycated LDL was significantly reduced (Gonen et al., 1981). Accumulation of cholesterol is a typical feature 
of atherosclerosis and known to be more prevalent in diabetie patients (Garcia et al., 1974). This accumulation may be the result of both cross-linking of glycated LDL to matrix components and decreased endocytosis of glycated LDL.

In contrast to the impaired recognition of glycated LDL by fibroblasts, a macrophage receptor has been identified that specifically recognizes those proteins to which advanced glycation end products are bound. These receptors enable macrophages to remove these proteins (Radoff et al., 1987). When advanced glycation end products on myelin are recognized by macrophages, the complex will be taken up. This process may be involved in the segmental demyelinisation observed in diabetics as well as in normal aging.

Studies in both animals and humans have shown that non-enzymatic glycation of proteins, especially formation of advanced glycation end products, affects several physiological processes. Since many of these processes are impaired in diabetics and formation of advanced glycation end products is accelerated during hyperglycaemia, this strongly suggests that the central pathological features of various longterm diabetic complications are the result of non-enzymatic glycation. Support for this hypothesis comes from a recent study where the formation of advanced glycation end products was inhibited pharmacologically by aminoguanidine hydrochloride. In this study in diabetic rats, an increase in the thickness of the glomerular basement membrane was successfully prevented by aminoguanidine (Brownlee et: al., 1988). With the discovery of a method for inhibiting the formation of advanced glycation end products, it has become possible to evaluate more accurately the role of this phenomenon in the development of chronic diabetic complications. In the future, pharmacological inhibition of the formation of advanced glycation end products may contribute to the prevention of structural lesions due to diabetes mellitus.

\section{References}

Abell DA. The significance of abnomal glueose tolerance (hyperglycemia and hypoglycenia) in pregnancy.

Br J Obstet Gynaecol 86: 214-221, 1979.

Allen DW, Schroeder WA. Balog J. Observations on the chromatographic heterogeneity of nom adult and fetal human hemoglobin: a study of the effects of crystallization and chromatography on the heteromgeneity and isoleucine content.

J Am Chem Soc 80: 1.628-1.634, 1958.

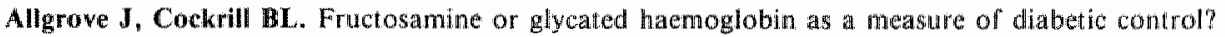
Arch Dis Child 63: 418-422, 1988. 
Al-Shawal T, Moghraby $\mathbf{5}$, Alkel A. Does impatired gucose tolerance imply a risk in pregnancy? Br J Obstet Gynateol 95: 1036.1941, 1988(a).

Al-Sthawat T, Akiel A Moghiraby SAS. Gestational diabetes and impared glucose tolenance of pregnancy in Riyadh.

Br J Obstet Gyndecol 95: 84-90, 1988(b).

Armbraster DA. Fructosamine structure, analysis, and clinical usefulness.

Clin Chen 33: 2153-2163, 1987 .

Artal R, Mosley GM, Dorey IJ. Glycohemoglobin as a screening test for gestational diabetes.

Am J Obstet Gynecol 148: 412-414, 1984.

Bacigalupo $\mathbf{G}$, Langwer $\mathrm{K}$, Saling $\mathbb{L}$. Glycosylated hemoglobin $\left(\mathrm{HbA}_{1}\right)$, glucose tolerance and neonatal outcome in gestational diabetic and non-diabetic mothers.

J Perinat Med 12: 137-145, 1984 .

Baker JR, O'Connor JP, Metcalf PA, Lawson MR, Johnson RN. Clinical usefulness of estimation of serum Pructosamine concentration as a screening test for diabetes mellitus.

Bir Med J 287: 863-867, 1983.

Baker JR, Johnson RN, Scott DJ. Serum fructosamine concentrations in patients with type II (noninsulin-dependent) diabetes mellitus during changes in management.

Br Med $3288: 1484-1486,1984$.

Baynes JW, Thorpe SR, Murtiashaw MH. Nonenzymatic glucosylation of lysine residues in albumin. Method Enzymol 106: 88-98, 1984.

Brownlee M, Vlassara $\mathbf{H}$, Ceramil A. Measurement of glycosylated amino acids and peptides from urine of diabetic patients using affinty chromatography.

Diabetes 29: 1044-1047, 1980.

Brownlee $\mathbf{M}$, Cerami A. The biochemistry of the complications of diabetes mellitus. Ann Rev Biochem 50: 385-432, 1981 .

Brownlee M, Vlassara H, Cerami A. Nonenzymatic glycosylation reduces the susceptibility of fibrin to degradation by plasmin.

Diabetes 32: $680-684,1983$.

Arownlee $M_{*}$ Vlassara H, Cerami A Nonenzymatic glycosylation and the pathogenesis of diabetic complications.

Ann Intern Med 101: 527-537, 1984(a).

Brownleo M, Vhassara H, Cerami A. Inhibition of heparin-catalyzed human antithrombin III activity by nonenzynatic glycosylation: possible role in fibrin deposition in diabetes.

Diabetes 33: $532-535,1984(\mathrm{~b})$.

Brownlee $\mathbf{M}_{\text {, VIassara }} \mathbf{H}$, Cerami A. Nonenzymatic glycosylation products on collagen covalently trap low-density lipoproteins.

Diabetes 34: 938-941, 1985.

Brownlee M, Cerami A, Vlassara H. Advanced glycosylation end products in tissue and the biochemical basis of diabetic complications.

N Engl J Med 318: 1315-1321, 1988.

Butala R, Model P. Cerami A. Modification of DNA by reducing sugars; a possible mecthanism for mucleic acid aging and age-related dysfunction in gene expression.

Proc Natl Acad Sci USA 81: 105.109, 1984. 
Bunn $\mathbf{H F}$, Briehl RW. The interaction of 2,3-diphosploglycerate with various human hemoglobins: IJ Clin Invest 49: 1088-1095, 1970.

Bunn HF, Haney DN, Kamin S, Gabbay KH, Gallop PM. The biosynthesis of human hemoglobin $A_{1 \mathfrak{R}^{*}}$ J Clin Invest $57: 1652-1659,1976$.

Bumn HF, Gabbay $\mathbb{K H}$, Gallop PM. The glycosylation of hemoglobin: relevance to diabetes mellitus. Science 200:21-27, 1978.

Buysschaer M, Galanti L, Mpoy M, et al. Le dosage de la fructosamine: un novel index de contrôte glyeémique [Letter].

Louvain Med 105: 381-382, 1986.

Cefalu WT, Parker TP, Johnson CR. Validity of serum fructosanine as index of short-term glycemic control in diabetic outpatients.

Diabetes Care 11: $662-664,1988$.

Ceramu A, Stevens VJ, Monnier VM. Role of nonenzymatic glycosylation in the development of the sequellae of diabetes mellitus.

Metabolism 28: 431-439, 1979 .

Cerami A, Vlassara H, Brownlee M. Glucose and aging.

Sci Am 256(5): 82 90, 1987.

Chung CS, Myrianthopoulos NC. Effect of maternal diabetes on congenital malformations.

Birth Defects vol XI, no 10: 23-37, 1975 .

Coradello H, Pollak A, Pagano M, Leban J, Lubec G. Nonenzymatic glycosylation of cathepsin B: possible influence on the conversion of proinsulin to insulim.

IRCS Biochem 9: 766-767, 1981 .

Cousins L, Dattel BI, Hollingsworth DR, Zettner AZ. Glycosylated hemogjobin as a screening test for carbohydrate intolerance in pregnancy.

Am J Obstet Gynecol 150: 455-460, 1984 .

Coustan DR, Imarah J. Prophylactic insulin treatment of gestational diabetes reduces the incidence of macrosomia, operative delivery, and birth trauma.

Am J Obstet Gynecol 150: 836-842, 1984.

Cromme PVM, van der Veen EA, Bezemer PB, Kuik DJ. De waarde van de bepaling van de fructosamine concentratie in het serum als sereening-test voor diabetes mellitus.

Ned. Tijdschr Geneeskd 130:2॥12, 1986.

Cummings ST, Fraser CG, Variability of capillary plasma glucose in healthy individuals in repeated $75 \mathrm{~g}$ oral glucose tolerance tests.

Ann Clin Biochem 25: 634-637, 1988.

Cunha-Vaz JG. Pathophysiology of diabetic retinopathy.

Br \& Ophthalmol 62: $351-355,1978$.

Dahl-Jorgensen K, Brinchmann-Hansen $O$, Hanssen $\mathbb{K}^{\mathrm{F}}$, et al. Effect of near normoglycaemia for two years on progression of early diabetic retinopathy, nephropathy, and neuropathy: the Oslo study, Br Med J 293: 1195-1199, 1986.

Daubresse $\mathrm{JC}_{\text {, Laurent }} \mathbf{E}$, Ligny $\mathbf{C}$, et al. The usefulness of fructosamine determination in diabetic pa tients and its relation to metabolic control.

Diabete Metab 13: 217-221, 1987. 
Day JW, Thomburig RW, Thorpe SR, Aaynes JW. Nonenzymatic glucosylation of rat albumin.

I Biol Chrm 254: $9394-9400,1979$.

Day JI, Ingebretsen CG, Ingebretsen WR, haynes JW, Thorpe SR. Nonenzynatic glucosylation of serum protens and hemoglobin: response io changes in blood glucose levels in diabetic rats.

Diabetes 29:524-527, 1980 .

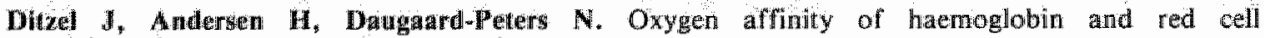
2,3-duphosphoglycerate in ohildhood diabetes.

Arta Paediatr scand 64: $395-361,1975$.

Dods WF, Bohmey C. Glycosylated hemoglobin assay and oral ghcose rolierance test compared for dretec Lion of diabetes mellitus.

Gin Chem 25: 764-768, 1979 .

Dothofer IR, Wieland OH. Olycosylation of serum albumin: elevated glycosyl-abumin in diabetic patiments.

TEBS Let $103: 282-286,1979$.

Dothofer R, Wiehand OH. Increased glycosylation of serum abumin in diabetes mellitus. Diabetes $29: 417-422$, 1980 .

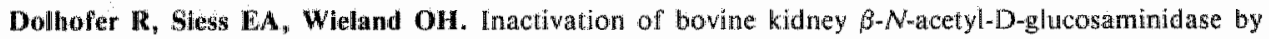
nonerizynatic glucosylation.

Hoppe-Seyler's Z Physiol Chem 363: 1427-1436, 1982.

Dumn PJ, Cole RA. Soeldnet JS, ell al. Temporal relationship of glycosylated haemoglobin concentrations to glucose control in diabetics.

Diabetologia $17: 213-220,1979$.

Eble AS, Thorpe SR, Baymes JW. Nonenzymatic glucosylation and glucose-dependent crossunking of protein.

J Biol Chem 258: $9406-9412,1983$.

Erikssoin U., Dahlstrom $\mathbf{V E}_{*}$ Lithell HO. Diabetes in pregnancy: influence of genetic background and maternal diabetic state on the incidence of skeletal mallormations in the fetal rat.

Acta Endocrinol (suppl) 277:66-73, 1986.

Iadel HE, Elseweidy MM, Abrabam EC. Glycosylated hemoglobirn and protein levels in normal and diabetic pregnancies: retation tho birth weight.

Obstet Gynecol $67: 533.536,1986$

Fulurmann $\mathbf{k}$. Tight metabolic control during early pregnancy prevents malformation in offspring of insultio-dependent diabetic women.

In: Perintual madicin. MTP Press Lumited, USA. Clinch J (ad), 259-267, 1984.

Gabbay KH, Hasty K, Breslow JL, Dilison RC, Bunn HF, Gallop PM. Glycosylated hemoglobins and longuerm gucose control in diabetes thellitus.

J Clin Endocrinol Metab 44: $859-864,1977$.

Catbe S6, Mestmin JH, Freman RK, Anderson GV, lowensohn RT Management and outcome of class A diaberes mellitus.

Anu J Obstei Gyneod 127:465-469, $1977(\mathrm{a})$.

Gibbe SG, Mestman JH, Freemain RK, et al. Managentent and outcome of pregnancy in diabetes mellitus, classes $B$ to $R$.

Am J Obstet Gynecol 129:723-732, 1977(b). 
Garcia MJ, McNamara PM, Gordon T, Kanmal WB. Morbidity and mortality in diabetics in the Framingham population.

Diabetes 23: 105-111, 1974.

Ghiggeri GM, Candiano G, Delfino G, Queirolo $C$. Characterization of the phenythydrazone derivates of 'glycated albumin' purified fron diabetic sera.

Carbohydr Res 153: 314-317, 1986.

Gilimer MDG, Beard RW, Brooke FM, Oakley NW. Carbohydrate metabolism in pregnancy. Part I. Diurnal plasma glucose profile in normal and diabetic pregnancy.

Br Med J 3: 399-404, 1975.

Gonen B, Rubenstein AH, Rochman $\mathbf{H}$, Tanega SF, Horwitz DL. Haemoglobin $\mathrm{A}_{4}$ : an indicator of the metabolic control of diabetic patients.

Lancet ii: $734-737,1977$.

Gonen B, Baenziger J, Schonfeld G, Jacobson D, Farrar P. Non-enzymatic glycosylation of low density lipoproteins in vitro.

Diabetes 30: $875-878,1981$.

Gould BJ, Hall PM, Cook JGH. A sensitive method for the measurement of glycosylated plasma proteins using affunity chromatography.

Arn Clin Biochem 21: 16-21, 1984.

Griffiths RJ, Vinall PS, Stickland MH, Walles JK. Haemoglobin $A_{16}$ levels in normal pregnancies.

Eur J Obstet Gynecal Reprod Biol 24: 195-200, 1987.

Gyves MT, Rodman HM, Little AB, Fanaroff AA, Merkatz IR. A modern approach to management of pregnant diabetics: A two-year analysis of perinatal outcomes.

Am J Obstet Gynecol 128: 606-616, 1977.

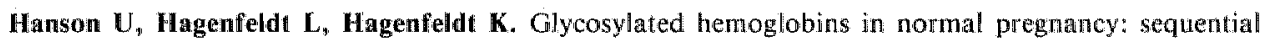
changes and relation to birth weight.

Obstet Gynecol 62: 741-744, 1983.

Higgins PJ, Bunn MF. Kinetic analysis of the non-enzymatic glycosylation of hemoglobin.

J Biol Chem 256: 5204-5208, 1981.

Hindle FJ, Rostron GM, Gatt JA. The estimation of serum fructosamine: an alternative measurement to glycated haemoglobin.

Ann Clin Biochem 22: 84-89. 1985.

Hindle EJ, Rostron GM, Clark SA, Gat JA. Serum fructosamine and glycated haenoglobin measure ments in diabetic control.

Arch Dis Childhood 61: 113-117, 1986.

Holman RR, Turner RC. Maintenance of basal plasma glucose and insulin concentrations in maturity onset diabetes.

Diabetes 28: $227-230,1979$.

Holman RR, Turner RC. The basal plasmaglucose: a simple relevant index of maturity onset diabetes. Clin Endocrinol 14: $279 \cdot 286,1980$.

Holman RR, Dornan TL, Mayon-White $\mathrm{V}$, al. Prevention of deterioration of renal and sensory-nerve function by more intensive management of insulin-dependent diabetic patients: a two-year randomised prospective study.

Lancet: 204-208, 1983. 
Howey JEA, Browning MCK, Fraser CG. Assay of serwm frutosamine that miminizes standardization and matrix problems: use to assess components of biological variation.

Clin Chem $33: 269-272,1987$.

Hytten FE, Lind T: Volume and composition of the blood. Diagnostic indices in pregnancy. Documenta Geigy: $36-53,1973$.

Jaffe $\mathbf{A S}$, Spadaro $\mathbf{M}$, Sthechinan $\mathrm{K}$, et al. Increased congestive heart fallure after myocardial infarction of modsst extent iri patients with diabetes mellitus.

Ami Heart J 108: 31-37, 1984 .

James WPT, Research in malnutrition and its application to parenteral feeding.

In: Advances in parenteral nutrition. MTP Press Lid, Lancaster. Johnston IDA (ed); 521-533, 1978.

Jerntorp $\mathbb{P}$, Sundkvist $G$, Fex $G$, Jeppson JO. Clinical utility of serum fructosamine in diabetes mellitus compared with hemoglobin $A_{16}$.

Clin Chim Acta 175: 135 142, 1988.

John WG, Webib AMC, Jones AE. Glycosylated haemoglobin and glycosylated albumin in non-diabetic and diabetic mothers, and their babies.

Diabetic Med 2: 103-104, 1985.

Johnson RN, Metcalf PA, Baker JR. Fructosamine: a new approach to the estimation of serum glycosylprotein. An index of diabetic control.

Clin Chim Acta 127: 87-95, 1982.

Jones IR, Owens DR, Williams S, et al. Glycosylated serum albumin: an intermediate index of glucose control.

Diabetes Care 6: 501-503, 1983.

Kalkhoff RK. Therapeutic results of insulin therapy in gestational diabetes mellitus.

Diabetes 34 (suppl.2): 97×100, 1985.

Karlsson K, Kjellmer I. The outcome of diabetic pregnancies in relation to the mother*s blood sugar level. Am J Obstet Gynecol 112: 2113-220, 1972.

Kennedy L, Mehl TD, Riley WJ, Merimee TJ. Non-enzymatically glycosylated serum protein in diabetes mellitus: an index of short-term glycaemia.

Diatbetologia 21: $94498,1981$.

Key TC, Giuffrida R, Moore TR. Predictive value of early pregnancy glycohemoglobin in the insulin. treated diabetic patient.

Ain J Obstet Gynecol 156: 1096*1100, 1987.

Kitsmiller $\mathbf{J L}_{\text {; }}$ Cloherty JP, Younger MD, et al. Diabetic pregnancy and perinatal morbidity. Am Jobstet Gynecol 131: 560-580, 1978.

Kobberling J, Kerlin A, Creutzeldt W. The reproducibility of the oral ghcose tolerance test over long (5 years) and short periods (1 week).

Klin Wochenschr 58: $527.530,1980$.

Koenig RJ, Peterson CM, Jones RL, Saudek C, Lehrman M, Cerami A. Correlation of glacose regulation and hemoglobin $A_{1 c}$ in diabetes mellitus..

N Engl J Med 295: 417-420, 1976.

Koenig RJ Blobstein SH, Cerami A. Structure of carbohydrate of hemoglobin $A_{10}$.

J Biol Chem 25: 2992-2997, 1977 . 
Koskinen P, Irjala K, Wiikari J, Panula-Ontto $\mathbf{R}$, Matikaunen MT. Setwm fructosamine in the assessment of glycaemic control in diabetes mellitus.

Scand J Clin Lab Irnest 47: 285-292, 1987.

Krause M, Pfuller H, Herbst D, Kruse K. Bedeutung des Serum Fruktosamins fur die Stoffwechselkontrolle bei Kindern und Jugendlichen nit Diabetes mellitus Typ 1.

Monatsschr Kinderheilkd 135: 200-203, 1987.

Krishnamoorthy $\mathbf{R}$, Gacon $G$, Labie $\mathbf{D}$. Isolation and partial characterization of $\mathrm{HbA}_{4 \mathrm{~b}}$. FEBS Letters. 77: 99-102, 1977.

Kroc collaborative study group. The kroc study patients at two years: a report on further retinal changes [Abstract].

Diabetes 34 (suppl 1): 39A. 1.985 .

Kucera $\mathbf{J}$. Rate and type of congenital anomalies among offspring of diabetic women.

J Reprod Med 7: 61-70, 1971.

Kutter D, Thoma J. Serum-Fructosamine, ein neuer Parameter zur indirekten Bestimmung des GlukoAlbumins und zur Halblangzeitüberwachung des Diabetikers.

Lab Med 9: 327-330, 1985 .

Kyle C, Baker J, Metcalf P, Johnson $\mathbf{R}$, Norris $\mathbf{R}$. Serum fructosamine as a screening method for diabetes mellitus in patients with suspected acute myocardial infarction.

Austr NZ J Med 17: 467-471, 1987.

Landon MB, Gabbe SG, Piana R, Mennuti MT, Main EK. Neonatal morbidity in pregnancy complicated by diabetes mellitus: Predictive value of maternal glycemic profilles.

Am J Obstet Gynec 156: 1089-1095, 1987.

Langer O, Mazze RS. Diabetes in pregnancy: Evaluating self-monitoring performance and glycemic control with memory-based reflectance meters.

Am J Obstet Gynecol 155: 635-637, 1986.

Leslie RDG, Pyke DA, John PN, White JM. Haemoglobin $A_{1}$ in diabetic pregnancy. Lancet 958-959, 1978.

Lester E, Frazer AD, Shephard CA, Woodroffe FJ. Glycosylated haemoglobin as an alternative to the glucose tolerance test for diagnosis of diabetes mellitus.

Anm Clin Biochem 22: 74-78, 1985.

Lim YS, Staley MJ. Measurement of plasma fructosamine evaluated for monitoring diabetes.

Clin Chem 31: 731-733, 1985 .

Lind T, Billewicz WZ, Brown G. A serial study of changes occurring in the oral glucose volerance test during pregnancy.

J Obstet Gynaecol Br Commonw 80: 1033-1039, 1973.

Lind T, Cheyne GA. Effect of normal pregnancy upon the glycosylated haemoglobins.

Br J Obstet Gynaecol 86: 210-213, 1979.

Lips JP. Het aantal kinderen met aangeboren afwijkingen van wrouwen met diabetes mellitus iype I in verband met het percentage geglycosyleerd hemoglobine wroeg in de zwangerschap.

Ned Tijdschr Geneeskd 1.32: 357-360, 1988(a).

Lips JP. Zwangerschap en insuline-afthankelijke diabetes. Klinisch en experimenteel onderzoek.

Thesis, Rotterdam. 1988(b). 
Litle RK, England JO, Wiedmeyer HM, et al. Relationship of glycosylated hemoglobin to oral glucose tolerance. Implications for diabetic screening.

Diabetes $37: 60-64,1988$.

Lioyd $\mathbf{D}$, Marples $\mathbf{J}$. Simple colorimetry of gilycated serum protein in al centrifugal analyzer.

Clin Chem 30: 1686-1688, 1984.

Lloyd D, Marples $J$. Serum fruetosamine and thyroid function [Letter].

Cin Chem $32: 1985,1986$.

Luber $\mathrm{G}_{\mathrm{s}}$ Pollak A. Reduced suspectibility of nonenzymatically glucosylated glomerular basement membrane to proteases: is thickening of diabetic glomerular basement membranes due to reduced proteolytic degradation?

Renal Physiol 3: 4-8, 1980.

Maillard LC. Réaction générales des acides aminés sur les sucres: ces conséquences biologique.

CR Soc Biol 72: 599-601, 1912.

Mefarland $\mathbf{K F}$, Catalano $\mathbf{E W}$, Day JF, Thorpe $\mathbf{S R}$, Baynes JW. Nonenzymatic glucosylation of serum proteins in diabetes mellitus.

Diatbetes $28,1011-1014,1979$.

MeDonald M.J, Shapiro R, Bileichman M, et al. Glycosylated minor components of human adult hemogloinin.

IBiol Chem 253:" 2327-2332, 1978.

Mereish KA, Rosenberg $\mathbf{H}$, Cobby J. Glucosylated alburnin and its influence on salicylate binding. J Pharm Sei 71: 235.238, 1982.

Micheel F, Klemer A. d-Glucosederivate von Proteine.

Chem Ber 89: 1238-1242, 1956.

Miedema K. Hemoglabine $A_{1 \mathrm{c}}$.

Thesis, RU Groningen. 1981.

Miedema $\mathbf{K}$, Casparie T. Glycosylated haemoglobins: biochemical evaluation and clinical utility. Ann Clin Biochem 21: 2-15, 1984.

Miller $\mathbf{E}$, Hare JW, Cloherty JP, et al. Elevated matermal hemoglobin $\mathrm{A}_{\mathrm{le}}$ in early pregnancy and major congental anomalies in infants of diabetic mothers.

N Engl J Med 304: 1331-1334, 1981 .

Mills JL., Baker $\mathrm{L}_{\mathrm{ip}}$ Goldman AS. Malformations in infants of diabetic mothers occur before the sewenth gestrational wek. Implications for treatment.

Diabeles $28: 292-293,1979$.

Milunsky A, Alpert E, Kitzmiller JL, Younger MD, Neff RK. Prenatal diagnosis of neural tube defects. VIII. The importance of serum alpha-fetoprotein screening in diabetic wonen.

Am J Obstet Gynecol $142: 1030-1032,1982$.

Monnier VM, Cerami A. Nonenzymatic glycosylation and browning of proteins in vivo.

In: Waller GR, Feather MS, eds. The Maillard reaction in foods and nutrition. American Chemical Society Symposium Series No. 215. Washington, D.C.: The American Chemical Society; 431.439, 1983.

Momier VM, Kohn RR, Cerami A. Accelerated age-related browning of human collagen in diabetes mellitus.

Proc Natl Acad Sci USA 81: $583-587,1984$. 
Monnier VM, Vishwanath V, Frank KE, et al. Relation between complications of type I diaberes mellius and collagen-linked fluorescence.

N Engl J Med 314: 403-408, 1986.

Moore JC, Outaw MC, Barnes AJ, Turner RC. Glycosylated plasma protein measurement by a semiautomated method.

Ann Clin Biochem 23: 198 203, 1986.

Moore TR, Hollingsw orth DR, Kolterman O, Nager $C$. Continuous subcutaneous insulin infusion in an obese insulin-resistant pregnant woman with type II diabetes: accelerated fetal growth and neonatal complications.

Obstet Gynecol 70: $480-485,1987$.

Morris MA, Grandis AS, Litton J. Glycosylated hemoglobin concentration in early gestation associated with neonatal outconve.

Am J Obstet Gynecol 153: 651-654, 1985(a).

Morris MA, Grandis AS, Litton J. The correlations of glycosylated serum protein and glycosylated hemoglobin concentrations with blood glucose in diabet ic pregnancy.

Am J Obstet Gynecoll 153:; 257-260, 1985(b).

Morris MA, Grandis AS, Litton J. Glycosylated hemoglobin: a sensitive indicator of gestational diabetes.

Obster Gynecol 68: 357-361, 1986(a).

Morris MA, Preddy L. Glycosylation accelerates albumin degradation in normal and diabetic dogs, Biochern Med Metab Biol 35: 267-270, 1986(b).

Mortensen HB. Glycated hemogliobin. Reaction and biokinetic studies. Clinical applications of hemoglobin $A_{\mathbb{l c}}$ in the assessment of metabolic control in children with diabetes mellitus.

Dan Med Bull 32: 309-329, 1985.

Mosca A, Carenini A, Zoppi F, et al. Plasma protein glycation as measured by fructosamine assay. Clin Chem 33: 1141-1146, 1987.

Nanjou S, Fujii S, Morita J, Ueda $\mathbf{K}$, Komano T. Sequence-specific alkali-labile lesions in DNA caused by $D$-isoglucosamine.

Biochim Biophys Acta 866: 44-52, 1986.

National Diabetes Data Group of the USA. Classification and diagnosis of diabetes mellitus and other categories of glucose intolerance.

Diabetes 28: 1039-1057, 1979.

Nelson DM, Barrows HJ, Clapp DH, Ortman-Nabi J, Whitehurst RM. Glycosylated serum protein levelis in diabetic and nondiabetic pregnant patients: An indicator of shorterm glycernic control in the diabetic patient.

Am J Obstet Gynecol 151: 1042-1047, 1985.

O'Sulliwan JB, Mahan CM. Glucose tolerance test. Variability in pregnant and nonpregnant women. An J Clin Nutr 19: 345-351, 1966.

O'Sullivan JB, Charles D, Mahan CM, Dandrow RV. Gestational diabetes and perinatal mortality rate. Am J Obstet Gynecol 116: 901-904, 1973(a).

O'Sulliwan JB, Mahan CM, Charles D, Dandrow RV. Screening criteria for high-risk gestational diabetic patients.

Am J Obstet Gynecol I:16:895-900, 1973(b). 
Oswald $\mathrm{GA}$, Smith $\mathrm{CC}$, Betteridge DI, Yudkin JS. Determinanks and impontance of stress hiyperglycae mia in non-diabetic patients with myocardial infarction.

Bir Med J 293: 917.922, 1986.

Palsey DB, Macfarlane $\mathrm{DG}_{\text {, sherriff }} \mathrm{AI}$, al al. The relationship between glycosylated haemoglobin and home capillary blood glucose levels in diabetics.

Diaberologia 19: 31-34, 1980.

Pecoraro RE, Koepsell TD, Chen MS, et al. Comparative clinical reliability of fasting plasma glucose concentration and glyoosylated hemoglobin in non-insulin-dependene diabetes mellitus.

Diabetes Care 9: $370.375,1986$.

Pedersen $\mathbf{J}$. The pregnant diabetic and her newborn. Problems and managentent. Second edition. Murikggard, Copenhagen; 1977.

Phelps RL, Honig GR, Green D, at al. Biphasic changes in hemoglobin $\mathrm{A}_{\text {ic }}$ concentrations during normal pregnancy.

Am 1 Obstêt Gynecol 147:651-653,1983.

Poll T, Lapotla A, Plebani M, Franchin A, Fedele D. Glycated serum protein determination: comparison between thiobarbituric acid and fructosamine assays.

Acta Diabetol Lat 24: 241-247, 1987.

Pollak A, Coradello H, Leban J et al. Inhibition of alkahine phosphatase activity by glucose. Clin Chim Acta 133: 15-24, 1983.

Radoff S, Vlassara H, Cerami A. Isolation of a macrophage receptor for proteins modified by advanced glycosylation end products (AGE) [Abstract].

Fed Proc 46: $2116,1987$.

Rahbar S, Blumenfeld O, Ranney HM. Studies of an unusual hemoglobin in patients with diabetes mellitus.

Biochem Biophys Res Comm 36: 838-843, 1969.

Raskin P, Pietra A, Unger R, Shannon WA Jr. The effect of diabetic control on the width of skeletalmuscle capillary basement membrane in patients with type $I$ diàbetes mellitus.

N Engl I Med 309: 1546-1550 "1983.

Raskin P, Rosenstock J. Blood glucose control and diabetic complications. Ann Intern Med 105: 254263, 1986.

Roberts AB, Batker JR, Court DJ, et al. Fructosamine in diabetic pregnancy. Lancet: $998.1000,1983$.

Roberts AB, Baker $\mathbf{A R}$. Serum fructosamine: a screening test for diabetes in pregnancy. Am J Obstet Gynecol 154: 1027-1030, 1986.

Roberts AB, Maker JR. Relationship between fetal growth and maternal fructosamine in diabetic pregnancy.

Obstel Oynecol 70: $242-246,1987$.

Roberts AB, Baker JR, James AJ, Henley P. Fructosanine in the management of gestational diabetes. Am J Obstet Gynecol 159: 66-71, 1988.

Roth M. 'Glycated hemoglobin,', not 'glycosylated' or "glucosylated" [Letter].

Clin Chem 29: 1991, 1983. 
Salemans THB, Van Dieijen-Visser MP, Brombacher PJ. The value of $\mathrm{HbA}$, and fructosanune in predicting abnormal glucose tolerance - an altermative to OGTT to detect diabetes mellitus or gestational diabetes?

Ann Clin Biochem 24: 447-452, 1987.

Schleicher E, Wieland OH. Specific quantification by HPLC of protein (lysine) bound glucose in human serum albumin and other glycosylated proteins.

J Clin Chem Clin Biochem 19: 81.-87, 1981.

Schleicher $\mathbb{E D}$, Gerbiti $\mathbf{K D}$, Dolhofer $\mathbf{R}_{\text {, }}$ et al. Clinical utility of nonenzymatically glycosylated blood proteins as an index of glucose control.

Diabetes Care 7: $548-556,1984$.

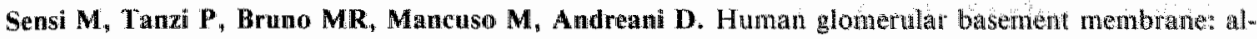
tered binding characteristics following in vitro non-enzymatic glycosylation.

An NY Acad Sci 488: 549-552, 1986.

Service Fl, Molnar GD, Taylor WF. Urine glucose analyses during continuous blood glucose monitoring.

JAMA 222: 294-298, 1972.

Service FJ, O'Brien PC, Rizza RA. Measurements of glucose control.

Diabetes Care 10: 225-237, 1987.

Shaklai N, Garlick RL, Bunn HF. Non-enzymatic glycosylation of human serum albumin alters it conformation and function.

J Biol Chem 259: 3812-3817, 1984.

Siperstein MD. The glucase tolerance test: a pitfall in the diagnosis of diabetes mellitus.

Adv Intern Med 20: 297-323, 1975.

Smart LM, Howie AF, Young RJ, et al. Comparison of fructosamine with glycosylated hemoglobin and plasma proteins as measures of glycemic control.

Diabetes Care 11: 433-436, 1988.

Stevens VS, Rouzer CA, Monnier VM, Cerami A. Diabetic cataract formation; potential role of glycosylation of lens crystallins.

Proc Natl Acad Sci USA 75: 2918-2922, 1978.

Swai ABM, Harrison K, Chuwa LM, et al. Sceening for diabetes: does measurement of serum fructosamine help?

Diabetic Med 5: 648-652, 1988 .

Teramo K, Aula P, Stenman UH, Kesaniemi-Kuokkanen T, Vlinen K. Increased risk of minor and major fetal malformations in diabetes with high hemoglobin $A_{\text {ic }}$ in early pregnancy.

In: Abstracts of the IX European Congress of Perinatal Medicine Dublin, Ireland. Clinch $\mathrm{J}$. Mathews $T$ (ed). 155, 1984.

Timperly WR, Ward JD, Preson FE, at al. Clinical and histological studies on diabetic neuropathy. Diabetologia 12: 237-243, 1976 .

Trivelli LA, Ranney HN, Lai HT. Hemoglobin components in patients with diabetes melifus.

N Engl J Med 284: 353-357, 1971.

Van Dieijen-Visser MP, Salemans THB, Van Werseh JWJ, Schellekens LA, Brombacher PJ . Gilycosylated serum proteins and glycosylated haemoglobin in normal pregnancy.

Ann Clin Blochem 23: 661-666, 1986(a). 
Vat Heyningen $\mathrm{C}$, Hand $\mathrm{TK}$, Hopkins 1 . Glycosylated haemoglobin by affinity chromatography in diabetic and non-diabetic children.

Ann Clin Biochem 23: $425-428,1986$.

Vracko R, Bendit EP. Restricted replicative life-span of diabetic fibroblasts in vitro: its relation to microangiopathy.

Fed Proc 34: 68-70, 1975.

WHO. Diabetes mellitus. Report of a WHO study group.

World Health Organization, Geneva. Technical report series $727,1985$.

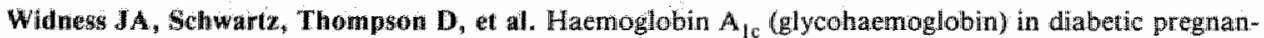
cy: an indicator of glucose control and fetall size.

Br J Obstet Gynaecol 85: $12-817,1978$.

Widness JA, Cowett RM, Coustan DR, Carpenter MW, Oh W. Neonatal morbidities in infants of mothers with glucose intolerance in pregnancy.

Díabetes 34 (suppl.2): 61-65, 1985.

Worthi R, Potter JM, Drury J, Fraser RB, Cullen DR. Glycosylated haemoglobin in normal pregnancy: a longitudinal study witli two independent methods.

Díbetologia 28: $76-79,1985$.

Yatseoff RW, Tewaarwerk GJM MacDonald JC. Quantification of nonenzymatically glycated albumin and total serum protein by affinity chromatography.

Clin Chem 30: 446-449, 1984. 


\section{Chapter 3}

\section{The fructosamine assay}

\subsection{Principle of the fructosamine assay}

In 1982 Johnson and co-workers introduced the fructosamine test, a new colorimetric method for the quantitation of GSPs (figure 2.1). The test is based on the ability of ketoamines (fructosamines) to reduce nitroblue tetrazolium (NBT) in an alkaline solution. In this medium, the reducing activity of ketoamines can be quantitated without significant interference from other reducing substances such as glucose and labile Schiff's bases (Gottschalk, 1952; Johnson et al., 1982). Fructosamine in alkaline medium is transformed to eneaminol which reduces NBT. This reduction is parallelled by the formation of formazan, a compound which can be measured spectrophotometrically (figure 3.1). The rate of formazan formation is directly proportional to the fructosamine concentration.

The exact mechanism of the reduction of NBT by fructosamine is not yet clear although, according to a recent report, a superoxide radical intermediate may be involved (Jones et al., 1987; figure 3.1).

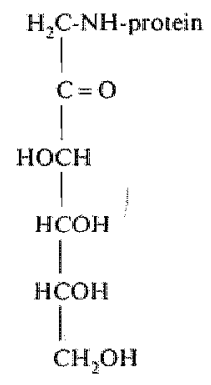

Tructosamine

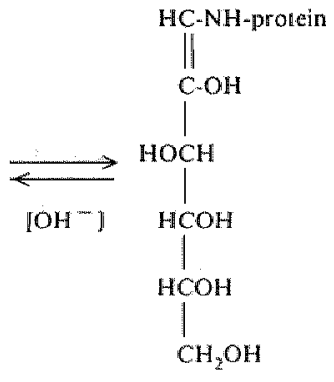

enetaminol

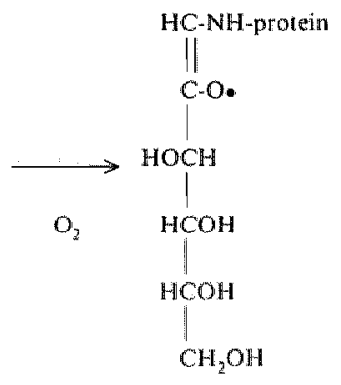

meaminol radical

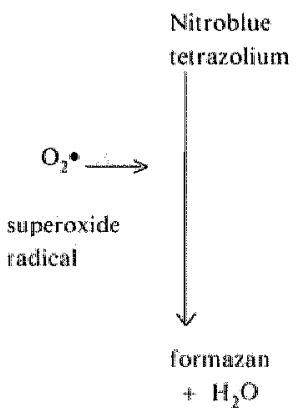

Figure 3' I Principle of the frwchosamine assay and possible mechanism for the involvement of superaxide radical ( $)$ in the fructosawine reaction

\subsection{Measurement of the serum fructosamine concentration}

In the present study we used the fructosamine assay according to Johnson and coworkers (1982) with test kits from Roche Diagnostics, Basel, Switzerland (product no. 0711217). Serum samples were analysed on a Cobas Bio centrifugal fast 
analyser (Roche). $20 \mu$ of serum and $50 \mu \mathrm{l}$ of deionized water were mixed with 200 $\mu$ of reagent, containing $0.25 \mathrm{mmol} / \mathrm{I} \mathrm{NBT}$ in $100 \mathrm{mmol} / \mathrm{I}$ sodium carbonate buf fer at pH $10.35\left(25^{\circ} \mathrm{C}\right)$. After incubation for 10 minutes at $37^{\circ} \mathrm{C}$, the increase of absorbance at $530 \mathrm{~nm}$ was measured between 10 minutes and 15 minutes after the start of the reaction. The 10 minutes incubation time is necessary to allow fast reacting interfering substances such as ascorbate and glutathione to react (Johnson et al., 1982). Because glucose reduces NBT at a $\mathrm{pH}$ above 11 but does not react between $\mathrm{pH} 10$ and 11 , there is no need to remove endogenous glucose from the patients' blood samples. The calibrator in the test kit contained a glycated protein standard, calibrated on 1-desoxy-1-morpholinofructose (DMF), a synthetic Amadori rearrangement product. In each run two or three different control sera were included for additional assay control. The fructosamine concentrations were calculated according to the equation:

$\frac{\left(A_{1+15 \sin }-A_{t=10 m i n}\right) \text { sample }}{\left(A_{t=15 \min }-A_{t \infty 10 m i n}\right) \text { standard }} \times[C]$ standard

A: absorbance at $530 \mathrm{~nm}$ at time $\mathrm{t}$

$\mathrm{C}$ : fructosamine concentration in $\mathrm{mmol} / \mathrm{l}$

\subsection{Evaluation of the assay}

\subsubsection{Linearity of the assay; effect of dilution of the sample}

The relation between the absorbance at $530 \mathrm{~nm}$ and the fructosamine concentration is linear up to $8 \mathrm{mmol} / \mathrm{I}$ DMF equivalents (Jehnson et al., 1982), as has been confirmed by own (unpublished) results. Samples with fructosamine concentrations exceeding $8 \mathrm{mmol} / 1$ should be diluted.

The effect of serum sample dilution on the fructosamine concentration was studied as follows. A 1:1 dilution of 15 serum samples in distilled water or saline gave rise to an overestimation of the fructosamine concentration by about $20 \%$ (table 3.1). Dilution with various albumin-containing solutions led also to an overestimation. Overestimation could only be prevented by diluting the serum under investigation in pooled serum (table 3.1). The skewing caused by dilution in protein-free fluids is probably a result of the matrix-dependent optical absorbance characteristics of formazan (Johnson et al., 1982). The optical density of a given formazan solution varies depending on the composition and concentration of proteins in the diluent solution. 
Table 3.1 Effect of serum sample dilurion in different media on the fructosamine concentra tion

\begin{tabular}{lll}
\hline Solution & $\begin{array}{l}\text { Mean recovery* }(\%) \text { after } \\
1: 1 \text { dilution of } 15 \text { serum } \\
\text { samples }\end{array}$ & $\begin{array}{l}\text { SD } \\
(\%)\end{array}$ \\
\hline Distilled water & 123 & 4.4 \\
Saline & 122 & 4.0 \\
Albumin $20 \mathrm{~g} / \mathrm{I}^{* *}$ & 121 & 5.0 \\
Albumin $30 \mathrm{~g} / \mathrm{l}$ & 116 & 3.7 \\
Albumin $35 \mathrm{~g} / 1$ & 112 & 4.1 \\
Albumin $40 \mathrm{~g} / 1$ & 114 & 3.3 \\
Pooled serum & 100 & 1.2 \\
\hline
\end{tabular}

* Fructosamine concentration expressed as a percentage of the concentration in the undiluted sample.

* Albumin solutions were all prepared with distilled water.

** A correction was made for the fructosamine concentration of the pooled serum.

\subsubsection{Assay precision}

To evaluate the assay precision, intra-run and inter-run variations were determined. The intra-run precision was estimated by analysing, in 20-fold, 5 control sera in one single run. The inter-run precision was obtained by repeating the analysis of these 5 control sera daily over a period of 10 days. The results are listed in table 3.2. The low intra-run as well as inter-run assay variation agree well with reports of other investigators (Zeyen et al., 1986; Koskinen et al., 1987; Kverneland et al., 1987), and emphasize the high precision of the method.

Table 3.2 Precision of the fructosamine assay

\begin{tabular}{llllll}
\hline & \multicolumn{2}{c}{$\begin{array}{l}\text { Intra-run } \\
(\mathrm{n}=20)\end{array}$} & & \multicolumn{2}{c}{$\begin{array}{l}\text { Inter-run } \\
(\mathrm{n}=10)\end{array}$} \\
\cline { 2 - 3 } \cline { 5 - 6 } Control serum & Mean* & CV $(\%)$ & & Mean $^{*}$ & CV (\%) \\
\hline Monitrol I (LTD 205) & 6.51 & 1.5 & 6.40 & 2.1 \\
Monitrol II (PTD 107) & 6.16 & 1.4 & & 6.06 & 2.7 \\
Merck and Dade & 4.31 & 0.9 & & 4.27 & 1.7 \\
Roche N (lot P1039) & 4.60 & 0.5 & & 4.40 & 2.2 \\
Roche P (lot P2439) & 5.41 & 0.9 & 5.31 & 2.7 \\
\hline
\end{tabular}

* Mean fructosamine concentration (mmol/1)

CV: coefficient of variation. 
3.3.3 Effect of freezing; thawing, and long-term storage on the fructosamine concentration

In the laboratory, serum is often stored in a freezer before analysis. To study the effect of freezing and thawing on the fructosamine concentration, two different batches of pooled sera were divided into aliquots and stored in a freezer at $-20^{\circ} \mathrm{C}$. Every time fructosamine measurements were performed, aliquots of the two pooled sera were also thawed and analysed. During a one year period, the fructosamine concentrations of the two frozen pooled sera remained virtually unchanged with coefficients of variation not exceeding the one determined for the inter-run assay (table 3.3). We therefore conclude that the fructosamine concentration is not affected by the long-term storage of serum at $-20^{\circ} \mathrm{C}$.

Furthermore, the fructosamine concentrations of lyophilized control samples (Autonorm) were measured in every series of fructosamine measurements to serve as an extra control of the assay. These samples showed a slightly higher variation than did the pooled sera (table 3.3).

From the above, it follows that frozen pooled serum may be used as an (secondary) standard with confirmed stability for more than one year. The use of such a standard neatly overcomes matrix problems in the analysis.

Table 3.3 Effect of freezing, thawing, and long-term storage on fructosamine stability

\begin{tabular}{lllllll}
\hline & $\begin{array}{l}\text { Length of } \\
\text { storage } \\
\text { period } \\
\text { (weeks) }\end{array}$ & $\begin{array}{l}\text { Number of } \\
\text { measure- } \\
\text { ments dur- } \\
\text { ing storage }\end{array}$ & $\begin{array}{l}\text { Fructosamine } \\
\text { concentration } \\
\text { (mmol/1) }\end{array}$ & $\begin{array}{l}\text { CV } \\
(\%)\end{array}$ & $\begin{array}{l}\text { Range of } \\
\text { fructosamine } \\
\text { concentration } \\
\text { (mmol/D) }\end{array}$ \\
\hline Pooled serum A* & 52 & 118 & 2.53 & 0.07 & 2.8 & $2.36-2.68$ \\
Pooled serum 13* & 48 & 146 & 2.51 & 0.07 & 2.9 & $2.36-2.72$ \\
Autonorm Low * & 28 & 71 & 3.06 & 0.09 & 3.0 & $2.89-3.24$ \\
Autonorm 244* & 35 & 97 & 4.37 & 0.16 & 3.8 & $4.06-4.82$ \\
Autonorm High** & 28 & 65 & 6.70 & 0.29 & 4.3 & $6.13-7.26$ \\
\hline
\end{tabular}

* Storage in aliquots at $-20^{\circ} \mathrm{C}$

Lyophilized control samples

CV: Coefficient of variation

\subsection{Sensitivity to rapid glycaemic change}

Non-enzymatic glycation of proteins is initiated by the formation of Schiff's base. This reaction between glucose and protein is reversible and the aldimine formed, if not eliminated during the assay, might cause rapid changes in the glycated protein concentration, as has been observed for glycated haemoglobin (Svendsen et al., 
1980). However, we confirmed the previously suggested (Lemon and Forrest, 1986; Mosca et al., 1987) negligible effect of rapid glycaemic changes on the fructosamine test in five randomly selected patients in whom an OGTT was performed. In the three hour period after the $75 \mathrm{~g}$ glucose load, a brief elevation in blood glucose concentration had no appreciable effect on the fructosamine concentration. The intraindividual (intra-run) variation within this period was less than $3 \%$ (table 3.4). Therefore, blood for fructosamine measurement can be sampled at any time during the day; analysis results are independent of the time since the last meal.

Table 3.4 Effect of $75 \mathrm{~g}$ oral glucose load on the fructosamine concentration

\begin{tabular}{llllll}
\hline Patient nr. & 1 & 2 & 3 & 4 & 5 \\
\hline $\begin{array}{l}\text { Minutes after } \\
\text { glucose load }\end{array}$ & & & Fructosamine (mmol/l) & \\
\hline 0 & 2.31 & 2.22 & 2.21 & 1.94 & 2.02 \\
30 & 2.21 & 2.16 & 2.31 & 2.02 & 2.12 \\
60 & 2.24 & 2.13 & 2.15 & 2.01 & 2.09 \\
90 & 2.22 & 2.19 & 2.30 & 1.98 & 2.08 \\
120 & 2.19 & 2.15 & 2.26 & 2.07 & 2.15 \\
180 & 2.26 & 2.10 & 2.29 & 2.08 & 2.11 \\
Mean & 2.24 & 2.16 & 2.25 & 2.02 & 2.10 \\
S.D. & 0.04 & 0.04 & 0.06 & 0.05 & 0.04 \\
& & & Coefficient of variation (070) & \\
& 1.9 & 2.0 & 2.8 & 2.6 & 2.1 \\
\hline
\end{tabular}

\subsection{The influence of variations in the albumin or total protein concen- tration on the serum fructosamine concentration}

It has been suggested that the serum fructosamine concentration is independent of the albumin or total protein concentration if the serum albumin concentration is higher than $30 \mathrm{~g} / 1$ (Baker et al., 1983) or $35 \mathrm{~g} / 1$ (Lloyd and Marples, 1984). In hospitalised subjects who are usually immobilised and in a supine position, the serum protein concentration is often reduced to a levell below $30 \mathrm{~g} / \mathrm{l}$ due to increased catabolism and redistribution of body water and albumin. Nevertheless, serum fructosamine concentrations in hospitalised non-diabetic patients were found to be comparable with those in ambulatory non-diabetic subjects (Lim and Staley, 1985). In order to define more precisely the role of serum proteins on the concentration of fructosamine, we studied the relation between these two variables. The serum concentrations of fructosamine, albumin and total protein were measured in $103 \mathrm{pa}$ tients who had no obvious signs of diabetes mellitus and whose fasting glucose con- 
centrations were below $5.5 \mathrm{mmol} / \mathrm{l}$. The population sample studied included $84 \mathrm{pa}-$ thents with albumin concentrations above $30 \mathrm{~g} / \mathrm{l}$ and 19 patients with allbumin concentrations below $30 \mathrm{~g} / \mathrm{l}$. The serum fructosamine concentration was found to be correlated $(p<0.001)$ with both the serum albumin and total serum protein concentrations. The slope of the regression line calculated for the 84 patients with albumin concentrations above $30 \mathrm{~g} / 1$ showed virtually no change when this group was supplemented with the 19 patients who had low albumin concentrations (table 3.5 ). This suggests that the mathematical relationship between fructosamine and serum protein is similar over the entire range of serum protein concentrations $(21-46 \mathrm{~g} / 1$ albumin) in this particular group of patients.

Table 3.5 Linear regression of serum fructosamine as the dependent variable (y) with serum albumin $(g / l)$ and total serum protein $(g / l)$ as the independent variables $(x)$, respectively. The $r$ represents the Pearson correlation coefficient.

\begin{tabular}{lrll}
$\mathrm{x}$ & $\mathrm{n}$ & $\mathrm{r}$ & regression line \\
\hline Albumin $(>30 \mathrm{~g} / \mathrm{l})$ & 84 & 0.50 & $\mathrm{y}=0.023 \mathrm{x}+1.22$ \\
Allbumin (all) & 103 & 0.66 & $\mathrm{y}=0.026 \mathrm{x}+1.10$ \\
& & & \\
Total protein (alb $>30 \mathrm{~g} / \mathrm{l})$ & 84 & 0.52 & $\mathrm{y}=0.020 \mathrm{x}+0.69$ \\
Total protein (all) & 103 & 0.67 & $\mathrm{y}=0.023 \mathrm{x}+0.44$
\end{tabular}

All correlations are significant $(\mathrm{p}<0.001)$

From the regression equation in table 3.5 it can be deduced that a decrease in serum albumin of $1 \mathrm{~g} / \mathrm{I}$ requires an increase of the fructosamine concentration actually measured with $0.026 \mathrm{mmol} / \mathrm{l}$, or roughly $1 \%$ fructosamine correction per gram albumin change. For correction (standardisation) of the fructosamine concentration to $40 \mathrm{~g}$ albumin $/$, the following equation can be used:

$F r_{\text {com }}=\mathrm{Fr}+0.026[40-\mathrm{Alb}]$,

where $\mathrm{Fr}_{\text {serr }}$ is the corrected fructosamine concentration (mmol/l), $\mathrm{Fr}$ represents the fructosamine concentration actually measured $(\mathrm{mmol} / \mathrm{l})$, and $\mathrm{Alb}$ the serum albumin concentration $(\mathrm{g} / \mathrm{l})$ measured concomitantly.

It goes without saying that correction for variations in the albumin concentration within the inter-run error of the albumin assay $(\mathrm{CV}=5 \%$ ) is trivial. Therefore, this correction is only recommended when the fructosamine concentration is measured intermittently in patients in whom the serum albumin concentration fluctuates over a wide range $(>10 \mathrm{~g} / \mathrm{l})$. In general, correction of the fructosamine concentration for the albumin level is not necessary. 


\section{References}

Baker $\mathbf{J R}_{\text {" }}$ O'Connor $\mathbf{J P}_{\text {" }}$ Metcalf PA, Lawson MR and Johnson RN. Clinical usefulness of estimation of serum fructosamine concentration as a screening test for diabetes mellitus.

Br Med J 287: 863-867, 1983.

Gotschalk A. Some biochemically relevant properties of $\mathrm{N}$-substituted fructosamines derived from amino-acids and $\mathrm{N}$-arylglucosylamines.

Biochem J 52: 455-460, 1952.

Johnson RN, Metcalf PA, Baker JR. Fructosamine: a new approach to the estimation of serum glycosylprotein. An index of diabetic control.

Clin Chim Acta 127: 87-95, 1982.

Jones Af, Winkles JW, Thornalley PJ, et al. Inhibitory effect of superoxide dismutase on fructosamine asssay.

Clin Chem 33: 147-149, 1987.

Koskinen P, Irjala K, Viikari J, Panula-Ontto R, Matikainen MT. Serum fructosamine in the assessment of glycaemic control in diabetes mellitus.

Scand J Clin Lab Invest 47: 285-292, 1987.

Kwerneland $\mathbf{A}$, Lundgren $\mathbf{J}$, Binder $\mathbf{C}$. Fructosamine in assessment of glycaemic control in IDDM. Acta Endocr 115 (suppl 282): 33, 1987.

Lemon M, Forrest ARW. Fructosamine activity of proteins in serum.

Clin Chem 32: 2101, 1986.

Lim YS, Staley MJ. Measurement of plasma fructosamine evaluated for monitoring diabetes.

Clin Chem 31: 731-733, 1985 .

Lloyd D, Marples J. Simple colorimetry of glycated serum protein in a centrifugal analyzer.

Clin Cheri 30: 1686-1688, 1984.

Mosca A, Carenini A, Zoppi F, et al. Plasma protein glycation as measured by fructosamine assay. Clin Chem 33: 1141-1146, 1987.

Svendsen PA, Christiansen JS, Soegaard $V$, Welinder BS, Nerup G. Rapid changes in chromatographically determined haemoglobin $A_{1 c}$ induced by short-term changes in glucose concentration.

Diabetologia 19: 130-136, 1980.

Zeyen LJJM, Vermes I, Van der Veen EA. Serum fructosamine, een nicuwe parameter voor diabétescontrole.

Tijidschrifi NVKC 11:8-11, 1986. 



\section{Chapter 4}

Comparison of fructosamine, glycated haemoglobin and postprandial blood glucose concentrations as measures of glycaemic control in non-insulin dependent diabetics

T.H.B. Salemans, M.P. Van Dieijen-Visser, F.A.Th. Lustermans, P.J. Brombacher.

(submitted for publication)

\section{Summary}

In this study we determined the value of fructosamine and $\mathrm{HbA}_{1}$ relative to that of postprandial glucose as measures of glycaemic control in patients with non-insulin dependent diabetes mellitus (NIDDM). To this end, the relation between venous plasma glucose two hours after breakfast, fructosamine and $\mathrm{HbA}_{\mathrm{f}}$ was studied in 180 elderly NIDDM patients. The fructosamine and $\mathrm{HbA}_{\|}$concentrations were found to correlate with the glucose concentration two hours after breakfast $(r=0.66, p<0.0001$ and $r=0.74, p<0.0001$, respectively). They were also related to each other $(r=0.75, p<0.0001)$. The strength of the correlation between fructosamine and the other two variables did not increase by correcting the fructosamine concentration for the albumin concentration.

A literature surwey on the relation between glucose control, fructosamine and $\mathrm{HbA}_{1}$ is included for comparison with data published elsewhere. It is concluded that fructosamine may serve as an attractive alternative to $\mathrm{HbA}_{1}$ for control of the more recent glycaemic status in NIDDM patients. 


\section{Introduction}

Effective management of diabetic patients requires a reliable method for the regular evaluation of the glycaemic status. Such a method should be accurate, easy to perform, and inexpensive. Moreover, the method should be independent of food intake and physical activity, in order to allow random measurement. Unfortunately, none of the methods currently employed measure up to all these criteria.

Nowadays, self-monitoring of blood glucose has gained widespread application in the clinical assessment of the glycaemic status. However, a drawback of selfmonitoring is its dependence on patient compliance. Even in presumably wellmotivated pregnant diabetics who were aware of the importance of normoglycae$\mathrm{mia}$, it has been demonstrated that the self-reported glucose concentrations were significantly lower and less variable than the true glucose values simultaneously obtained with a memory-based reflectance meter (Langer and Mazze, 1986).

Fasting blood glucose measurement as an outpatient is inconvenient and it has been demonstrated that its value for evaluating the glycaemic status should be interpreted with caution, especially in insulin-dependent diabetics (Service et al., 1987).

In order to check the glycaemic status, the value of random blood glucose measurement is limited because the blood glucose concentration in diabetics depends on many factors and may fluctuate widely.

As food ingestion forms the most important challenge for endogeneous blood glucose control, the postprandial blood glucose measurement provides useful information about the body's capacity to prevent the blood glucose concentration increasing excessively. In the management of diabetics, the peak in venous plasma glucose concentrations 90 to 120 minutes after a meal should not exceed $11.1 \mathrm{mmol} / \mathrm{l}$ (WHO Report, 1985). However, the peak in postprandial blood glucose may be difficult to determine as it varies with intestinal absorption, carbohydrate composition and quantity in the meal, and physical exercise in the period between meal and blood sampling (Service et al., 1983; Bantle et al., 1983). Nevertheless, the method is commonly used in the management of diabetics.

In contrast to the glucose concentration, the concentration of non-enzymatically glycated proteins provides indirect information on glucose control over a prolonged period. The glycated haemoglobin $\left(\mathrm{HbA}_{1}\right)$ concentration reflects the mean blood glucose concentration over the preceding 6-10 weeks (Koenig et al., 1976; Gonen et al., 1977; Gabbay et al., 1977; Bunn et al., 1978), whereas the glycated serum protein (GSP) concentration is an estimate of the average blood glucose concentration over the past 1-3 weeks (Mc Farland et al., 1979; Dolhofer and Wieland, 1979). These characteristics of the latter two variables imply that the information generated is complementary to glucose measurements. Since these tests are not influenced by short-term fluctuations in blood glucose level (chapter 3), they are independent of patient compliance and can be determined irrespective of the times of meals. Unfor- 
tunately, the introduction of the HbA, and GSP measurements as routine clinical methods in the management of diabetics has often been hampered by the laborious and expensive measurement techniques required.

Johnson and co-workers (1982) described a simple, cheap, rapid, automated and precise method for measurement of the GSP concentration, the so-called fructosamine assay. Tó determine whether the measurement of the fructosamine concentration may be an alternative to the currently used parameters of glucose control in NIDDM patients, we compared the fructosamine concentrations with simultaneously measured plasma glucose concentrations two hours after breakfast and with $\mathrm{HbA}_{1}$ concentrations.

\section{Patients}

During a period of sixteen months ending January 1989, 180 elderly NIDDM patients at the diabetic clinic of the De Wever Hospital in Heerlen agreed to participate in this study. The group comprised 64 males and 116 females. Their ages ranged from 34 to 88 years with a mean of 67 years. Diabetic control was accomplished by diet, occasionally supplemented with oral hypoglycaemic drugs. In many elderly patients glycaemic control was poor, often due to low motivation to comply with the treatment regimen advised.

The patients were instructed to have their blood sampled at the time of their subsequent visit at 2 hours after breakfast. The concentrations of plasma glucose, fructosamine, $\mathrm{HbA}_{1}$, and albumin were determined in this sample.

\section{Analytical techniques}

\section{Glucose}

Blood for venous plasma glucose measurement was collected into tubes containing fluoride (Sarstedt). Immediately after centrifugation at $3000 \mathrm{rpm}$ for 5 minutes, the plasma sample was analysed on a Cobas ${ }^{\circledast}$ Bio centrifugal fast analyser using the Gluco-quant glucose test combination (Boehringer, Mannheirn, Germany; product no. 245178). This test is based on the hexokinase/glucose-6-phosphate dehydrogenase reaction. 


\section{Glycated haemoglobin}

For the measurement of glycated haemoglobin, $5 \mathrm{ml}$ blood was collected into tubes containing $\mathbb{K}_{3} H$.EDTA. The analysis was performed with the haemoglobin $A_{1}$ ionexchange column test (Biorad, Richmond, USA; product no. 1917001).

\section{Fructosamine}

The fructosamine assay was performed according to Johnson et al. (1982). The test is based on the non-enzymatic formation of fructosamine from glucose and proteins, which can be quantitated by nitroblue tetrazolium reduction in an alkaline medium. Serum samples were analysed on a Cobas ${ }^{\circledast}$ Bio centrifugal fast analyser with instrument setting as described by Roche (Roche Diagnostics, Basel, Switzerland; product no. 0711217) (see chapter 3 ). In table 4.1 the assay precision, time of analysis and costs of the $\mathrm{HbA}_{1}$ determination are compared with those of the fructosamine determination. The fructosamine measurement has a better intra-run and inter-run precision, and is less time-consuming and expensive than the microcolumn $\mathrm{HbA}_{1}$ measurement.

Table 4.I Assay precision, determination time and costs of fructosamine measurement compared with those of $H b A$,

\begin{tabular}{lll}
\hline & $\begin{array}{l}\mathrm{HbA}_{1} \\
\text { column } \\
\text { chromatography }\end{array}$ & Fructosamine \\
\hline Intra-run precision & $2-4 \%$ & $1-2 \%$ \\
Inter-run precision & $4-7 \%$ & $2-4 \%$ \\
Time per run (min) & 180 & 15 \\
Determinations per hour & 16 & 90 \\
Reagent cost per determination (Dfl) & 6.50 & 0.65 \\
\hline
\end{tabular}

\section{Albumin}

Serum albumin was measured on a Cobas ${ }^{(0)}$ Bio centrifugal fast analyser using Bromocresol green as a reagent (Electro-Nucleonics, Breda, Netherlands; product no. R5-1). Albumin concentrations were measured to allow correction of fructosamine concentrations by using the following equation:

$\mathrm{Fr}_{\text {corr }}=\mathrm{Fr}+0.026[40-\mathrm{Alb}]$,

where $\mathrm{Fr}_{\text {corr }}$ is the corrected fructosamine concentration (mmol/l), Fr represents the measured serum fructosamine concentration $(\mathrm{mmol} / \mathrm{l})$ and $\mathrm{Alb}$ the measured serum allbumin concentration $(\mathrm{g} / \mathrm{l})$ (chapter 3$)$. 


\section{Statistical analysis}

Correlations were determined by linear regression analysis with the least squares method. A probability of less than $5 \%(\mathrm{p}<0.05)$ was considered significant.

\section{Results}

The relations between the various parameters are presented as scattergrams in figure 4.1 $(\mathrm{A}, \mathrm{B}, \mathrm{C})$. Both the fructosamine and the $\mathrm{HbA}_{1}$ concentrations correlated with the postprandial glucose level. A correlation was also found between the fructosamine and $\mathrm{HbA}_{1}$ concentrations. Correction of the fructosamine concentration for the albumin concentration did not improve the correlations. The mean values, standard deviations and ranges of the measurements are listed in table table 4.2, whereas the correlation coefficients for each of the relationships tested are presented in table 4.3. All correlations are highly significant $(p<0.0001)$.

Table 4.2 Mean, standard deviation (S.D) and range of various measurements in 180 NIDDM patients

\begin{tabular}{llll}
\hline & Mean & S.D & Range \\
\hline Glucose $2 \mathrm{~h}$ after breakfast $(\mathrm{mmol} / \mathrm{l})$ & 12.4 & 5.03 & $4.0-28.0$ \\
Albumin $(\mathrm{g} / \mathrm{l})$ & 39.2 & 2.70 & $28-47$ \\
Fructosamine $(\mathrm{mmol} / \mathrm{l})$ & 3.13 & 0.54 & $2.09-4.80$ \\
$\mathrm{HbA}_{1}(\%)$ & 10.1 & 2.1 & $5.9-1.6 .4$ \\
\hline
\end{tabular}

Table 4.3 Correlation coefficients (r) calculated for a mumber of relations bet ween various parameters of glycaemic control in 180 NIDDM patients

\begin{tabular}{lll}
\hline $\begin{array}{l}\text { Dependent } \\
\text { variable }(y)\end{array}$ & $\begin{array}{l}\text { Independent } \\
\text { variable }(\mathrm{x})\end{array}$ & 0.66 \\
\hline Fructosamine & Glucose $2 \mathrm{~h}$ after breaklast & 0.67 \\
Fructosamine* & Glucose $2 \mathrm{~h}$ after breakfast & 0.74 \\
Haemoglobin $\mathrm{A}_{1}$ & Glucose $2 \mathrm{~h}$ after breakfast & 0.75 \\
Fructosamine & Haemoglobin $\mathrm{A}_{1}$ & 0.77 \\
Fructosamine & Haemoglobin $\mathrm{A}_{1}$ & \\
\hline
\end{tabular}

Fructosamine*: fructosamine corrected to $40 \mathrm{~g}$ albumin/ $($ see text for correction method). All correlations are significant $(p<0.0001)$. 


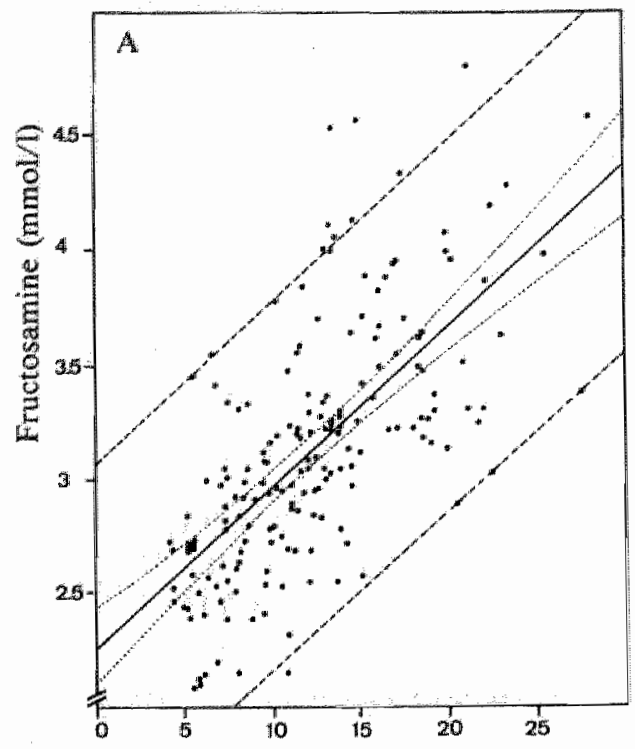

Glucose concentration $2 \mathrm{~h}$ after breakfast (mmol/l) $y=2.26+0.07 x ; r=0.66$

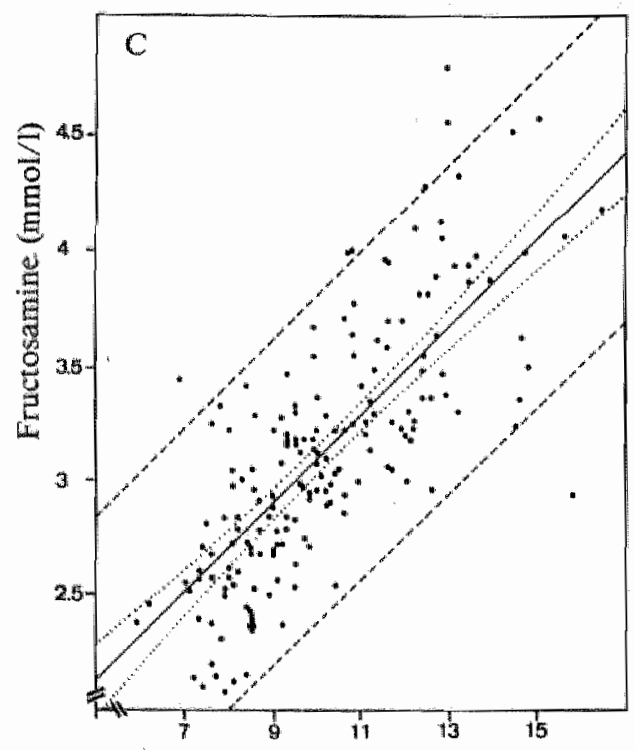

$\operatorname{HbA}_{1}(\%)$

$y=1.18+0.19 x_{r} r=0.75$

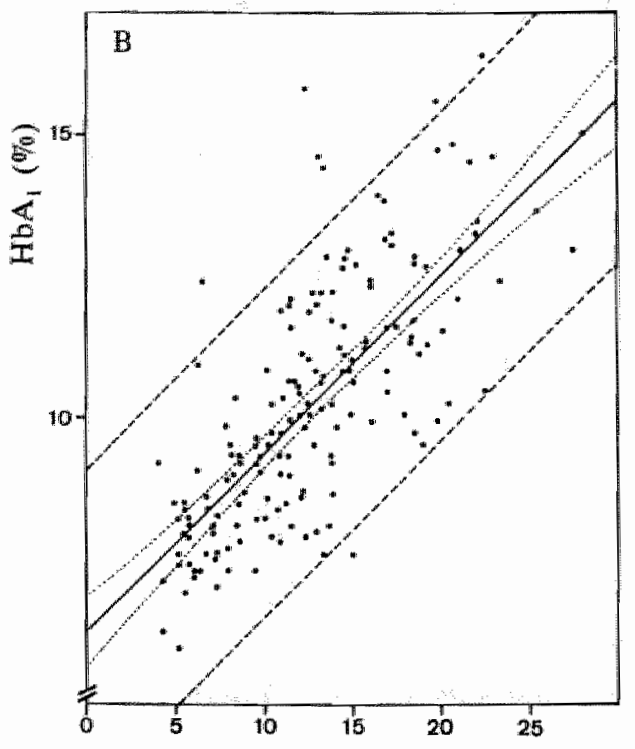

Glucose concentration $2 \mathrm{~h}$ after breakfast (mmol/l) $y=6.29+0.31 x ; r=0.74$
Figure 4.1

Relation between fructosamime and postprandial glucose $(A), H b A$, and postprandial gitucose $(B)$, and $H b_{1} A_{1}$ and fructosamine (C) in 180 non-insulin dependent diabetics.

The linear regression (_including $95 \%$ confidence limits of regression line (..........) and $95 \%$ prediction limits of sample points (- - -) are shown. 


\section{Discussion}

In diabetics, maintenance of normoglycaemia either by diet, oral hypoglycaemic drugs or insulin is important to reduce diabetic symptoms and to prevent or delay specific complications commonly associated with the disease. Various prospective trials have provided evidence that long-term near normoglycaemia may postpone the development and/or diminish the severity of late diabetic complications (Deckert et al., 1983; Holman et al., 1983; Raskin et al., 1983; Dahl-Jorgensen et al., 1986).

In clinical practice, routine diabetic control is often performed by measuring the glucose concentration 90 to 120 minutes after a meal. In NIDDM patients we have shown that both the fructosamine and the $\mathrm{HbA}_{1}$ concentrations correlate well with the glucose level 2 hours after breakfast, an observation in agreement with the results from a recent study in 104 NIDDM patients (Smart et al., 1988).

Although the fructosamine concentration does co-vary with the serum albumin concentration (chapter 3), this relationship has little practical consequence for ambulatory patients. This is suggested by the lack of improvement in the correlation between fructosamine and postprandial glucose levels when the fructosamine concentrations were 'standardised' at $40 \mathrm{~g} / \mathrm{I}$ albumin, in spite of a wide variation in albumin concentrations $(28-47 \mathrm{~g} / \mathrm{l})$.

Table 4.4 presents a review of the literature on relations between glucose control, fructosamine and $\mathrm{HbA}_{1}$. This table illustrates that most studies in diabetics report a good correlation between the fructosamine and $\mathrm{HbA}_{1}$ concentrations on the one hand and the quality of glucose control on the other. The correlations are not influenced by the method of $\mathrm{HbA}_{1}$ measurement. From table 4.4 it can also be deduced that in NIDDM patients both the fructosamine and $\mathrm{HbA}_{1}$ measurements provide a better estimate of glycaemic control than in IDDM patients (Mosca et al., 1987; Smart et al., 1988). This may be related to the narrower range between which glucose fluctuates in NIDDM than in IDDM patients.

Although most authors report good correlations between glucose control, fructosamine and $\mathrm{HbA}_{b}$, it should be emphasized that the wide variations of glucose concentrations in the patients studied have some positive effect on the correlations. For clinical practice one should realize that small short-term oscillations in glucose level around the mean have virtually no influence on the fructosamine and $\mathrm{HbA}_{1}$ concentrations. It is likely that the low screening value of the fructosamine and $\mathrm{HbA}_{1}$ measurements for identifying patients with impaired glucose tolerance is a consequence of this characteristic (Salemans et al., 1987). 


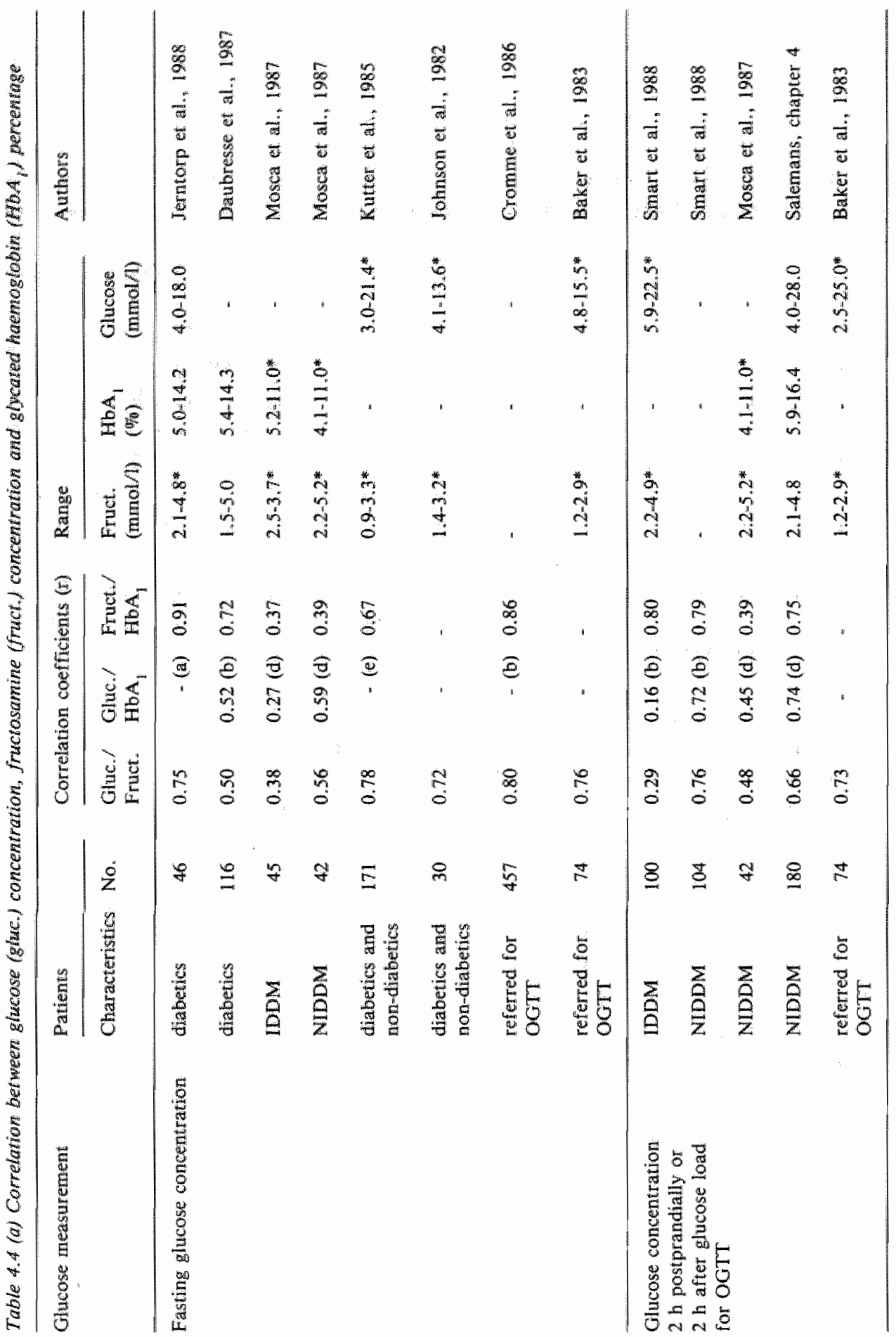




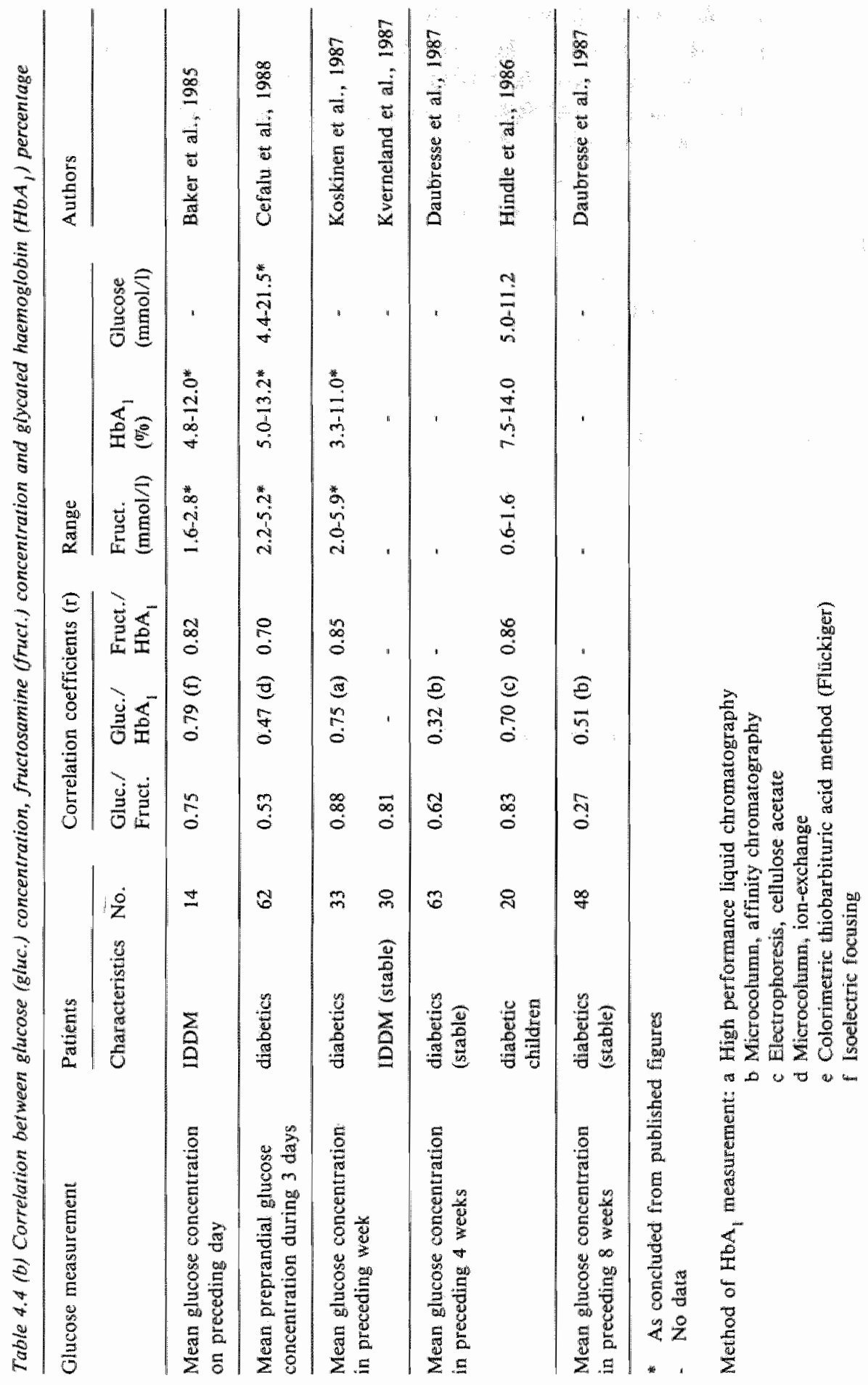


Fructosamine measurement has been found by many investigators to be as valuable as $\mathrm{HbA}_{1}$ measurement for use in the evaluation of the glucose control over a period up to 4 weeks, especially in NIDDM (table 4.4). Because fructosamine measurement is less expensive and easier to perform than most $\mathrm{Hb}_{1}$ measurement techniques, the former should be preferred for this purpose. Moreover, the fructosamine measurement is theoretically preferable to the $\mathrm{HbA}_{1}$ measurement for the estimation of glucose control over the preceding 4 weeks; fructosamine, with a half-life of 2-3 weeks, provides a better representation of the glycaemic status over this period than $\mathrm{HbA}_{1}$ which has a half-life of 10 weeks. This presumption also implies that the $\mathrm{HbA}_{1}$ determination should be held as the method of choice for the assessment of long-term glycaemic control (table 4.4, Daubresse et al., 1987), especially in patients with IDDM.

In short, both fructosamine and $\mathrm{HbA}_{1}$ seem to deserve a place in the evaluation of the glycaemic control in diabetics and may be regarded complementary rather than competitive tests.

\section{References}

Baker JR, O'Comner JP, Metcalf PA, Lawson MR, Johnson RN. Clinical usefulness of estimation of serum fructosamine concentration as a screening test for diabetes mellitus.

Br Med J 287: 863 $1867,1983$.

Baker JR, Metealf PA, Holdaway IM, Johnson RN. Serum fructosamine concentration as measure of blood glucose control in type $I$ (insulin depencient) diabetes mellitus.

Br Med J 290: 352-355, 1985.

Bante JP, Laine DC, Castle GW et al. Postprandial glucose and insulin responses to meals containing different carbohydrates in normal and diabetic subjects.

N Engl J Med 309: 7.12, 1983.

Bunn HF, Gabliay KH, Gallop PM. The glycosylation of hemoglobin: relevance to diabetes mellitus. Science 200: $21-27,1978$.

Cefalu WT, Parker TP, Johnson CR. Validity of serum fructosamine as index of short-term glycemic control in diabetic outpatients.

Diabetes Care 11: 662-664, 1988.

Cromne PVM, van der Veen EA, Bezemer PB, Kuik DJ. De waarde van de bepaling van de fructosanine concentratie in het serum als screening-test voor diabetes mellitus.

Ned Tijdschr Geneeskd 130: 2112, 1986.

Dahl-Jorgensen K, Brinchmanin-Hansen O, Hanssen KF, et al. Effect of near normoglycaemia for two years on progression of early diabetic retinopathy, nephropathy, and neuropathy: the Oslo study.

Br Med J 293: 1195-1199, 1986. 
Daubresse JC, Laurent $\mathrm{E}$, Ligny $\mathrm{C}$, et al. The usefulness of fructosamine determination in diabetic patients and its relation to metabolic control.

Diabete Metab 13: 217-221, 1987.

Deckert T, Lamritzen T, Parving H, Christensen JS, Steno Study Group. Effeet of two years of strict metabolic control on kidney function in long-term insulin-dependent diabetics:

Diabetic Nephropathy 2: 6-10, 1983.

Dolhofer $\mathbf{R}$, Wielland $\mathbf{O H}$. Glycosylation of serum albumin: elevated glycosyl-albumin in diabetic patients.

FEBS Lett 103: 282-286, 1979.

Gabbay KH, Hasty K, Breslow JL, et al. Glycosylated hemoglobins and long-term glucose control in diabetes mellitus.

J Clin Endocrinol Metab 44: 859-864, 1977.

Gonen B, Rubenstein AH, Rochman H, Tanega SF, Horwitz DL. Haemoglobin A : an indicator of the metabolic control of diabetic patients.

Lancet ii: $734-737,1977$.

Hindle EJ, Rostron GM, Clark SA, Gatt JA. Serum fructosamine and glycated haemoglobin measurements in diabetic control.

Arch Dis Childhood 61: 113-117, 1986.

Holman RR, Dornan TL, Mayon-White $V$, et all. Prevention of deterioration of renal and sensory-nerve function by more intensive management of insulin-dependent diabetic patients: at two-year randomised prospective studly.

Lancet: $204-208,1983$.

Jerntorp P, Sundkvist G, Fex G, Jeppson JO. Clinical utility of serum fructosamine in diabetes meilitus compared with hemoglobin $A_{1}$.

Clin Chim Acta 175: 1.35-142, 1988.

Johnson RN, Metcalf PA, Baker JR. Fructosamine: a new approach to the estimation of serum glycosylprotein. An index of diabetic control.

Clin Chim Acta 127: 87-95, 1982.

Koenig RJ, Peterson CM, Jones RL, et al. Correlation of glucose regulation and hemoglobin $\mathrm{A}_{\mathrm{fe}}$ in diabetes mellitus.

N Engl J Med 295: 417-420, 1976.

Koskinen P, Irjala K, Wiikari J, Panula-Ontio R, Matikainen MT. Serum fructosamine in the assessment of glycaemic control in diabetes mellitus.

Scand I Clin Lab Invest 47: 285.292, 1987.

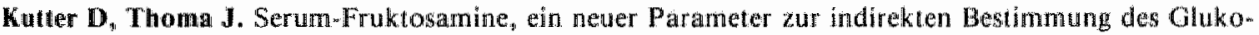
Albumins und zur Halblangzeituiberwachung des Diabetikers.

Lab Med 9: $327-330,1985$.

Kverneland $\mathbf{A}$, Lundgrem $\mathbf{J}$, Binder $\mathbf{C}$. Fructosamine in assessment of glycaemic control in IDDM. Acta Endoct 115 (suppl 282): 33, 1987.

Langer O, Mazze RS. Diabetes in pregnancy: Ewaluating self-monitoring performance and glycemic con. trol with memory-based reflectance meters.

Am J Obstet Gynecol 155: 635-637, 1986. 
MeFarand KF, Catallatio EW, Day JF, Tharpe $\mathbf{S R}$, Baynes JW. Nonenzynatic glucosylation of serum proteins in diabetes mellitus,

Diabetes 28, 1011-1014, 1979 .

Mosca A, Carenimi A, Zoppi F, all. Plasma protein glycation as measured by fructosamine assay. Clin Chem 33: 1141-1146, 1987 .

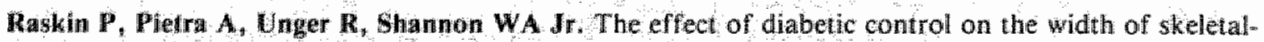
muscle capillary basenent membrane in patients with type I diabetes mellitus.

N Engl I Med: 309: 1546-1550, 1983.

Salemans THB, Van Dielgen-Visser MP, Brombacher PJ. The value of HbA, and fructosamine in predicting abnomal glucose tolerance - an alternative to the OGTT to detect diabetes mellitus or gestational diabetess?

Ann Clin Biochem 24: 447 452, 1987.

Service FJ, Hall CD, Westland RE et al. Effects of size, time of day and sequence of meal ingestion on carbohydrate tolerance in normal subjects.

Diabetologia $25: 316-321,1983$.

Service FJ, O'Brien PC, Rizza RA. Measurements of glucose control.

Diatbetes Care 10: 225-237, 1987.

Smart LM, Howie AF, Young RJ, et al. Comparison of fructosamine with glycosylated hemoglobin and plasma proteins as measures of glycemic control.

Diabetes Care 11: 4334436, 1988.

WHO. Diabetes Mellitus. Report of a WHO study group.

Technical Report Series 727. Geneva: World Heallh Organization, 1985. 


\section{Chapter 5}

The value of fructosamine and haemoglobin $A_{1}$ measurements for screening and diagnosis of impaired glucose tolerance, diabetes mellitus and gestational diabetes

T.H.B. Salemans, M.P. Van Diejen-Visser, P.J. Brombacher.

Part of this study has been published in Annals of Clinical Biochemistry 24: 447-452, 1987.

(with permission)

\section{Summary}

In this study the value of fructosamine and $\mathrm{HbA}_{1}$ measurements as screening and diagnostic tests for impaired glucose tolerance (IGT), diabetes mellitus (DM), and gestational diabetes was assessed in a selected population. Patients were classified on the basis of standard $75 \mathrm{~g}$ oral glucose tolerance tests (OGTT).

In non-pregnant patients with IGT $(n=41)$ or DM $(n=56)$ both fructosamine and $\mathrm{HbA}_{1}$ concentrations were elevated relative to control patients $(\mathrm{n}=96)$ and to patients with a normal OGTT $(n=215)$. The value of fructosamine and HbA, measurements as screening tests for IGT and DM could be demonstrated by a simple yet sophisticated analytical technique, the receiver operating characteristic curve. On the other hand, the diagnostic value of these tests for IGT and DM was disappointing.

In patients with gestational diabetes $(n=14)$, the fructosamine and $H b A_{1}$ concentrations were similar to those in control patients $(n=88)$ and in pregnant patients with a normal OGTT $(\mathrm{n}=236)$. It was demonstrated that in the pregnant population studied, fructosamine and $\mathrm{HbA}_{1}$ measurements both lacked screening as well as diagnostic power with respect to gestational diabetes. 


\section{Introduction}

The $\mathrm{HbA}_{1}$ concentration is nowadays generally considered to provide valuable retrospective information about the quality of glycaemic control in patients with diabetes mellitus; the $\mathrm{HbA}_{1}$ concentration correlates well with the mean blood glucose concentration over the preceding 6-10 weeks (Koenig et al., 1976; Bunn et al., 1978). Since the first reports on $\mathrm{HbA}_{1}$, this phenomenon has led several investigators to study the value of this variable for identifying patients with impaired glucose tolerance (IGT) or diabetes mellitus (DM). However, interpretation and comparison of the reported values is difficult due to the lack of uniformity in selecting the upper limit for a normal $\mathrm{HbA}_{1}$ concentration and differences in conducting and interpreting the OGTT (Dods and Bolmey, 1979; Dix et al., 1979; Miedema and Casparie, 1984; Albutt et al., 1985).

Because the fructosamine concentration provides information about the glycaemic status over the previous 1-3 weeks, its measurement has (in comparison to $\mathrm{HbA}_{1}$ ) promising potential as a screening and/or diagnostic test for IGT, DM and gestational diabetes (Baker et al., 1983; Roberts and Baker, 1986). However, the tests have not yet been thoroughly evaluated for this purpose.

The present study was designed to evaluate the use of fructosamine and $\mathrm{HbA}_{\text {, }}$ measurements as screening and diagnostic tests for IGT, DM and gestational diabetes.

\section{Patients}

\section{Non-pregnant patients suspected of diabetes mellitus}

During a two-year period ending in July 1987,312 consecutive patients ( 163 women, 149 men) suspected of having diabetes mellitus were studied. All were referred for an OGT"T. Their ages ranged from 13 to 82 years.

Reference values of $\mathrm{HbA}_{1}$ and fructosamine concentrations were obtained from a group of 96 healthy subjects of comparable age without signs of diabetes mellitus and with fasting venous plasma glucose concentrations below $5.5 \mathrm{mmol} / 1$.

\section{Pregnant women suspected of gestational diabetes}

A total of 250 pregnant women between 17 and 43 years of age were screened for gestational diabetes by an OGTT during an eighteen-month period ending in Janu- 
ary 1987. These patients were selected on the basis of classical risk factors, such as age over 30 years, obesity, family history of DM and excessive growth of the uterus. The reference group for these 250 patients consisted of 88 randomly selected healthy pregnant women of comparable age attending the antenatal clinic, but without suspicion of gestational diabetes and having fasting glucose concentrations below 5.5 mmol/l. Their ages ranged from 19 to 40 years.

\section{Methods}

\section{Oral glucose tolerance test (OGTT)}

Patients were instructed to take an unrestricted diet with more than $150 \mathrm{~g}$ of carbohydrate daily for at least three days prior to testing. The OGTT was performed after an overnight fast of 10-16 hours. Smoking was not permitted during the test. Each patient was given an oral dose of $75 \mathrm{~g}$ of glucose in $250-300 \mathrm{ml}$ of water. Venous plasma glucose concentrations were measured in a fasting blood sample and in five samples obtained $30,60,90,120$ and 180 minutes after the glucose intake. In accord with the WHO criteria (1985), only the fasting glucose concentration and that 2 hours after a $75 \mathrm{~g}$ oral glucose load were used for classifying the result of the OGTT. The same cut-off values were used in pregnant and non-pregnant patients. Diagnostic interpretation of the OGTT is summarized in table 1.1. According to the WHO criteria, three groups of non-pregnant patients were formed: normal glucose tolerance, impaired glucose tolerance (IGT) and diabetes mellitus (DM) "In the pregnant patients the following groups were formed: normal glucose tolerance, gestational impaired glucose tolerance (GIGT) and gestational diabetes mellitus (GDM). The term gestational diabetes was applied to patients with either GIGT or GDM.

\section{Laboratory measurements}

The techniques by which glucose, fructosamine, $\mathrm{HbA}_{1}$ and albumin were measured, have been described in chapter 4 .

Fructosamine, $\mathrm{HbA}_{\mathrm{l}}$ and albumin concentrations were measured in a blood sample withdrawn together with that for the fasting blood glucose sample during the OGTT. Serum for later measurement of fructosamine and albumin was stored at $-20^{\circ} \mathrm{C}$ before analysis. Because the fructosamine concentration may be influenced by the albumin concentration, the latter was measured to allow correction of the fructosamine concentration to a standard albumin concentration (for correction method see chapter 3 ). 


\section{Statistical analysis}

Correlations were determined by linear regression analysis with the least squares method. Differences between means were evaluated by Student's unpaired $t$-test. A probability of less than $5 \%(\mathrm{p}<0.05)$ was considered significant. The value of fructosamine and $\mathrm{HbA}_{1}$ Levels as screening and diagnostic tests was determined by constructing receiver operating characteristic (ROC) curves (Sackett et al., 1985; Richardson et al., 1985). The value of this method lies in providing a clear graphic analysis of the screening and diagnostic possibilities of a test over its entire range of values.

\section{Results}

\section{Non-pregnant subjects}

The results obtained in the non-pregnant subjects are listed in table 5.1. Both the fructosamine and the $\mathrm{HbA}_{1}$ concentrations were higher in the IGT patients than in controls and patients with a normal OGTT $(p<0.05)$. In patients with $\mathrm{DM}$, the fructosamine and $\mathrm{HbA}_{1}$ levels were higher still than those in the IGT group $(\mathrm{p}<0.01)$. Correction of fructosamine to a standard albumin concentration had no appreciable effect on the differences between the various patients groups.

Table 5.1 Fructosamine and $H b A_{1}$ concentrations in 312 subjects undergoing an OGTT and in 96 controls

\begin{tabular}{|c|c|c|c|c|c|c|}
\hline & & \multirow[b]{2}{*}{$\mathrm{n}$} & \multicolumn{2}{|c|}{$\begin{array}{l}\text { Fructosamine } \\
\text { (mmol/l) }\end{array}$} & \multicolumn{2}{|l|}{$\begin{array}{l}\mathrm{HbA} \\
(\%)\end{array}$} \\
\hline & & & Mean & $\mathrm{SD}$ & Mean & $\mathrm{SD}$ \\
\hline $\mathrm{A}$ & Normal OGTT & 2115 & 2.21 & 0.22 & 6.9 & 0.9 \\
\hline $\mathrm{B}$ & IGT & 41 & 2.30 & $0.21^{*}$ & 7.2 & $0.7^{*}$ \\
\hline $\mathrm{C}$ & DM & 56 & 2.66 & $0.42 *$ & 9.2 & $2.1^{* * 4}$ \\
\hline $\mathrm{D}$ & Control group & 96 & 2.19 & 0.18 & 6.7 & 0.9 \\
\hline
\end{tabular}

* $\mathrm{p}<0.05(\mathrm{~B} / \mathrm{A} ; \mathrm{B} / \mathrm{C} ; \mathrm{B} / \mathrm{D})$

* $\mathrm{p}<0.01(\mathrm{C} / \mathrm{A} ; \mathrm{C} / \mathrm{B} ; \mathrm{C} / \mathrm{D})$

The sensitivity, specificity and predictive values (table 2.2) of fructosamine and HbA, measurements for the combined DM/IGT group and for the DM group alone are listed in table 5.2. The upper limits for normal fructosamine and $\mathrm{HbA}_{1}$ concentrations (cut-off values) were defined as the value which was $2 \mathrm{SD}$ 
above the mean for the control group ( $2.55 \mathrm{mmol} / \mathrm{l}$ and $8.6 \%$, respectively). The sensitivity of fructosamine for identifying patients in the combined IGT/DM group and in the DM group alone was slightly higher ( $43 \%$ and $63 \%$, respectively) than that of $\mathrm{HbA}_{1}(34 \%$ and $55 \%$, respectively). In contrast, the positive predictive value of $\mathrm{HbA}_{1}$ in the two groups $(79 \%$ and $74 \%$, respectively) was higher than that of fructosamine ( $71 \%$ and $59 \%$, respectively).

Table 5.2 Sensitivity, specificity and predictive values (PV) of fructosamine and $H b A_{4}$ measurements for IGT or DM, or DM alone $(n=312)$

\begin{tabular}{lll}
\hline & $\begin{array}{l}\text { Fructosamine } \\
2.55 \mathrm{mmol} / \mathrm{l}\end{array}$ & $\begin{array}{c}\mathrm{HbA}_{1} \\
8.6 \%\end{array}$ \\
\hline Cut-off value & & \\
IGT or DM & 43 & 34 \\
Sensitivity $(\%)$ & 92 & 96 \\
Specificity $(\% \%)$ & 71 & 79 \\
PV pos $(\%)$ & 78 & 76 \\
PV neg $(\%)$ & & \\
& & \\
DM & 63 & 55 \\
Sensitivity $(\%)$ & 91 & 96 \\
Specificity $(\% 0)$ & 59 & 74 \\
PV pos $(\%)$ & 92 & 91 \\
PV neg $(\%)$ & & \\
\hline
\end{tabular}

To evaluate the sensitivity and specificity of fructosamine and $\mathrm{HbA}_{1}$ measurements over their entire range of (cut-off) values, ROC curves were constructed (figure 5.1). The pattern of the ROC curves indicate that both tests do have screening potential. Figure 5.1 also illustrates that the sensitivity of fructosamine and $\mathrm{HbA}_{1}$ measurement is similar at any given value for specificity, both for detecting patients with either IGT or DM (figure 5.1 (A)), and for detecting patients with DM (figure $5.1(\mathrm{~B})$ ).

\section{Pregnant subjects}

The results of the fructosamine and $\mathrm{HbA}_{1}$ measurements obtained in the pregnant subjects are listed in table 5.3. The fructosamine and $\mathrm{HbA}_{1}$ concentrations in the gestational diabetics (GIGT) were comparable with those in control patients and patients with a normal OGTT $(p>0.05)$. 

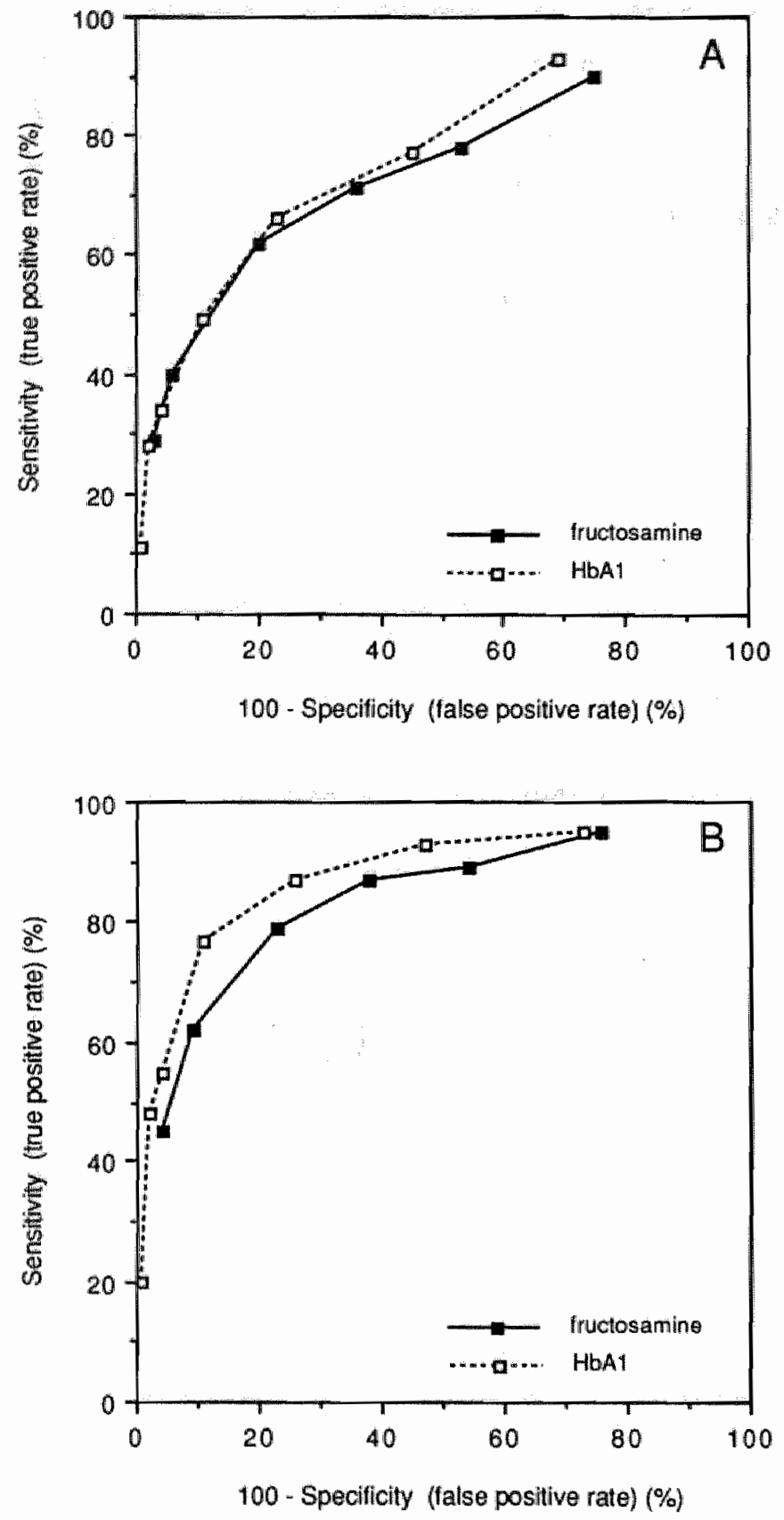

Figure 5.l ROC-curves of fructosamine and HbA $A_{1}$ for predicting DM or IGT (A), and for predicting $D M$ alone $(B)$.

Cut-off values for the different methods (from left to right in the graph):

Fructosamine (mmol/1): $2.60 ; 2.50 ; 2.40 ; 2.30 ; 2.20 ; 2.10$.

$\mathrm{HbA}_{1}(\%): 10.0 ; 9.0 ; 8.6 ; 8.0 ; 7.5 ; 7.0 ; 6.5$. 
Table 5.3 Fructosamine and HbA, concentrations in 250 pregnam subjects undergoing an OGTT and in 88 controls

\begin{tabular}{|c|c|c|c|c|c|}
\hline & \multirow[b]{2}{*}{$\mathrm{n}$} & \multicolumn{2}{|c|}{$\begin{array}{l}\text { Fructosamine } \\
(\mathrm{mmol} / \mathrm{)})\end{array}$} & \multicolumn{2}{|l|}{$\begin{array}{l}\mathrm{HbA}_{1} \\
(\%)\end{array}$} \\
\hline & & Mean & $\mathrm{SD}$ & Mean & $\mathrm{SD}$ \\
\hline Nornial OGTT & 236 & 2.01 & 0.17 & 6.4 & 0.7 \\
\hline GIGT & 13 & 2.05 & 0.17 & 6.7 & 0.6 \\
\hline GDM & 1 & 2.36 & & 7.5 & \\
\hline Control group & 88 & 2.05 & 0.12 & 6.3 & 0.8 \\
\hline
\end{tabular}

Table 5.4 lists the sensitivity, specificity, and predictive values of $\mathrm{HbA}_{1}$ and fructosamine measurements for gestational diabetes. The upper limits of normal for $\mathrm{HbA}_{1}$ and fructosamine concentrations were defined as the values which were 2 $\mathrm{SD}$ above the means for the pregnant control group $(7.8 \%$ and $2.30 \mathrm{mmol} / \mathrm{l}$, respectively). Both fructosamine and $\mathrm{HbA}_{1}$ measurements performed poorly in the detection of gestational diabetes. Only in 3 of $14(21 \%)$ gestational diabetics was the fructosamine concentration abnormal, whereas in only 1 of $14(7 \%)$ of these patients was the $\mathrm{HbA}_{1}$ percentage abnormal. Moreover, the positive predictive values of fructosamine and $\mathrm{HbA}_{1}$ measurements were very low. In only 1 of $3(33 \%)$ and 1 of $6(17 \%)$ patients with abnormal fructosamine or $\mathrm{HbA}_{\|}$values, respectively, was gestational diabetes diagnosed.

Furthermore, the ROC curves as shown in figure 5.2 indicate that neither fructosamine nor $\mathrm{HbA}_{1}$ had any value as screening or diagnostic tests for gestational diabetes.

Table 5.4 Sensitivity, specificity and predictive values (PV) of fructosamine and $H b A_{1}$ measurements for gestational diabetes $(n=250)$

\begin{tabular}{lll}
\hline Cut-off value & Fructosamine & HbA \\
& $2.30 \mathrm{mmol} / 1$ & $7.8 \%$ \\
\hline Sensitivity $(\%)$ & 21 & 7 \\
Specificity $(\%)$ & 97 & 97 \\
PV pos $(\%)$ & 33 & 17 \\
PV neg $(\%)$ & 95 & 94 \\
\hline
\end{tabular}




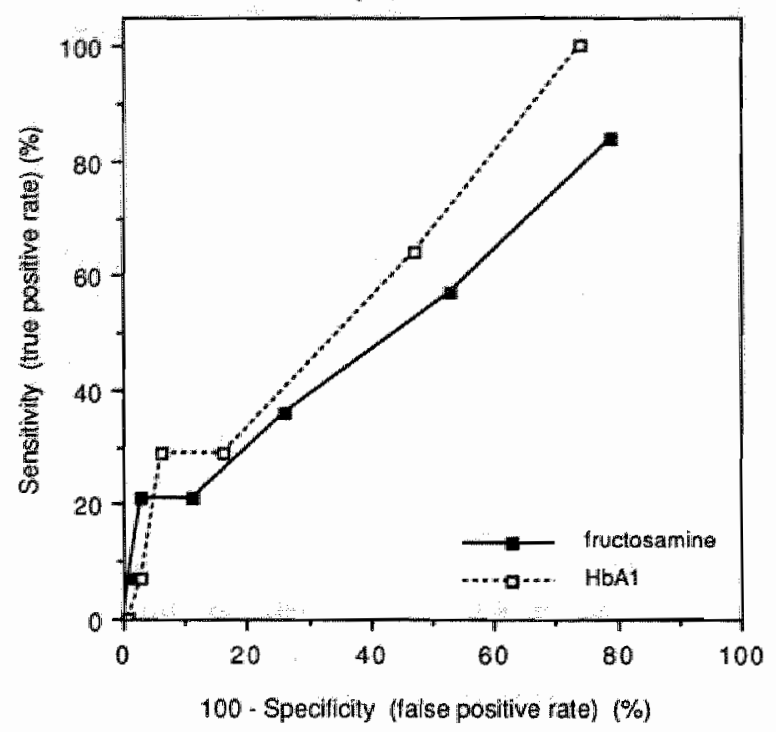

Figure 5.2 ROC-curves of fructosamine and $\mathrm{HbA}$, for predicting gestational diabetes. Cut-off values for the different methods (from left to right in the graph):

Fructosamine (mmol/1): $2.40 ; 2.30 ; 2.20 ; 2.10 ; 2.00 ; 1.90$.

$\mathrm{HbA}_{1}(\%): 8.0 ; 7.8 ; 7.5 ; 7.0 ; 6.5 ; 6 ; 0$.

\section{Discussion}

\section{Impaired glucose tolerance and diabetes mellitus}

The OGTT has been used for decades as a reference method for defining patients with abnormal glucose tolerance. The OGTT is not a prerequisite for identifying patients with DM which can also be diagnosed on the basis of a fasting venous plasma glucose concentration of $7.8 \mathrm{mmol} / 1$ or higher. In the asymptomatic patient an additional test with a value in the diabetic range is desirable (WHO Report, 1985). On the other hand, IGT can only be diagnosed by means of an OGTT. One should however realize that the 'golden standard' (OGTT) has been associated with a certain false positive rate (O'Sullivan and Mahan, 1966; Siperstein, 1975). The response to an oral glucose load may be influenced by several factors such as drugs, physical activity, infection, and food intake (Siperstein, 1975). All these factors are known to reduce the reproducibility of the OGTT (Coelingh Bennink, 1980; O'Sullivan and Mahan, 1966; Kobberling et al., 1980).

$\mathrm{HbA}_{1}$ (Dods and Bolmey, 1979) and fructosamine measurements (Baker et al., 1983) have both been suggested as alternative tests for detecting individuals with 
IGT or DM. These tests are not influenced by the factors mentioned above and therefore offer practical advantages over (OGTT) glucose measurements. In the present study, the fructosamine and $\mathrm{HbA}_{1}$ concentrations differed significantly between the patients with normal glucose tolerance on the one hand, and those with IGT or DM on the other (table 5.1). It was demonstrated that with respect to IGT and $\mathrm{DM}$ both fructosamine and $\mathrm{HbA}_{1}$ measurements did have (similar) screening value; for each cut-off point selected, the true positive rate was clearly higher than the false positive rate. Whereas for screening purposes a distinct percentage of false negative results of a test is usually acceptable, for diagnostic purposes this is not. Moreover, a diagnostic test should incur few false positive results. Because the true positive rates of fructosamine and $\mathrm{HbA}_{1}$ measurements with respect to IGT and DM only approximate to $100 \%$ for (low) cut-off values with concomitantily high false positive rates, the tests fail diagnostic power (figure 5.1).

The patterns of the ROC curves confirm that the average glucose concentration over a certain period as judged by fructosamine and $\mathrm{HbA}_{1}$ levels provides information about a different aspect of glucose metabolism than the response to a nonphysiological glucose load as measured by an OGTT. On the other hand, the correlations between the area under the OGTT-curve on the one hand and HbA, $(r=0.67, p<0.001)$ or fructosamine concentration $(r=0.53, p<0.001)$ on the other, indicate that these two aspects of glucose metabolism are interrelated.

The main advantage of early detection of subjects with impaired glucose handling is the prevention of long-term complications of the disease by early treatment. Diabetic complications develop as a direct consequence of chronic hyperglycaemia (Brownlee et al., 1984 and 1988) whereas normoglycaemia in these patients generally reduces the progression and severity of such complications (Raskin and Rosenstock, 1986). Since the fructosamine and $\mathrm{HbA}_{1}$ concentrations reflect average glucose levels over a certain time interval, the information provided by these two variables may be more valuable than that given by the OGTT in the selection of patients who may benefit from treatment. Long-term studies are needed to determine the risk of diabetic complications in individuals in whom an abnormal OGTT is parallelled by a repeatedly normal fructosamine and/or $\mathrm{HbA}_{1}$ concentration.

\section{Gestational diabetes}

Gestational diabetes is defined as glucose intolerance with onset or first recognition during pregnancy. The criteria for diagnosis are arbitrary and differ in various studies (National Diabetes Data Group, 1979; O'Sullivan et al., 1964; Abell, 1979; Coelingh Bennink, 1980; WHO Report, 1985). At any rate, many studies do report a higher perinatal morbidity in the offspring of gestational diabetics (Gabbe et al., 1977; Coustan and Imarah, 1984; Widness et al., 1985). Thus, screening for gesta- 
tional diabetics appears to be important in terms of identifying patients with increased risk for developing these complications.

To subject each patient to an OGTT is unfriendly to patients, cumbersome, timeconsuming and expensive. Screening for gestational diabetes on the basis of clinical risk factors may result in $37 \%$ of the population requiring OGTTs with a false negative rate of about 33\% (O'Sullivan et al., 1973; Gillmer et al., 1980). To our knowledge, the best documented screening test is measurement of the blood glucose concentration $1 \mathrm{~h}$ after a $50 \mathrm{~g}$ glucose load, regardless of the time since the last meal. By using a venous plasma glucose concentration of $7.7 \mathrm{mmol} / \mathrm{l}$ as cut-off value, approximately $8 \%$ of the population was selected for an OGTT (Gillmer et al., 1980). This approach appears to have reduced the false-negative rate to $21 \%$ instead of $33 \%$ (O'Sullivan et al., 1973). Screening by random blood glucose sampling has also been advocated (Lind and Anderson, 1984), but in a population with a high prevalence of IGT, the predictive value of this method was disappointing (Nasrat et al., 1988).

$\mathrm{HbA}_{1}$ and fructosamine measurements have been claimed to represent elegant alternative screening methods for gestational diabetes when compared to the glucose challenge tests (Morris et al., 1986; Roberts and Baker, 1986). However, the low sensitivity of these tests as recently suggested by Comtois and co-workers (1989) and confirmed by our own results, raises doubt about their value as screening tests. In this context it is important to stress the fact that the goal of screening for gestational diabetes should not be merely detection of an abnormal OGTT. The ultimate goal should be early detection of pregnant patients with elevated blood glucose levels in conditions of unrestricted food intake; only these patients require specific treatment in order to reduce the risk of the typical foetal and neonatal morbidity. It follows that fructosamine and $\mathrm{HbA}_{1}$ may prove to be better tests than the OGTT for sereening of pregnant patients at risk for hyperglycaemia-related foetal and neonatal complications.

\section{References}

Abell DA. The significance of abnormal glucose tolerance (byperglycaemia and hypoglycaemia) in pregnancy.

Br J Obstet Oynaecol 86:214-21, 1979.

Albut EC, Nattrass M, Northam BE. Glucose tolerance test and glycosylated haemoglobin measurement for diagnosis of diabetes mellitus - an assessment of the criteria of the WHO Expert Committee on Dialbetes Mellitus 1980.

Ann Clin Biochem 22: $67-73,1985$. 
Baker JR, O'Conner IP, Metealf PA, Lawson MR, Johnson RN. Clinicall usefulness of estimation of serum fructosamine concentration as a screening test for diabetes mellitus.

$\mathrm{Br}$ Med J 287: 863-867, 1983.

Brownlee $\mathbf{M}$, Vlassara $\mathbf{H}$, Cerami $\mathbf{A}$. Nonenzymatic glycosylation and the pathogenesis of diabetic com. plications.

Ann Intern Med 101: 527-537, 1984.

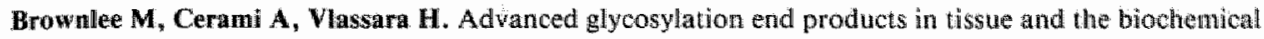
basis of diabetic complications.

N Engi J Med 318: 1315-1321, 1988 .

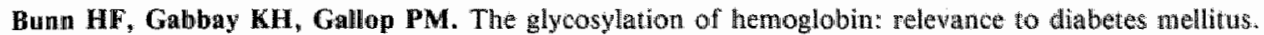
Science 200: $21-27,1978$.

Coelingh-Bennink HJT. Zwangerschapsdiabetes.

Thesis, Utrecht, 1980.

Comtois R, Desjarlais F, Nguyen M, Beauregard H. Clinical usefulness of estimation of serum fructosamine concentration as screening tesi for gestational diabetes.

Am J Obstet Gynecol 160: 651-654, 1989.

Coustan DR, Imarah J. Proplrylactic insulin treatment of gestational diabetes reduces the incidence of macrosomna, operative delivery, and birth trauma.

Am J Obstet Gynecol 150: 836-842, 1984.

Dix D, Cohen $\mathbf{P}$, Kingsley $\mathbf{S}$ et al. Glycohemoglobin and glucose tolerance tests compared as indicators of borderline diabetes.

Clin Chem 25: 877-879, 1979.

Dods RF, Bolmey C. Glycosylated hemoglobin assay and oral glucose tolerance test compared for detection of diabetes mellitus.

Clin Chem 25: 764-768, 1979.

Gabbe SG, Mestman JH, Freeman RK, Anderson GV, Lowensohn RI. Management and outcome of class A diabetes mellitus.

Am J Obstet Gynecol 127: 465-469, 1977.

Gillmer MD, Oakley NW, Beard RW, Nithyananthan R, Cawston M. Screening for diabetes during preg. nancy.

Br J Obstet Gynaecol 87: $377-382,1980$.

Kollbberling J, Kerlin $\mathbf{A}_{*}$ Creutafeldt $\mathbf{W}$. The reproducibility of the oral glucose tolerance test over long (5 years) and short periods (I week).

Klin Wochenschr 58: $527-530,1980$.

Koemig RJ, Peterson CM, Jones RL, ef al. Correlation of ghcose regullation sand hernoglobin $\mathrm{A}_{1 \text {. }}$ in diabetes mellitus.

N Engl J Med 295: 417-420, 1976.

Lind $\mathbf{T}$, Anderson J. Does random blood glucose sampling outdate testing for glycosuria in detection of diabetes during pregnancy?

Br Med J 289: 1569-1571, 1984.

Miedema $\mathbf{K}$, Casparie T. Glycosylated haemoglobins: biochemical evaluation and clinical utility. Ann Clin Biochem 21: 2-15, 1984. 
Morris MA, Grandis AS, Litton J. Glycosylated hemoglobin: a sensitive indicator of gestational diabetes:

Obstet Oynecol $68: 357-361,1986$.

Nasinat AA, Johinstone FD, Hasan SAM. Is random plasma glucose an efficient screening test for abnormal glucose tolerance in pregnancy?

Pr J Obstet Gynaecol 95: 855-860, 1988.

Natlonal Diabetes Data Group of the USA. Classification and diagnosis of diabetes mellitus and other categories of glucose intolerance.

Diabetes 28: 1039-1057, 1979.

O'Sullivan JB, Mahan CM, Broston AB. Criteria for the oral glucose tolerance test in pregnancy.

Diabetes 13: $278-285 ; 1964$.

O'Sullivan JB, Malhan CM. Glucose tolerance test. Variability in pregnant and non-pregnant women. Am J Clin Nutr 19: 345-351, 1966.

O'Sullivan JB, Mahan CM, Charles D, Dandrow RV. Screening criteria for high-risk gestational diabetic patients.

Am I Obstet Gynecol 116: 895-900, 1973.

Raskin P, Rosenstock J. Blood glucose control and diabetic complications.

Ann Intern Med 105: 254-263, 1986.

Richardson DK, Schwartz JS, Weinbaum PJ, Gabbe SG. Diagnostic tests in obstetrics: A method for improved evaluation.

Am J Obstet Gynecol 152:613-618, 1985 .

Roberts AB, Baker JR. Serum fructosamine: a screening test for diabetes in pregnancy.

Am J Obstet Oynecol 154: 1027-1030, 1986.

Sackett DL, Haynes RB, Tugwell P. Clinical epidemiology.

Little Brown Company, Boston, Toronto: 101-106, 1985.

Siperstein MD. The glucose tolerance test: A pitfall in the diagnosis of diabetes mellitus.

Adv Intern Med 21: 297-323, 1975.

WHO. Diabetes mellitus: Report of a WHO study group.

World Health Organization, Geneva. Technical report series 727, 1985.

Widness JA, Cowet RM, Coustan DR, Carpenter MW, Oh W. Neonatal morbidities in infants of mothers with glticose intolerance in pregnancy.

Diabetes 34 (suppl 2): 61-65, 1985. 


\section{Chapter 6}

\section{Fructosamine and glycated haemoglobin in normal pregnancy}

M.P. Van Dieijen-Visser, T.H.B. Salemans, J.W.J. Van Wersch, L.A. Schellekens, P.J. Brombacher.

Part of this study has been published in Annals of Clinical Biochemistry 23: $661-666,1986$.

(with permission)

\section{Summary}

Glycated haemoglobin $\left(\mathrm{HbA}_{1}\right)$ and fructosamine concentrations were measured in 276 pregnant patients with a normal oral glucose tolerance test (OGTT). In the course of pregnancy the $\mathrm{HbA}_{1}$ concentration remained unchanged. The results were similar for a chromatographic (Biorad) and an electrophoretic (Corning) technique for $\mathrm{HbA}_{1}$ measurement.

In contrast, in the course of pregnancy a small but significant decrease in the fructosamine concentration was observed $(r=-0.17, p<0.01)$. This change appeared to be attributable to a concomitant decrease in the albumin concentration $(r=-0.69$, $p<0.0001$ ). When the fructosamine concentration was corrected for the albumin concentration, the (corrected) fructosamine concentration remained unchanged throughout pregnancy. The decrease of the fructosamine concentration during pregnancy was so small that correction for albumin and/or gestational age in a clinical setting appears to unnecessary.

During normal pregnancy glucose tolerance decreased, as indicated by an increase of the area under the OGTT-curve $(+17 \%)$ and a rise of the 2 -hours OGTT glucose value $(+24 \%)$. On the other thand, the fasting glucose concentration decreased by $10 \%$. Balance between these opposite effects may explain why fructosamine and $\mathrm{HbA}_{1}$ concentrations in normal pregnancy change little. 


\section{Introduction}

Measurement of the glycated haemoglobin $\left(\mathrm{HbA}_{1}\right)$ concentration is nowadays considered a useful parameter in the quality control of the glycaemic status over a prolonged period. The $\mathrm{HbA}_{\mathrm{f}}$ concentration represents an indirect estimate of the mean blood glucose concentration over the preceding 6-10 weeks (Koenig et al., 1976; Gonen et al., 1977; Bunn et al., 1978). Recently, a highly practicable method, the fructosamine test, has been developed to measure the concentration of glycated serum proteins (GSPs) (Johnson et al., 1982; Baker et al., 1983; see also chapter 3). The much shorter half-life of GSPs than that of $\mathrm{HbA}_{1}$ not only offers interesting possibilities of obtaining indirect information about the mean glucose concentration during the preceding 1-3 weeks (Daubresse et al., 1987; Koskinen et al., 1987), but is also likely to respond faster to a change in the mean blood glucose concentration. In addition the GSP concentration may follow more closely changes in the mean blood glucose concentration than does the $\mathrm{HbA}_{1}$ concentration since the latter varies with the glucose concentration within the red cells rather than with that in serum.

Inasmuch as early recognition and subsequent treatment of maternal hyperglycaemia during pregnancy is important in reducing neonatal morbidity (Landon et al., 1987), both fructosamine and $\mathrm{HbA}_{\|}$measurements may be of help for identifying pregnant patients at risk of the sequelae of hyperglycaemia. As pregnancy is a dynamic state, the balance of many physiological processes changes continuously. Therefore, it is important that the study of the clinical applicability of fructosamine and $\mathrm{HbA}_{1}$ measurements during pregnancy should be preceded by a reference study which describes the changes in these two variables in the course of normal pregnancy. Reports on both the trend in fructosamine (Nelson et al., 1985; Roberts and Baker, 1986) and $\mathrm{HbA}_{1}$ concentrations (Schwartz et al., 1976; Lind and Cheyne, 1979; Leslie et al., 1978; Fadel et al., 1979) during pregnancy are conflicting. Part of the reported discrepancies appear to be due to the limited amount of data in these studies, whereas also the lack of consistency in the definition of 'normality" has contributed to the confusion.

The present study was designed to evaluate the relationship of fructosamine and $\mathrm{HbA}_{1}$ levels with gestational age. Pregnancy in this context was considered 'normal" when the $75 \mathrm{~g}$ OGTT had a normal outcome. The $\mathrm{HbA}_{1}$ concentration was measured by two different techniques. Because fructosamine predominantly consists of glycated albumin and the albumin concentration decreases in the course of pregnancy, we also studied the possible contribution of changes in this variable to the relation between fructosamine concentration and gestational age. Finally, the evolution of glucose tolerance in the course of normal pregnancy was described. 


\section{Patients}

During a period of 20 months all pregnant women registered at the antenatal clinic and referred for an OGTT were informed about the study and invited to participate. These patients constituted approximately $20 \%$ of the total intake of pregnant patients in our clinic. They were selected on the basis of clinical risk factors for gestational diabetes. These factors included obesity, age over 30 years, clinical suspicion of a large foetus, family history of diabetes mellitus, polyhydramnios, glycosuria, and an obstetrical history suspected for gestational diabetes. The latter referred to a previous birth of a large infant, unexplained stillbirth and recurrent miscarriage. Patients in whom the OGTT was abnormal $(n=37)$ or in whom the expected date of confinement was not confirmed by first trimester ultrasound $(n=18)$, were excluded from the study. The remaining 276 patients with normal glucose tolerance and reliable expected dates of confinement were studied.

\section{Methods}

\section{Oral glucose tolerance test}

Standard $75 \mathrm{~g}$ OGTTs were performed according to WHO recommendations (1985) (see chapter 5). Diagnostic interpretation of the OGTT is summarized in table 1.1 .

\section{Laboratory measurements}

The techniques by which glucose, fructosamine and albumin levels were measured, have been described in chapter 4 . Both an ion-exchange chromatographic $\mathrm{HbA}_{1}$ microcolumn test (Biorad, product no. 1917001; intra-run precision 2-4\%, inter-run precision 4-7\%), and an electrophoretic $\mathrm{HbA}_{1}$ test (Corning, product no. 470055; intra-run precision 4-7\%, inter-run precision 6-8\%), were used for $\mathrm{HbA}_{1}$ measurement. Fructosamine, $\mathrm{HbA}_{1}$, and albumin concentrations were measured in a blood sample withdrawn together with that for the fasting blood glucose sample during the OGTT. Serum for later measurement of fructosamine and albumin was stored at $-20^{\circ} \mathrm{C}$. 

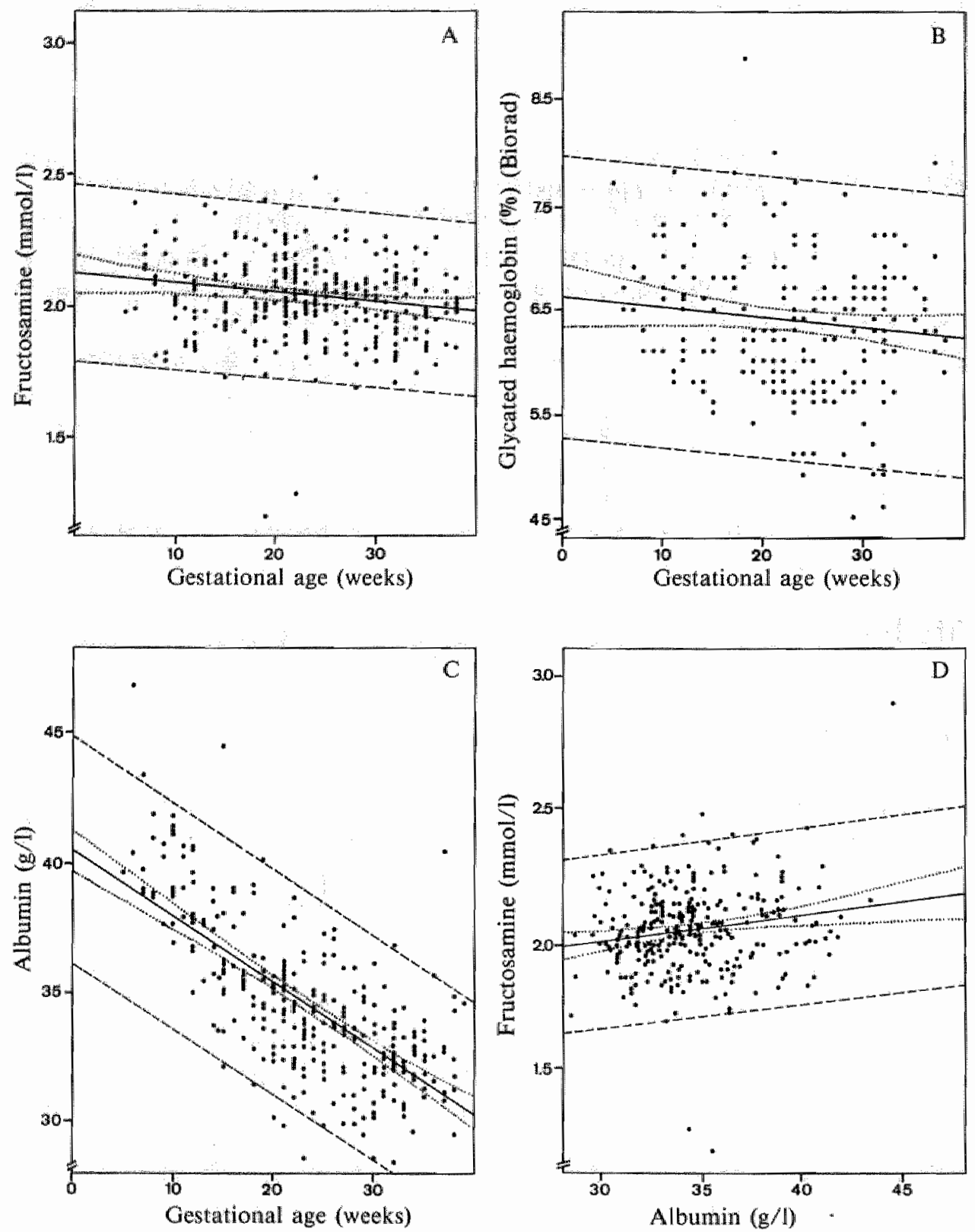

Figure 6.l Relation between serum fructosamine $(A), H b A,(B)$, serum albumin $(C)$ concentrations, respectively, and gestational age. Also the relation between serum fructosamine and serum albumin concentrations $(D)$ is shown.

The limear regression lines (-) including $95 \%$ confidence limits of regression lines (.........) and $95 \%$ prediction limits of sample points (- - ) are shown. The regression equations with their correlation coefficients are listed in table 6.1 . 


\section{Statistical analysis}

Correlations were determined by linear regression analysis with the least squares method. A probability of less than $5 \%(\mathrm{p}<0.05)$ was considered significant.

\section{Results}

The following parameters were correlated with gestational age: fructosamine, $\mathrm{HbA}_{4}$, albumin, fasting blood glucose, glucose 2 hours after glucose load and the area under the OGTT curve. The results are summarized in table 6.1.

Table 6.1. Correlation between several parameters (y) and' gestational age in weeks (x) for 276 normal pregnancies.

\begin{tabular}{|c|c|c|c|c|c|}
\hline Dependent variable $(y)$ & $r$ & $\mathrm{p}$ & regression equat & tion & \\
\hline Albumin $(\mathrm{g} / 1)$ & -0.69 & $<0.0001$ & $y=-0.254 x$ & + & 40.4 \\
\hline Fasting glucose (mmol/l) & -0.27 & $<0.0005$ & $y=-0.013 x$ & + & 5.03 \\
\hline 2h glucose OGTT (mmol/l) & 0.23 & $<0.005$ & $y=0.03 x$ & + & 5.02 \\
\hline Area OGTT (min.mmol $/$ ) & 0.24 & $<0.0001$ & $y=4.16 x$ & +9 & 953 \\
\hline Fructosamine (mmol/l) & -0.17 & $<0.01$ & $y=-0.0035 x$ & + & $2 . \Perp$ \\
\hline HbA, (electrophoresis) $(\%)^{*}$ & -0.11 & $>0.10$ & $y=-0.0078 x$ & + & 6.18 \\
\hline $\mathrm{HbA}_{1}$ (column) $(0)$ & -0.11 & $>0.10$ & $y=-0.0092 x$ & + & 6.58 \\
\hline
\end{tabular}

* $n=162$

Figure $6.1(\mathrm{~A}, \mathrm{~B}$, and $\mathrm{C}$ ) illustrates the relationships between the fructosamine, $\mathrm{HbA}_{1}$ and albumin concentrations, respectively, on the one hand, and gestational age on the other. The relationship between fructosamine and albumin levels is illastrated in figure 6.1 (D).

It was demonstrated that the $\mathrm{HbA}_{1}$ concentrations as measured by two different techniques varied independently of the gestational age. Apart from that, the $H b \mathrm{~A}_{\text {, }}$ concentrations measured by the chromatographic column method were systematically higher than those measured by the electrophoretic method (table 6.1).

Whereas the $\mathrm{HbA}_{1}$ concentrations varied independently of gestational age, the fructosamine concentrations decreased $(p<0.01)$ with advancing pregnancy (figure 6.1 (A)). Although the slope of the regression equation for the relationship between the fructosamine $(y ; \mathrm{mmol} / \mathrm{l})$ and the albumin concentration $(\mathrm{x} ; \mathrm{g} / \mathrm{l})$ was small $(y=0.01 x+1.69, r=0.18, p<0.005$; figure $6.1(D))$, it did have relevance: the con- 
comitant decline in albumin and fructosamine concentrations in pregnancy suggests that the changes in fructosamine concentrations merely reflect those in albumin concentrations. This apparent covariance was confirmed by correction of the fructosamine concentrations for this albumin effect: the relationship between fructosamine concentration and gestational age disappeared.

The mean fasting blood glucose concentration decreased gradually in the course of pregnancy by a total of $0.52 \mathrm{mmol} / 1(-10 \%)$. In contrast, the near-term glucose concentration 2 hours after glucose load $(+24 \%)$ and the area under the OGTT curve $(+17 \%)$ had gradually increased in the course of pregnancy (table 6.1) indicating a fall in glucose tolerance with pregnancy.

\section{Discussion}

\section{Glycated haemoglobin}

In the present study $\mathrm{HbA}_{1}$ varied independently of gestational age, an observation at variance with the results of most other studies in which $\mathrm{HbA}_{1}$ was found to decrease in the first half of pregnancy (Lind and Cheyne, 1979; Hanson et al., 1983; Worth et al., 1985). It is possible that the lack of correlation between $\mathrm{HbA}_{1}$ concentrations and gestational age in our study was caused by the cross-sectional set-up of the present study. The increased scatter associated with such a set-up may have masked a possibje small decline in the $\mathrm{HbA}_{\|}$concentrations in early pregnancy as reported by others. A decline in $\mathrm{HbA}_{4}$ concentration in early pregnancy may be the result of a fractional rise in young erythrocytes in early pregnancy. These young cells with shorter exposure to the glycaemic environment are likely to have a lower $\mathrm{HbA}_{1}$ fraction than mature erythrocytes (Hytten and Lind, 1973).

Data reported about the trend in $\mathrm{HbA}_{1}$ concentration in the second half of pregnancy are also conflicting, with studies reporting either a rise (Phelps et al., 1983; Griffiths et al., 1987) or a fall (Hanson et al., 1983). These conflicting results appear to be related to differences in population samples as suggested by differences in fasting glucose concentrations; moreover, in these studies the glucose tolerance was not determined. Inasmuch as in the present study only those pregnant subjects were included who had a normal OGTT, our results provide information on the trend of the $\mathrm{HbA}_{1}$ concentration in the course of pregnancies with confirmed normal glucose tolerance. In these patients $\mathrm{HbA}_{1}$ concentrations were found to vary independently of gestational age. 


\section{Fructosamine}

In the present study a small but consistent decrease in the fructosamine concentration in the course of pregnancy was found. Several authors also investigated the relationship between fructosamine and gestational age. Their results indicate either no change (Nelson et al., 1985) or a slight gradual decrease throughout pregnancy (Roberts and Baker, 1986). The latter study agrees with our data as we also found a weak negative correlation between fructosamine concentration and gestational age. However, the latter correlation lacks physiological meaning since it appears entirely attributable to covariation with the concomitant decrease in albumin in the course of pregnancy. Inasmuch as the changes in the fructosamine concentration with pregnancy are less than $5 \%$, which approximates to the assay error (chapter 3 ), correction of the fructosamine concentration for gestational age as well as for albumin concentration in a clinical setting appears to unnecessary.

\section{Glucose tolerance}

With respect to glucose tolerance, theoretically, in pregnancy two opposite factors are operative which may influence both the fructosamine and $\mathrm{HbA}_{1}$ concentrations. The $10 \%$ decrease observed in the fasting glucose concentration in the course of pregnancy is likely to have a lowering effect on the concentrations of both parameters. On the other hand, in the course of pregnancy the fructosamine and $\mathrm{HbA}_{1}$ concentrations may rise as a result of a decrease of glucose tolerance towards term, as demonstrated by an increase in the glucose concentration 2 hours after glucose load by $24 \%$ and an increase in the area under the OGTT curve by $17 \%$. Balance between these opposite effects may explain why fructosamine and $\mathrm{HbA}_{1}$ concentrations in normal pregnancy change little.

In short, in the clinical setting both $\mathrm{HbA}_{1}$ and fructosamine concentrations should be considered to vary independent of gestational age.

\section{References}

Baker JR, O'Connor JP, Metcalf PA, Lawson MR. Johnson RN. Clinicall usefulness of estimation of serum fructosamine concentration as a screening test for diabetes mellitus.

Br Med J 287: 863-867, 1983.

Bunn HF, Gabbay KH, Gallop PM. The glycosylation of haemoglobin: relevance to diabetes mellitus. Science 200; $21-27,1978$. 
Dusbresse IC, Lauren $\mathbb{E}_{\mathrm{q}}$ Ligny $\mathrm{C}$, et all. The usefulatss of fructosamine determination in diabetic pa tients and its relation to metabolic control.

Diabete Metiab 13: 217-221, 1987 .

Fadel HE, Hammond $\mathrm{SO}$, Huff TA, Harp RJ. Glycosylated haemoglobins in normal pregnancy and gertational diabetes.

Obstet Oynecol $54: 322-326,1979$.

Gonen $\mathrm{B}$, Rubenisteín AH, Rochman H, Tanega $5 F$, Horwitz DL. Haemoglobin $\mathrm{A}_{1}$, an indicator of the metabolic control of diabetic patients.

Lancet in: $734-737,1977$.

Griffihs RJ, Vinall PS, Stichland MH, Wales JK. Haemoglobin $A_{1 c}$ lewels in nomal pregnancies. Eur I Obstel Gynecol Reprod Biol 24: 195:200, 1987.

Hanson $U_{*}$ Hagenfeldi $L$, Hagenfeldt $K$. Clycosylated hernoglobins in normal pregnancy: sequential charnges and relation to birth weight.

Obostet Gynecol 62: 741-744, 1983.

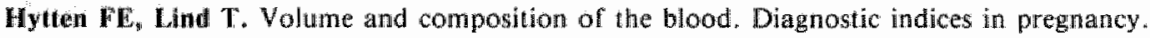

Doctmenta Geigy, Basel: $36-53,1973$.

Johnson RN, Meicall PA, Baker JR. Fructosamine: a new approach to the estimation of serum glycosylprotein. An index of diabetic control.

Clin Chim Acta 127: 87-95, 1982.

Koenig RJ, Petersion CM, Jones RL, et al. Correlation of glucose regulation and hemoglobin $\mathrm{A}_{1 \mathrm{c}}$ in diabetes mellitus.

N Engl J Med 295: 417-420, 1976.

Koskinen P, Irjala K, Viükari J, Panula-Ontto R, Matikainen MT. Serum fructosamine in the assessment of glycaemic control in diabetes mellitus.

Scand J Cin Lab Invest 47:285-292, 1987.

Landon MB, Gabbe SG, Piana R, Mennuti MT, Main EK. Neonatal morbidity in pregnancy complicated by diabetes mellitus: Predictive value of maternal glycemic profiles.

Am I Obstet Gynec 156: 1089-1095, 1987.

Leslie RDG, Pyke DA, John PN, White JM. Haemoglobin $A_{i}$ in diabetic pregancy.

Lancet in: $958-959,1978$.

Lind T, Cheyne GA. Effect of normal pregnancy upon the glycosylated haenogiobins.

$\mathrm{Br} J$ Obstet Gynaceol 86: 210-213, 1979.

Nelson DM, Barrows HJ, Clapp DH, Ortman-Natbi J, Whitehurst RM. Glycosylated serum protein levels In diabetic and nondiabetic pregnant patients: An indicator of short-term glycemic control in the diabetic patient.

Am J Obstet Gynecol 151: 1042-1047, 1985.

Phelps RL, Honig GR, Green D, et al. Biphasic shanges in hemoglobin $A_{1 \varepsilon}$ concentrations during nor mal pregnancy.

Am J Obstet Gynecol 147:651653, 1983.

Roberts AB, Baker JR. Serum fructosamine: a screening test for diabetes in pregnancy.

Am J Obstet Gynecol 154: 1027-1030, 1986. 
Schwartz HC, King KC, Schwartz AL, Edinunds D, Schwartz R. Effects of pregnancy on hatemoglobin $A_{1 c}$ in normal, gestationall diabetic, and diabetic women.

Diabetes $25: 1118-1122,1976$.

Van Dieijen-Visser MP, Sallemans THB, Van Wersch JWJ, Schellekens LA, Brombacher PJ. Glycosylat" ed serum proteins and glycosylated haemoglobin in normal pregnancy.

Ann Clin Biochem 23: 661-666, 1986.

WHO. Diabetes mellitus. Report of a WHO Study Group.

World Health Organization, Geneva. Technical Report Series $727,1985$.

Worth R, Potter JM, Drury J, Fraser RB, Cullen DR. Glycosylated haemoglobin in normal pregnancy: a longitudinal study with two independent methods.

Diabetologia 28: 76-79, 1985. 


\section{Chapter 7}

\section{The value of fructosamine measurement for the prediction of hyperglycaemia-related adverse neonatal outcome and large-for-gestational-age births}

T.H.B. Salemans, M.P. van Dieijen-Visser, P.J. Brombacher, L.L.H. Peeters.

(Submitted for publication)

\section{Summary part 1}

Over a period of 18 months, 765 consecutive patients were studied to determine the ability of maternal serum fructosamine measurements to identify patients at risk for the sequelae of hyperglycaemia. The birth weight ratio (BWR) was higher $(\mathrm{p}<0.05)$ in the offspring of patients in whom fructosamine concentrations in pregnancy had been higher than $2.30 \mathrm{mmol} / \mathrm{l}$. In the offspring of these patients, the incidence of neonatal hypoglycaemia, hyperbilirubinaemia and respiratory distress syndrome was not increased. Although the BWR did vary as a function of the fructosamine concentration, only $1.4 \%$ of the variation in BWR was attributable to variation in the fructosamine concentration; this contribution was clearly lower than that of influences such as smoking $(10 \%)$, and weights of the infant's mother $(6.5 \%)$ or father $(2.8 \%)$. Receiver operating characterisatic curves confirmed the limited screening value of fructosamine measurements for identifying patients who were to give birth to a large-for-gestational-age (LGA) infant. It is concluded that in an unselected population fructosamine measurement is an insensitive method for predicting neonatal complications of maternal hyperglycaemia and LGA births. 


\section{Summary part 2}

A subpopulation of 175 patients from the original study sample was selected on the basis of clinical risk factors for gestational diabetes. The presence of these risk factors was reason to subject them to a $75 \mathrm{~g}$ oral glucose tolerance test (OGTT). In this selected population neither the fructosamine concentration alone, nor the combination of fructosamine concentration and OGTT outcome were sufficiently sensitive to identify patients whose offspring was destined to develop complications such as hypoglycaemia, hyperbilirubinaemia, or respiratory distress syndrome. The higher contribution of the fructosamine concentration to the variation in BWR in this subpopulation $(5.8 \%)$ relative to that in the unselected population $(1.4 \%)$ did not raise the independent screening value of fructosamine measurement for predicting LGA births. However, when fructosamine measurement was used in combination with the outcome of the OGTT, the predicting value for the subsequent birth of an LGA infant increased markedly. 


\section{Introduction}

For many years, diabetes mellitus antedating pregnancy has been recognized as an important cause of foetal death, birth defects, and increased neonatal morbidity. The infants of diabetic mothers are not only prone to macrosomia but show also a higher incidence of neonatal hypoglycaemia, respiratory distress sydrome (RDS) and hyperbilirubinaemia (Kitzmiller et al., 1978). Poor control of diabetes during pregnancy has often been held responsible for the increased incidence of these complications, whereas meticulous glucose control in pregnant diabetics is generally considered effective in reducing the risk of the neonatal sequelae of hyperglycaemia (Landon et al., 1987).

Gestational diabetics, in whom glucose intolerance is first detected during pregnan$\mathrm{cy}$, resemble pregnant diabetics with respect to pregnancy outcome. This is suggested by the higher incidence of macrosomia, neonatal hypoglycaemia, hyperbilirubinaemia and RDS in these patients (Gabbe et al., 1977). Moreover, it has been reported that the rate of large-for-gestational-age (LGA) infants in gestational diabetics may also be reduced by normalizing the mean blood glucose concentration (Langer and Mazze, 1988).

Measurement of the fructosamine concentration gives indirect information about the mean blood glucose concentration during the preceding 1-3 weeks (Hindle et al., 1986; Daubresse 1987). For management of both pregnant diabetics and gestational diabetics, the fructosamine measurement has been reported to provide useful information. In these patients, high fructosamine concentrations during pregnancy have been associated with macrosomia (Roberts and Baker, 1987; Roberts et al., 1988). However, the usefulness of fructosamine measurement as a screening test to identify pregnant women at risk of developing hyperglycaemia-related neonatal complications, has not yet been evaluated.

The present study was designed to assess the efficacy of fructosamine measurement during pregnancy for identifying patients at risk of the sequelae of hyperglycaemia. To this end, the relation between the fructosamine concentration during pregnancy and newborn weight was studied in a population with presumed low incidence of hyperglycaemia. In addition, the possible association between elevated fructosamine concentrations during pregnancy and increased incidences of neonatal hypoglycaemia, hyperbilirubinaemia or RDS was evaluated (part 1).

In a subpopulation with clinical signs or history suggesting an increased risk of glucose intolerance, the screening value of fructosamine measurement was compared 
with that of the OGTT. Finally, in the latter population the predictive value of the combination of the two methods with respect to the sequelae of hyperglycaemia was determined (part 2).

\section{Patients}

During an eighteen month period ending in August 1988, all pregnant women $(n=893)$ presenting at the antenatal clinic or delivery room at the De Wever Hospital, Heerlen, were informed about the study and were invited to participate. In the 816 patients who agreed to do so, fructosamine was determined at least once during pregnancy. Patients with no first trimester ultrasound confirmation of their expected dates of confinement $(n=33)$ were excluded from the study as were patients with multiple pregnancy $(n=12)$. Also excluded from the study were pregnant diabetics $(n=6)$. The remaining 765 patients entered the study population.

Table 7.1 lists some characteristics of these patients in comparison with a reference population, constituting a major fraction of those women who were delivered in hospital in The Netherlands in 1988 . In this table it is illustrated that the incidence of preterm birth was considerably lower in the study population than in the reference population. This could be a result of selection, since the criteria for entering the study excluded patients with multiple pregnancy and pregnant diabetics, both of whom tend to be delivered prematurely.

Table 7.1 Comparison of the study population with a reference population

\begin{tabular}{lcc}
\hline & $\begin{array}{l}\text { Study } \\
\text { population }\end{array}$ & $\begin{array}{l}\text { Reference } \\
\text { population } \\
\text { (S.I.G. data) }\end{array}$ \\
Number of patients & 765 & 60942 \\
\hline Age at delivery (yr) & $28 \pm 5$ & $28 \pm 5$ \\
Age $>34$ yr, nulliparous & $1.7 \%$ & $2.7 \%$ \\
Caucasian & $94.8 \% \%$ & unknown \\
Nulliparity & $45.2 \%$ & $50.4 \%$ \\
Preterm birtl & $6.3 \%$ & $13.0 \%$ \\
Caesarean section & $12.2 \% \%$ & $12.8 \%$ \\
Congenital anomalies & $2.9 \%$ & $3.70 \%$ \\
Female infants & $49.6 \%$ & $47.6 \%$ \\
\hline
\end{tabular}

* Stichting Informatiecentrum voor de Gezondheidszorg; Maliebaan 50, $3508 \mathrm{SC}$ Utrecht. 
Blood samples for fructosamine measurement were collected up to four times in each patient: in early pregnancy (before 16th week), mid-gestation (16-32 weeks), late pregnancy (after 32nd week), and 6 weeks post partum. The obstetricians were kept unaware of the results of the measurements.

Maternal age, ethnic origin, parity, height, and smoking were registered as were the fathers' heights and weights. Since only few patients could recall their prepregnancy weight, the first trimester weight $(10+/-2$ weeks $)$ was considered 'reference" maternal non-pregnant weight. Body mass index was calculated by dividing weight in kilograms by the height in meters squared. Obesity was defined as a body mass index over $30 \mathrm{~kg} / \mathrm{m}^{2}$ (Garrow, 1981). Patients were only considered to have a family history of diabetes mellitus when at least one first degree relative had the disease. Weight gain in pregnancy was defined as the difference between the weight determined prior to delivery and that in the first trimester.

Preterm birth was defined as birth at a gestational age of less than 37 completed weeks. Instrumental delivery was defined as labour in which the foetus was extracted by forceps or vacuum. The infant's birth weight ratio (BWR) (\%) was calculated by dividing its birth weight by the 50th weight centile for an infant of the same sex, gestational age, and parity, as reported by Kloosterman (1970). Infants were considered large-for-gestational-age (LGA) and small-for-gestational-age (SGA) when their BWRs were above $115 \%$ and below $81 \%$, respectively. These values corresponded with the 90 th and 10 th percentile of the BWRs of our population. The capillary plasma glucose concentration was determined at least once in all infants admitted to the neonatal care unit as well as in all LGA infants $(n=320)$. A newborn was considered hypoglycaemic when its plasma glucose concentration was less than $2.0 \mathrm{mmol} / \mathrm{l}$ at least once during the first 72 hours. A newborn was considered hyperbilirubinaemic whenever treatment was required according to Brown's guidelines (1979). Requirement of continuous positive airway pressure or artificial ventilation during more than 24 hours was defined as respiratory distress syndrome (RDS). The incidence of congenital malformation in the tables refers to those emerging during the first week after delivery. Minor anomalies such as congenital dislocation of the hip, inguinal hernia and an undescended testicle were not included.

The population studied embodied 14 insulin-treated and 13 diet-treated gestational diabetics, detected by OGTT in patients with clinical risk factors. Gestational diabetes was classified according to the WHO criteria (WHO report, 1985).

The study protocol was approved by the ethical committee of the hospital. 


\section{Anallytical techniques}

The techniques by which fructosamine and glucose were measured have been described in detail in chapter 4 .

\section{Statistical analysis}

Data are presented as means with their standard deviation (SD) or means with their standard error of the mean (SEM). Comparisons between groups were performed by the Mann-Whitney U-test. Continuous variables divided over two groups were evaluated by Spearman's correlation test. The Chi-square test was applied to compare categorical data, expressed as frequencies. In case of small sample size, the Fisher exact probability test was employed. For the purpose of trend detection, the longitudinal and cross-sectional observations of fructosamine concentrations, determined in adjacent periods in pregnancy and post partum, were compared with Student's paired and unpaired $t$-test, respectively. The relationship between fructosamine and age was quantitated by linear regression.

A probability of less than $5 \%(\mathrm{p}<0.05)$ was considered significant. The ROC curve technique (Sackett et al., 1985; Richardson et al., 1985) was applied to determine the screening value of a given test per se and of a given test relative to alternative tests. Multiple linear regression analysis was used to determine the fractional contribution to the variation in BWR of various maternal characteristics including that of fructosamine concentrations.

\section{Results}

\section{Fructosamine measurements}

Table 7.2 lists the number of patients and mean fructosamine concentrations in each pregnancy period and post partum. The post-partum fructosamine concentration served as the non-pregnant value. The mean differences between consecutive periods are also shown in this table. The fructosamine concentration was lower in pregnancy than in the non-pregnant state, irrespective of gestational age, both within and in between subjects. Even the longitudinal analysis did not show a consistent change in the fructosamine concentration with pregnancy. The intra-individual variation in pregnancy was considerable as indicated by the large SD. This agrees with data reported recently by Staley and co-workers (1988). 
Table 7.2 Fructosamine concentrations in the three pregnancy intervats and post-partum in the population studied

Fructosamine
mean $\pm \mathrm{SD}$

Inter-individual (cross-sectional)."
A Non-pregnant
B Early-pregnant ( $<16$ weeks)
C Mid-pregnant (16-32 weeks)
D Late-pregnant ( $>32$ weeks)

$\begin{array}{ll}291 & 2.31 \pm 0.18 \\ 209 & 2.20 \pm 0.19 \\ 359 & 2.16 \pm 0.17 \\ 709 & 2.17 \pm 0.18\end{array}$

Intra-individual (longitudinal):

Difference between $A$ and $B$

* A higher than $B, C$, and D; $p<0.001$; Student's unpaired t-test * $p<0.001$; Student's paired $t$-test

\section{Fructosamine measurement and prediction of $L G A$ births}

To evaluate the effect of gestational age on the value of fructosamine measurement to predict LGA births, ROC curves based on 3 periods of pregnancy were constructed (early-, mid-, late-pregnancy). This method allows evaluation of the value of the fructosamine measurement as a screening method for LGA births over the entire range of values. Moreover, the optimal measurement period in pregnancy and the optimal cut-off value can be derived. Figure 7.1 shows that in the population studied, fructosamine measurement had little value in predicting subsequent birth of an LGA infant, irrespective of the gestational period of measurement, as the ROC curves approached the 45-degree diagonal through the origin. Each point on this diagonal represents an equal likelihood of a true positive (sensitivity) and false positive (100-specificity) outcome as would occur by chance alone. The cut-off value $2.30 \mathrm{mmol} / \mathrm{A}$ in mid-pregnancy was found to provide the largest difference between true positive and false positive results with respect to the prediction of LGA births.

\section{Comparison of patients with different fructosamine concentrations}

In addition, the usefulness of fructosamine measurements for identifying pregnant women at risk of developing hyperglycaemia-related complications was evaluated by comparing patients with a 2 nd or 3 rd trimester fructosamine value above 2.30 $\mathrm{mmol} / 1$ with those in whom this value was below this level. In 748 patients the fructosamine concentration was measured at least once after the 16 th week of gestation. Because of the ROC curve patterns (figure 7.1) it was decided to chose the 


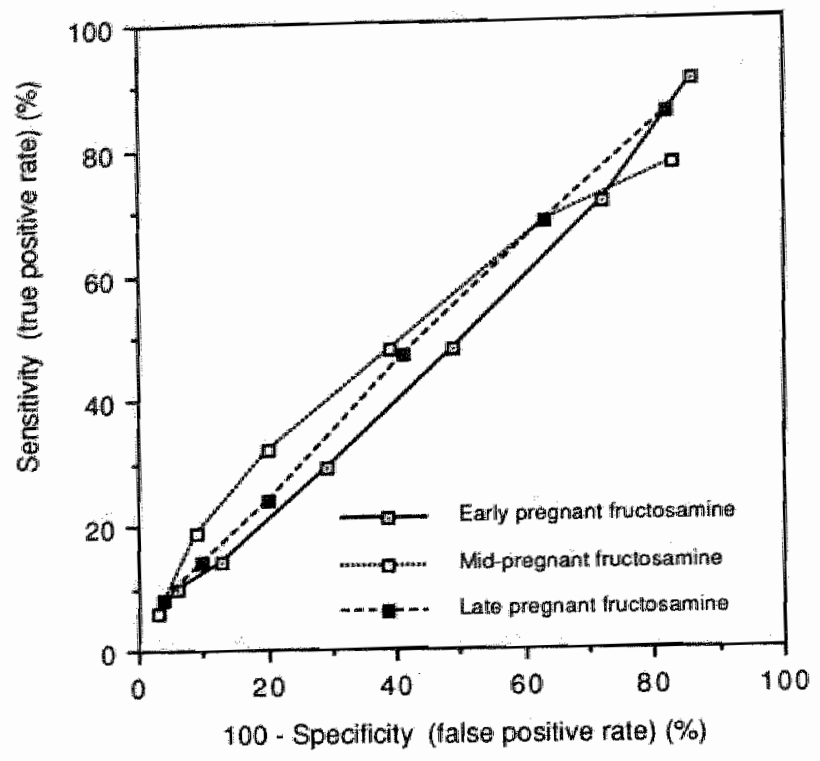

Figure 7.1 Receiver operating characteristic curves of early. mid-, and late pregnancy fructosamine concentrations for predicting the subseguent birth of an LGA infant

Cutoff values (mmolll) from lefi to right in the graph: $2.50 ; 2.40 ; 2.30 ; 2.20 ; 2.10 ; 2.00$.

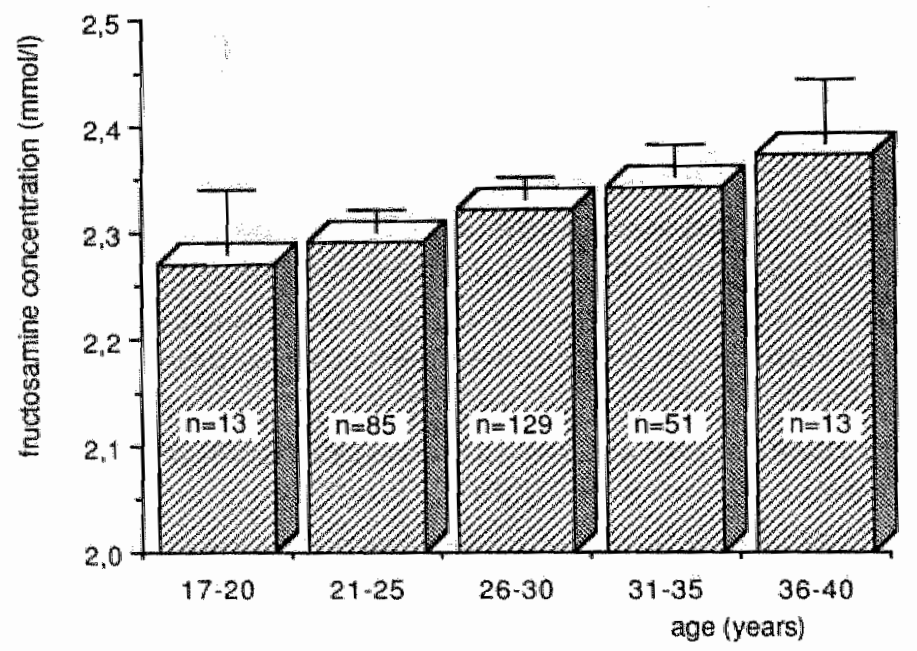

Figure 7.2 Relationship between maternal age and won pregnant fructosamine concentration $($ mean $\pm S E M)$ 
Table 7.3 Maternal characteristics and neonatal ontcone in patients whith fructosamine concentrations above 2.30 mmoll (high fructasamine group) and below 2.30 monoll (nomal fractosamine group) after the $16 \mathrm{th}$ week of gestation

\begin{tabular}{|c|c|c|c|}
\hline & $\begin{array}{l}\text { Normal } \\
\text { fructosamine } \\
\text { group }\end{array}$ & $\begin{array}{l}\text { High } \\
\text { fructosamine } \\
\text { group }\end{array}$ & \\
\hline Fructosamine (mmol/1) & $\leqslant 2.30$ & $>2.30$ & \\
\hline Number of patients & 596 & 152 & p-value \\
\hline Age $(y r)$ & $27 \pm 4$ & $29 \pm 5$ & $<0.0001$ \\
\hline Nulliparity & $47 \%$ & $390 \%$ & ns \\
\hline Family history diabetes & $16 \%$ & $20 \%$ & ns \\
\hline Maternal weight $(\mathrm{kg})$ & $65.7 \pm 12.2$ & $65.0 \pm 12.5$ & ns \\
\hline Obesity & $10 \%$ & $8 \%$ & ns \\
\hline Smokers & $31 \%$ & $24 \%$ & $\mathrm{~ns}$ \\
\hline Weight gain in pregnancy $(\mathrm{kg})$ & $10.8 \pm 4.3$ & $10.5 \pm 5.1$ & ns \\
\hline Preterm delivery & $6 \%$ & $4 \%$ & ns \\
\hline Caesarean section & $12 \%$ & $120 \%$ & ns \\
\hline Instrumental delivery & $130 \%$ & $16 \%$ & ns \\
\hline $\mathrm{pH}$ umbilical artery $<7.10$ & $6 \%$ & $4 \%$ & ns \\
\hline Newborn weight (g) & $3282 \pm 585$ & $3364 \pm 577$ & ns \\
\hline Birth weight ratio ( $\%$ ) & $97.7 \pm 14.1$ & $100.4 \pm 14.2$ & $<0.05$ \\
\hline LGA birth & $9 \%$ & $13 \%$ & $n s$ \\
\hline SGA birth & $10 \%$ & $10 \%$ & $\mathrm{~ns}$ \\
\hline Hypoglycaemiat & $1 \%$ & $2 \%$ & $\mathbf{n s}$ \\
\hline Hyperbilirubinaemia & $3 \%$ & $3 \%$ & ns \\
\hline Respiratory distress syndrome & $10 \%$ & $0 \%$ & $\mathrm{~ns}$ \\
\hline Malformations & $30 \%$ & $4 \%$ & nis \\
\hline
\end{tabular}

ns: non-significant

mid-pregnancy fructosamine value in the comparison unless only a late-pregnant value was available. The results are listed in table 7.3 .

The maternal characteristics of the normal and high fructosamine groups were com parable, except for age. By linear regression analysis the following regression equation was calculated for the relationship between non-pregnant fructosamine levels $(y ; m m o l / 1)$ and maternal age $(x ;$ years $)$ :

$y=0.0086 x+2.08(n=291, r=0.20, p<0.001)$.

This relationship was determined for the age interval between 17 and 40 years and is illustrated in figure 7.2. The effect of age appeared to be at least in part responsible for the difference in fructosamine concentrations between the two groups listed in table 7.3 . 
The incidence of neonatal hypoglycaemia, hyperbilirubinaemia, RDS and malformations was very low in both fructosamine groups.

\section{Fructosamine concentration and birth weight ratio}

More than $70 \%$ of the fructosamine values after the $16 \mathrm{th}$ week were higher than 2.05 $\mathrm{mmol} / \mathrm{l}$. In this range the $\mathrm{BWR}$ was correlated with the fructosamine concentration (Spearman's correlation test, $r=0.13, p<0.05$; see figure 7.3 ).

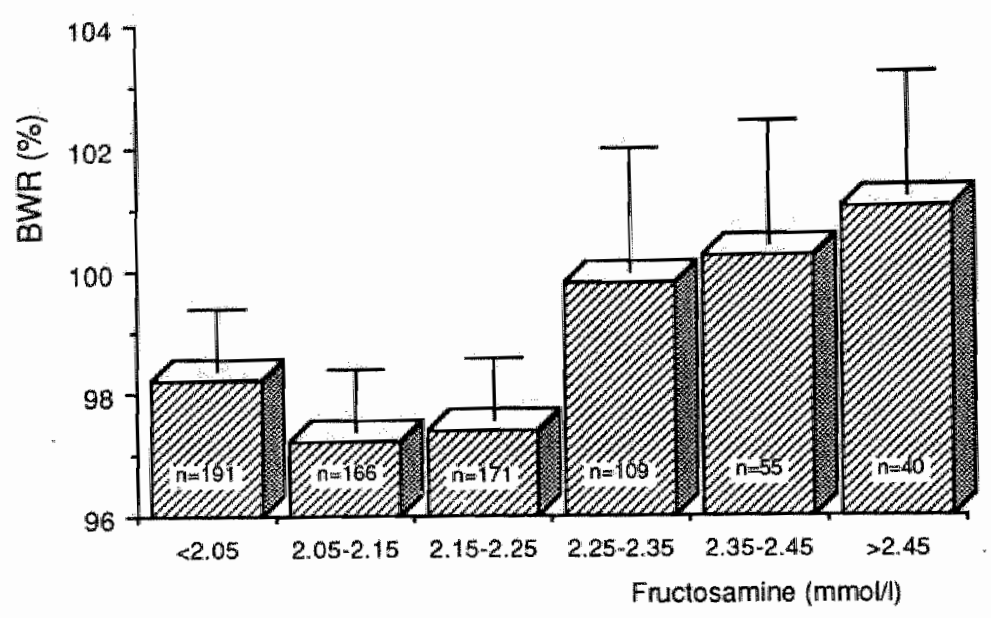

Figure 7.3 Relationship between birth weight ratio $(B W R)$ and fructosamine concentration after the 16 th week of pregnancy (mean $\pm S E M$ )

To determine whether the apparently weak relationship between fructosamine concentration and BWR in this range was due to covariance with other variables, multiple linear regression analysis was employed to quantitate the individual contribution to the variation in BWR of a number of independent variables with possible effect on foetal growth rate. These variables included maternal age and height, smoking habits, first trimester weight, first trimester diastolic blood pressure, first trimester haematocrit, as well as fructosamine concentration, father's weight and height. From these 9 variables, the following available parameters were selected by the regression: smoking, weight of the mother in early pregnancy, weight of the father, and fructosamine concentration after the 16 th week of gestation. The results are listed in table 7.4. The analysis demonstrated that $10.0 \%$ of the variation in BWR was àttributable to smoking, $6.5 \%$ to maternal weight, and $2.8 \%$ to the weight of the father. Variation in fructosamine concentration could only explain $1.4 \%$ of the 
Table 7.4 Contribunion of several parameters to the variation in birth weight ratio (BNA) quantitated by multiple linear regression analysis $(n=254)$

\begin{tabular}{lll}
\hline & $\begin{array}{l}\text { Explained } \\
\text { variation } \\
\text { in BWR } \\
\left(\mathrm{R}^{2}\right)\end{array}$ & p-value \\
\hline Smoking & $10.0 \%$ & $<0.0001$ \\
Weight of the mother & $6.5 \%$ & $<0.0001$ \\
Weight of the father & $2.8 \%$ & $<0.0005$ \\
Fructosamine after 16th wh & $1.4 \% \%$ & $<0.05$ \\
\hline
\end{tabular}

remaining variation in BWR. Although the effect was small, it was significant and not due to covariance with any of the other variables in the regression.

\section{Discussion}

Identification and treatment of hyperglycaemia during pregnancy has been advocated for many years in an attempt to reduce the unwanted sequelae normally found in the infant of the diabetic mother (Adashi et al., 1979). Screening all pregnant patients by random measurement of blood glucose concentration has been recommended by Lind and Anderson (1984), but has been proven inadequate in a population with a high prevalence of abnormal glucose tolerance (Nasrat et al., 1988). Screening pregnant patients by an OGTT on the basis of clinical risk factors will identify only $50 \%$ of all potentially hyperglycaemic patients (Lavin, 1985).

The decision to treat a patient with insulin or diet is determined in the first place by the patient's daily glucose profile in response to her own nutritional habits, irrespective of the result of the OGTT (Second International Workshop Conference on Gestational Diabetes, 1984). This implies that screening for hyperglycaemia can be considered more important than screening for an abnormal response to a nonphysiological glucose load (OGTT). As the fructosamine concentration is an indifect estimate of mean blood glucose, its measurement was expected to provide an attractive alternative for identifying pregnant patients at risk of the sequelae of hyperglycaemia.

In this study we ignored the potential effect of insulin treatment (Coustan and Imarah, 1984) for two reasons. Firstly, the incidence of LGA births in the insulintreated gestational diabetics $(n=14)$ was higher $(29 \%)$ than in the total population $(10 \%)$. Secondly, inadequate treatment would not only have resulted in a higher birth weight, but also in a higher fructosamine concentration (Roberts et al, 1988). 
The incidence of neonatal hypoglycaemia, hyperbilirubinaemia and RDS was evenly distributed over both the high and normal fructosamine groups. It should be realized that in this study population such apparently rare neonatal complications may result from disorders other than maternal hyperglycaemia. For instance, neonatal hypoglycaemia may also resuit from reduced hepatic glycogen reserve (low birth weight infants) and increased metabolic needs (hypothermia and systemic infections). In the study population hypoglycaemia was diagnosed in only eight newborns, three of which were born preterm, three were SGA and only one was LGA.

The extent of maternal hyperglycaemia is established as one factor responsible for infant macrosomia via the foetal hyperglycaemia - foetal hyperinsulinism mechanism, originally proposed by Pedersen (1977). Therefore, pregnant women with previous delivery of a LOA infant are often screened for hyperglycaemia by an OGTT. If hyperglycaemia is the cause of excessive foetal growth, diet and insulin treatment should normalize foetal growth rate and thus diminish the risk of traumatic delivery (Coustan and Imarah, 1984). As compared to AGA (appropriate-forgestational-age) and SGA infants, LGA infants have a higher risk of being delivered by forceps, vacuum or Caesarean section; this is supported by our experiences in the population studied ( $25 \%$ and $41 \%$, respectively). However, it should be stressed that LGA birth (and BWR) is the resultant of several growth-stimulating and growth-inhibiting factors, among which excessive glucose supply to the foetus is only one. The fructosamine concentration will only be related to that part of (over)growth which is associated with maternal glucose supply to the foetus. In order to estimate the real contribution of the fructosamine concentration to the variation in BWR, we determined its independent effect on this parameter. Multiple linear regression analysis demonstrated that the fructosamine concentration could only explain a small fraction $(1.4 \%)$ of the variation in BWR. In agreement with this finding was the weak correlation between BWR and the fructosamine concentration during pregnancy $(r=0.08, p<0.05)$. This correlation may explain the small but significant difference in mean $B W R$ between the high and normal fructosamine groups (table 7.3). These differences were too small to be associated with a higher incidence of instrumental delivery and/or Caesarean section in the highfructosamine group.

The results of this study provide convincing evidence that fructosamine measurement has little predictive value when used as a screening test for identifying LGA infants in a low-risk population. This observation may be the consequence of a low fractional contribution of maternal hyperglycaemia to the rather mixed LGA target group. As a matter of fact, the latter group is only put together on the basis of neonatal weight, without taking into account the preceding foetal growth rate and the impact of genetic and environmental influences on size.

From this study it can be concluded that fructosamine measurement should be considered as an insensitive method for predicting adverse neonatal outcome and LGA 
births caused by maternal hyperglycaemia. To determine whether this result is related to the low incidence of maternal hyperglycaemia or to the poor sensitivity of the test itself, we estimated the value of fructosamine in a population with a (presumed) higher incidence of hyperglycaemia. The results are given in the second part of this chapter. 


\section{Part 2}

\section{Introduction}

In the first part of this study it was coneluded that fructosamine measurement alone had little screening value when used in a low-risk population for identifying patients at risk of the sequelae of hyperglycaemia such as LGA births. This conclusion may not be valid for a high-risk population. In addition, the screening value of fructosamine may increase when the latter is evaluated in combination with some other potentially relevant variable such as the OGTT.

We therefore decided to determine the value of fructosamine measurement as a screening test in a population in whom the risk of maternal hyperglycaemia was higher. Furthermore, we evaluated the value of fructosamine measurement as a test to screen for LGA births and, also, whether this screening value would increase when the result of the OGTT was taken into account.

\section{Patients}

The study sample consisted of a subgroup of 175 patients selected from the original study sample as described in part 1. In these patients an OGTT was performed during pregnancy on the basis of clinical risk factors for gestational diabetes. These factors included obesity, age over 30 years, suspected LGA foetus, a family history of diabetes mellitus, polyhydramnios, glycosuria and/or typical problems in the obstetrical history such as previous birth of an LGA infant, unexplained stillbirth, congenital anomalies and recurrent miscarriages. A $75 \mathrm{~g}$ OGTT was performed and interpreted according to WHO recommendations (1985) (table 1.1). Patients with gestational diabetes mellitus and patients with gestational impaired glucose tolerance were both defined as gestational diabetics.

During the eighteen-month study period 27 gestational diabetics were identified, most of them in the second half of pregnancy. After the diagnosis had been made, all gestational diabetics were given dietary instruction by a dietician. Caloric intake of 1800-2200 kcal per day was prescribed, distributed over carbohydrates (50\%), protein $(20 \%)$, and fat $(30 \%)$. If dietary management did not result in fasting plas$\mathrm{ma}$ glucose concentrations below $5.8 \mathrm{mmol} / 1$ and 2-hour postprandial plasma glucose levels below $7.5 \mathrm{mmol} / \mathrm{l}$ on two or more occasions within a two-week interval, insulin therapy was initiated (recommendations of the Second International Workshop-conference on Gestational Diabetes Mellitus (1985) and the World Health 
Organization (1985)). According to these criteria, 13 gestational diabetics were treated with a diet only, whereas 14 patients required insulin supplementation.

Inherent to the selection procedure, in the OGTT subgroup a higher incidence of previous miscarriage, family history of diabetes, obesity, BWR, and LGA births was found than in the original study group (table 7.5).

However, the incidence of neonatal morbidity did not differ between the two groups.

Table 7.5 Maternal and neonatal characteristics of the original study sample and the OGTT subgroup

\begin{tabular}{lcl}
\hline & $\begin{array}{l}\text { Total study } \\
\text { population } \\
\text { (part 1) }\end{array}$ & $\begin{array}{l}\text { OGTT } \\
\text { subgroup } \\
\text { (part 2) }\end{array}$ \\
Number of patients & 765 & 175 \\
\hline Age (yr) & $28 \pm 5$ & $28 \pm 5$ \\
Previous miscarriage (>1) & $6 \% \%$ & $10 \%$ \\
Family history diabetes & $17 \%$ & $35 \%$ \\
Obesity & $9 \%$ & $16 \%$ \\
Smokers & $30 \%$ & $310 \%$ \\
BWR (\%) & $98.2 \pm 14.4$ & $101.4 \pm 15.0$ \\
LGA birth & $10 \%$ & $18 \%$ \\
Neonatal hypoglycaemia & $1 \% \%$ & $1 \% \%$ \\
Neonatal hyperbilirubinaemia & $3 \% \%$ & $3 \%$ \\
Neonatal RDS & $1 \% \%$ & $1 \%$ \\
\hline
\end{tabular}

Blood sampling for fructosamine measurement was performed as described in part 1. To allow comparison of the value of fructosamine measurement with that of the OGTT and to be able to evaluate the combination of both tests, those fructosamine measurements were selected which were performed in the same period of gestation as the OGTT.

\section{Analytical techniques and statistical analysis}

Analytical techniques and statistical analysis have been detailed in part 1 . 


\section{Results}

Prediction of hyperglycaemia-related adverse neonatal outcome and LGA births by fructosamine measurement

To estimate the value of fructosamine measurement in this presumably high-risk population, patients with fructosamine concentrations above and below 2.30 mmol/I were compared with each other in the same way as in part 1 . The results can be derived from table 7.6. Patients in the high fructosamine group $(n=37)$ were significantly older $(p<0.005)$ and seemed to be delivered more frequently of an LGA infant than patients in the normal fructosamine group $(n=138)(30 \%$ and $14 \%$, respectively). However, the latter difference did not reach significance. The incidence of neonatal morbidity was similar in the two groups.

\section{Prediction of hyperglycaemia-related adverse neonatal outcome and LGA births by OGTT}

Patients in whom the OGTT was abnormal $(n=27)$ were older $(p<0.02)$ and more often obese $(p<0.05)$ than patients with a normal OGTT $(n=148)$. The incidence of LGA births $(22 \%$ and $16 \%$, respectively $)$ and of delivery by forceps/vacuum/Caesarean section ( $18 \%$ and $32 \%$, respectively) did not differ significantly between patients with abnormal or normal OGTT results. The incidence of neonatal complications such as hypoglycaemia, hyperbilirubinaemia and RDS was very low in the 175 patients of the population sample. The discriminating value of the OGTT with respect to these complications could therefore not be tested (table 7.6).

Prediction of hyperglycaemia-related adverse neonatal outcome and LGA births by combining the fructosamine concertration with the outcome of the OGTT

The selection based upon the fructosamine concentration can be combined with that based upon the OGTT. The results of various combinations of these two parameters are listed in table 7.6 . With respect to the neonatal morbidity, no conclusions could be drawn since the incidence of neonatal morbidity was too low in all four groups. In patients with a normal OGTT, the fructosamine measurement did not increase the chance of identifying those women who were to give birth to an LGA infant or an infant with a higher BWR. However, in patients with an abnormal OGTT the BWR was higher and the predictive value with respect to the incidence of LGA births increased from $6 \%$ to $46 \%$ when the concomitant fructosamine value was higher instead of lower than $2.30 \mathrm{mmol} / \mathrm{l}$. 
Table 7.6 Maternal characteristics and neoratal outcome in patiens hawing different fructosanine concentrations with respect to the result of an OGTT

\begin{tabular}{|c|c|c|c|c|c|}
\hline \multirow[b]{2}{*}{ Fructosamine $(\mathrm{mmol} / 1)$} & \multicolumn{2}{|c|}{ Normal OGTT } & \multicolumn{2}{|c|}{$\begin{array}{l}\text { Abnormal OGTT } \\
\text { (gestational diabetes) }\end{array}$} & \multirow{4}{*}{$\begin{array}{l}\text { Significant } \\
\text { difference } \\
\text { between groups }\end{array}$} \\
\hline & $\leqslant 2.30$ & $>2.30$ & $\leqslant 2.30$ & $>2.30$ & \\
\hline Number of patients & 122 & 26 & 16 & 11 & \\
\hline Group & A & $\mathrm{B}$ & $\mathrm{C}$ & $\mathrm{D}$ & \\
\hline Age (yr) & $27 \pm 5$ & $30 \pm 5$ & $29 \pm 6$ & $32 \pm 3$ & $\mathrm{~A} / \mathrm{B}, \mathrm{A} / \mathrm{D}^{*}$ \\
\hline Nulliparity & $45 \%$ & $42^{\%}$ & $50 \%$ & $18 \%$ & $\mathrm{C} / \mathrm{D}^{* *}$ \\
\hline Family hisitory DM & $30 \%$ & $42 \%$ & $44 \%$ & $73 \%$ & $\mathrm{~A} / \mathrm{D}, \mathrm{B} / \mathrm{D}, \mathrm{C} / \mathrm{D}^{* *}$ \\
\hline Maternal weight $(\mathrm{kg})$ & $69.4 \pm 14.1$ & $65.1 \pm 11.5$ & $75.5 \pm 15.4$ & $77.4 \pm 20.3$ & $\mathrm{~B} / \mathrm{C}^{\mathrm{H}}$ \\
\hline Obesity & $13 \%$ & $4 \%$ & $38 \%$ & 270 & $\mathrm{~A} / \mathrm{C}, \mathrm{B} / \mathrm{C} *$ \\
\hline Srmokers & $31 \%$ & $31 \%$ & $25 \%$ & $27 \%$ & \\
\hline Weight gain $(\mathrm{kg})$ & $11.0 \pm 4.6$ & $11.4 \pm 5.3$ & $9.5 \pm 6.8$ & $6.3 \pm 3.5$ & $\mathrm{~A} / \mathrm{D}, \mathrm{B} / \mathrm{D}^{\mathrm{k}}$ \\
\hline Preterm delivery & $5 \%$ & $0 \%$ & $60 \%$ & $9 \%$ & \\
\hline Caesarean section & $16 \%$ & $12 \%$ & $0 \%$ & $18 \%$ & \\
\hline Instrumental delivery & $16 \%$ & $19 \%$ & $0 \%$ & $27 \%$ & \\
\hline $\mathrm{pH}<7.10$ & $8 \%$ & $0 \%$ & $0 \%$ & $9 \%$ & \\
\hline Newborn weight ( $g$ ) & $3361 \pm 655$ & $3402 \pm 609$ & $3324 \pm 651$ & $3542 \pm 862$ & \\
\hline Birth weight ratio $(\%)$ & $100.2 \pm 14.7$ & $102.5 \pm 16.3$ & $100.8 \pm 11.4$ & $111.7 \pm 17.1$ & $\mathrm{~A} / \mathrm{D}^{*}$ \\
\hline LGA birth & $15 \%$ & $23 \%$ & $6 \%$ & $46 \%$ & $A / D, C / D^{* * *}$ \\
\hline SGA birth & $7 \%$ & $12 \%$ & $13 \%$ & $0 \% / 0$ & \\
\hline Hypoglycaemia & $0 \%$ & $4 \%$ & $0 \%$ & $0 \%$ & \\
\hline Hyperbilirubinaemia & $30 \%$ & $8 \%$ & $0 \%$ & $0 \%$ & \\
\hline RDS & $10 \%$ & $0 \%$ & $00 \%$ & $0 \%$ & \\
\hline Malformations & $30 \%$ & $4 \%$ & $00 \%$ & $9 \% \%$ & \\
\hline
\end{tabular}

* Mann-Whitney U test

* * Fisher"s exact test

The screening value of fructosamine, the OGTT, and the combination of these two tests with respect to the subsequent birth of an LGA infant was also evaluated by the ROC-curve method. The ROC curve for the OGTT was constructed with the glucose concentration determined 2 hours after the glucose load. The ROC curve representing the combination of the tests described the screening value of fructosamine measurement in patients with an abnormal OGTT ( 2 hours glucose $7.8 \mathrm{mmol} / \mathrm{I}$ or higher). The curves depicted in figure 7.4 confirm that only the combination of the two tests has screening potential. However, merging of the two tests reduced the number of detectable LGA infants by $80 \%$, from 30 to 6 patients. It was not possible to determine whether this reduction was a 'purification' of the LGA subpopulation or an undesirable loss of a fraction of this subpopulation.

Figure 7.5 illustrates how a series of fructosamine concentrations predicts LGA births when the $2 \mathrm{~h}$ OGTT glucose concentration is taken into account. This figure 


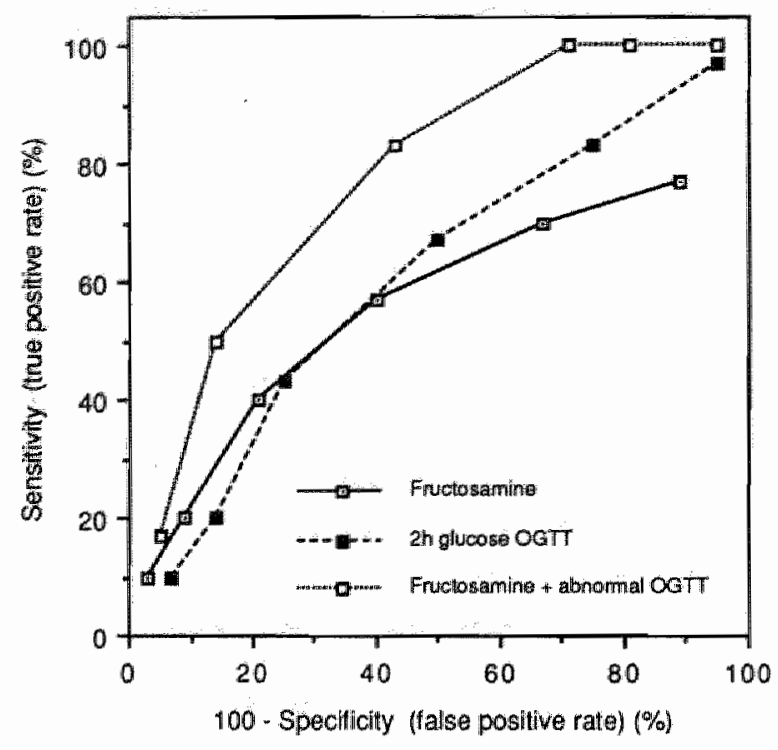

Figure 7.4 Receiver operating characteristic curves of fructosamine, $2 \mathrm{~h}$ glucose OGTT and the combination of fructosamine with an abnormal OGTT ( $2 \mathrm{~h}$ glucose OGTT $\geqslant 7.8 \mathrm{mmol} / \mathrm{l}$ ) for predicting $L G A$ births

Cut-off values for the different methods from left to right in the graph:

Fructosamine (mmol/l): $2.50 ; 2.40 ; 2.30 ; 2.20 ; 2.10 ; 2.00$.

2h glucose OGTT (mmol/l): $9.0 ; 7.8 ; 7.0 ; 6.0 ; 5.0 ; 4.0$.

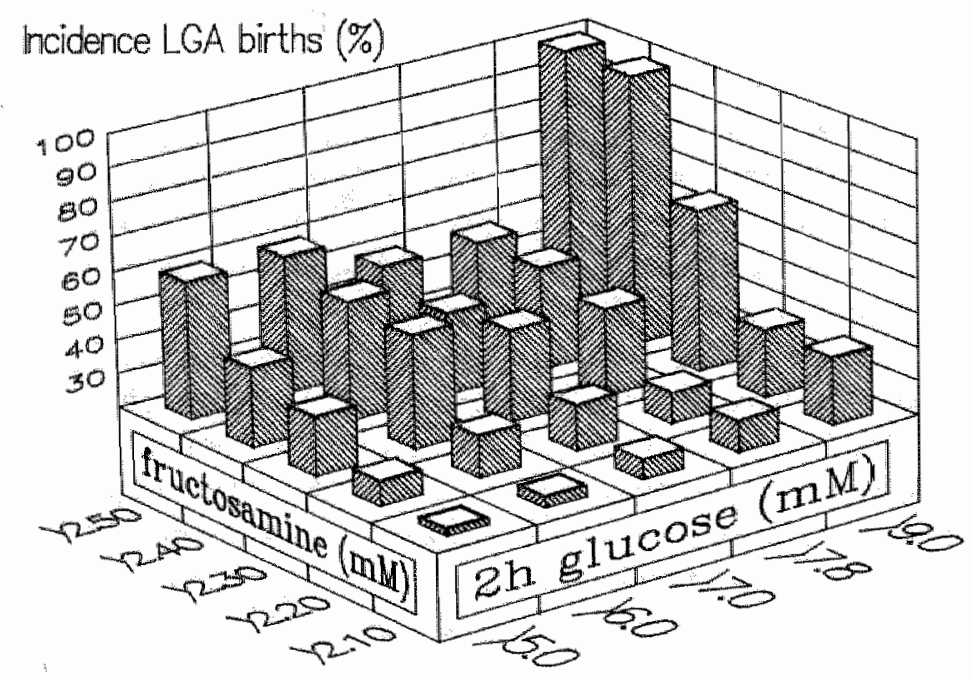

Figure 7.5 Prediction of $L G A$ oulcome at various levels of fructosamine and $2 h$ glucose OGTT 
allows evaluation of the contribution of the OGTT at different values for the 2 hours glucose. It is clear that increments in the 2 hours OGTT glucose concentration as well as in the fructosamine concentration are parallelled by a rise in LGA incidence over the entire range of tested values.

Contribution of fructosamine concentration and $2 h$ OGTT glucose concentration to the variation in birth weight ratio

The relationship of BWR with fructosamine and $2 \mathrm{~h}$ OGTT glucose concentrations was further studied by multiple linear regression analysis. By this method the independent contribution to the BWR of several relevant environmental influences in foetal growth, including fructosamine and $2 \mathrm{~h}$ OGTT glucose, could be determined (see also part 1). The results are listed in table 7.7. The analysis demonstrated that of the variation in BWR in this population, $12.1 \%$ was attributable to smoking. In contrast to what was observed in the total population (table 7.4), the contribution of the weights of mother and father to the variation in BWR was not significant. This may be the result of the smaller sample size ( 69 vs 254 in total population). The variation in fructosamine concentrations could explain $5.8 \%$ of the variation in BWR, with no additional contribution from the $2 \mathrm{~h}$ OGTT glucose concentration.

Table 7.7 Multiple linear regression analysis with some environmental factors known to influence foetal growth including fructosiamine and $2 \mathrm{~h}$ OGTT glucose concentrations as independent variables, and $B W R$ as the dependent variable $(n=69)$

\begin{tabular}{lll}
\hline & $\begin{array}{l}\text { Explained } \\
\text { variation } \\
\text { in BWR } \\
\left(\mathrm{R}^{2}\right)\end{array}$ & p-walue \\
\hline $\begin{array}{l}\text { Smoking } \\
\text { Weight of the mother }\end{array}$ & $12.1 \%$ & $<0.005$ \\
Weight of the father & - & - \\
Fructosamine & $5.8 \%$ & $<0.05$ \\
\hline 2h glucose OGTT & - & -
\end{tabular}

\section{Discussion}

The screening value of fructosamine, of the OGTT, and of these two tests combined, for identifying patients at risk for the sequelae of hyperglycaemia, was evaluated in a selected high-risk population. The incidence of neonatal hypoglycaemia, hyperbilirubinaemia and RDS in this subpopulation was as low as in the original study sample. The low incidence of these neonatal complications - which are known 
to occur more frequently in the offspring of hyperglycaemic mothers (Kitzmiller, 1978; Gabbe et al., 1977; Landon and Gabbe, 1985) - implies that it was not possible to discern a relationship with these neonatal complications. The low incidence of neonatal complications requires some further explanation. Neonatal hypoglycaemia, preferably in combination with an LGA birth, can be considered as the most certain sign of maternal hyperglycaemia during late pregnancy. In our original population neonatal hypoglycaemia was observed a total of eight times, with a high likelihood of preceding maternal hyperglycaemia (as suggested by the birth of an LGA infant) only in one occasion. If neonatal hypoglycaemia were indeed a major complication of gestational diabetes, a higher incidence in our high-risk population should have emerged. In fact, our approach to screening for gestationall diabetes has been reported to be inadequate since at least $50 \%$ of our gestational diabetics may remain undetected (Lavin, 1985). On the other hand, none of the missed cases developed the typical neonatal complications, whereas only one of 78 LGA infants developed hypoglycaemia in the immediate post-partum period. The mother of this infant had a normal OGTT and a fructosamine above $2.30 \mathrm{mmol} / \mathrm{l}$. It follows that even in our presumed high-risk population neonatal hypoglycaemia did not present itself as a major complication.

Although the incidence of the typical neonatal complications in the OGTT subgroup was as low as in the total population, 30 patients of this group gave birth to an LGA infant, which is almost twice as high as the rate in the total population $₫ 18 \%$ vs $10 \%$ ). As has been discussed before, an LGA birth does not always reflect the presence of excessive transplacental glucose supply. By definition, LGA represents a 10\% fraction of the biological spectrum of birth weights which, among others, includes macrosomia due to maternal hyperglycaemia. Nevertheless, it is generally accepted that excessive transplacental foetal glucose supply occurs more often in an LGA than in an AGA subpopulation (Langer and Mazze, 1988). Thus, the higher incidence of LGA birth in our OGTT subpopulation could indicate an increased fractional contribution of glucose-related overgrowth. Since both fructosamine measurement and OGTT outcome reflect different aspects of hyperglycaemia, we investigated the screening value for subsequent LGA births of each of these two parameters separately as well as the screening value of the two tests combined. In patients with an abnormal OGTT the incidence of LGA birth was no higher than in patients with a normal OGTT. The pattern of the $2 \mathrm{~h}$ OGTT glucose ROC-curve shown in figure 7.4 suggests that diet and/or insulin therapy had little effect on the incidence of LGA birth. As there is no sudden increase of foetal overgrowth at the cut-off value of $7.8 \mathrm{mmol} / \mathrm{l}$ (Weiner, 1988) and since all patients with a glucose concentration above this value were treated, a possible growth regulating effect of diet and/or insulin should have resulted in a fall in the incidence of LGA birth around this cut-off value. The smooth pattern of the ROC-curve around the $7.8 \mathrm{mmol} / \mathrm{h} \mathrm{cut-}$ off value makes such a presumed growth regulating effect of a diet and/or insulin in our population unlikely. However, in this respect it should be stressed that 
the limited number of cases does not allow firm conclusions on this matter. The limited value of the OGTT for predicting LGA births is also supported by the lack of an independent contribution of the $2 \mathrm{~h}$ OGTT glucose concentration to the variation in BWR, although a possible weak effect of the $2 \mathrm{~h}$ OGTT glucose concentration in the regression may have remained undetected due to the limited number of patients in the OGTT subgroup. This is supported by the concomitant inability of both maternal weight and weight of the father to contribute to the variation in BWR.

Although the incidence of LGA birth seemed to be higher in patients with high fructosamine concentrations ( $>2.30 \mathrm{mmol} / \mathrm{l}$ ) than in patients with normal fructosamine concentrations ( $30 \%$ and $14 \%$, respectively), this difference was not significant. The limited value of fructosamine measurement for predicting LGA births is further supported by the ROC curve pattern. At any cut-off point for fructosamine, the value of fructosamine measurement for predicting LGA births was poor (figure 7.4). Apparently, in the high-risk group the four times higher contribution of the fructosamine concentration to the variation in BWR (5.8\% vs $1.4 \%$ ) did not raise the value of fructosamine measurement as a screening test for LGA infants.

Although both OGTT and fructosamine alone had low predictive values for identifying LGA infants, the value of the combination of the two tests was definitely better than that of each test separately. Gestational diabetics with fructosamine concentrations above $2.30 \mathrm{mmol} / \mathrm{l}$ were delivered 7 times more often of an LGA infant than those with fructosamine concentrations below $2.30 \mathrm{mmol} / \mathrm{l}$. This could not be attributed to differences in treatment between the two groups since treatments with diet and insulin were evenlly distributed over the two groups. The apparently good performance of the combination of OGTT and fructosamine is illustrated in figure 7.5 for a set of fructosamine and $2 \mathrm{~h}$ OGTT glucose values as well as in figure 7.4 as a ROC curve for the subpopulation of gestational diabetics. In spite of the fact that the latter curve was only based on the results of 6 LGA infants, the favourable pattern of the curve suggests that at least in these 6 patients foetal overgrowth was most likely caused by excessive glucose supply due to maternal hyperglyaemia. However, LGA birth alone is too crude to serve as solid proof of preceding excess transplacental glucose supply.

The small proportion of LGA infants, 6 of 30 , which were picked up by using the result of the OGTT and fructosamine combined, may also be an indication of the low incidence of maternal hyperglycaemia which was severe enough to cause LGA birth. We have already expressed our surprise about finding such a low typical morbidity with our (presumably) inadequate screening practice. A low fractional contribution of maternal hyperglycaemia to the LGA subpopulation would confirm that the majority of the LGA newborns are large as a result of environmental, nutritional or genetic factors. Although the lack of a more sensitive indicator of excess glucose supply to the foetus complicates the discussion, the low incidence of hyperglycaemia-related neonatal morbidity supports the concept that until now the clinical need to identify patients with gestational diabetes in this particular population is questionable. 
In summary, even in a presumed high-risk population, both fructosamine and OCTT evaluated as independent variables were insensitive in predicting either neonatal complications of maternal hyperglycaemia or LGA births. However, the combination of fructosamine concentration and outcome of an OGTT gave rise to an interesting increase in predictive value for subsequent birth of an LGA infant.

\section{References}

Adashi EY, Pinto H, Tyson JE. Impact of maternall euglycemia on fetal outcome in diabetic pregnancy. Am J Obstet Gynec 133: 268-274, 1979.

Brown AK. Jaundice and hyperbilirubinemia in the newborn infant.

In: Nelson WE (ed). Textbook of pedfatrics. WB Saunders Company, Philadelphia: 442-449, 1979.

Coustan DR, Immarah J. Prophylactic insulin treatment of gestational diabetes reduces the incidence of macrosomia, operative delivery, and birth trauma.

Am J Obstet Gynecol 150: 836-842, 1984.

Daubresse $J C_{\text {, Laurent }} \mathbf{E}$, Ligny $\mathbf{C}$, et al. The usefulness of fructosamine determination in diabetic patients and its relation to metabolic control.

Diabete Metab 13: 217.221, 1987.

Gabbe SG, Mestman JH, Freeman RK, Anderson GV, Lowensohn RI. Management and outcome of class A diabetes mellitus.

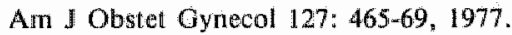

Garrow IS. Treat obesity seriously: a clinical manual.

Churchill Livingstone, Edinburgh, London, Melbourne, New York, $₫ 981$.

Hindle EJ, Rostron GM, Clark SA, Gatt JA. Serum fructosamine and glycatted haemoglobin measurements in diabetic control.

Arch Dis Childhood 61: 113-117, 1986

Kitzmiller $\mathrm{JL}_{\text {, }}$ Cloherty JP, Younger MD, et al. Diabetic pregnancy and perinatal morbidity.

An J Obstet Gynecol 131: 560-580, 1978.

Kloosterman GJ. On intraterine growih. The significance of prenatal care.

Int J Gynaecol Obstet 8: 895-912, 1970.

Langer $\mathbf{O}$, Mazze $\mathbf{R}$. The relationship between large-for-gestationalage unfants and glycemic control in women with gestational diabetes.

Am I Obstet Gynecol 159: 1478-1483, 1988.

Landon MB, Gabbe SG. Antepartim fetal surveillance in gestational diabetes mellitus.

Dimbetes 34 (suppl 2): 50-54, 1985.

Landon MB, Gabbe SG, Piana R, Mennuti MT, Main EK. Neonatal morbidity in pregnancy complicated by diabetes mellitus: Predictive value of maternal glycemic profiles.

Am J Obstel Gynee 156: 1089-1095, 1987. 
Lavin JP. Sereening of high-risk and general population for gestational diabetes. Clincal application and cost analysis.

Diabetes 34 (suppl 2): 24-27, 1985.

Lind T, Anderson J. Does random blood glucose sampling outdate testing for glycosuria in the detection of diabetes during pregnancy?

Br Med J 289: 1569-1571, 1984.

Nasrat AA, Johnstone FD, Hasan SAM. Is random plasma glucose an efficient screening test for albnormal glucose tolerance in pregnancy?

Br J Obstet Gynaecol 95: 855-860, 1988.

Pedersen J. The pregnant diabetic and her newborn. 2nd edition.

Munksgaard, Copenhagen: 34-66, 1977.

Richardson DK, Schwartz JS, Weinbaum PJ, Gabbe SG. Diagnostic tests in obstetrics: A method for improved evaluation.

Am J Obstet Gynecol 152: 613-618, 1985.

Roberts AB, Baker JR. Relationship between fetal growth and maternal fructosamine in diabetic pregnancy.

Obstet Gynecoll 70: 242-246, 1987.

Roberts AB, Baker JR, James AJ, Henley P. Fructosamine in the managenent of gestational diabetes. Am J Obstet Gynecol 159: 66-71, 1988.

Sackett DL, Haynes RB, Tugwell P. Clinical epidemiology.

Little Brown Company, Boston, Toronto: 101-106, 1985.

Second international workshop-conference on gestational diabetes summary and Recommendations. Diabetes 34 (suppl 2): $123-126,1985$.

Staley MJ, Murray-Arthur F. Plasma fructosamine in non-diabetic pregnancy.

Bir J Obstet Gynaecol 95: 265-270, 1988.

Weiner CP. Effect of varying degrees of 'normal' glucose metabolism on maternal and perinatal outcome.

An J Obstet Gynecol 159:862-870, 1988.

WHO. Diabetes mellitus, Report of a WHO study group.

World Health Organization, Genewa. Technical report series $727,1985$. 



\section{Chapter 8}

\section{Summary and conclusions}

Ever since diabetes mellitus became treatable, control of therapy and course of the disease has been an important subject of study. As the disease is primarily characterized by glucose intolerance, the control parameter most widely accepted in clinical practice has been the intermittant evaluation of blood glucose concentration: However, both in healthy persons and in patients suffering from diabetes mellitus, glucose values may vary over a wide range throughout the day, particularly with respect to time and composition of meals. This implies that evaluation of the disease on the basis of blood glucose values alone is hampered; stringent standardization of glucose measurement conditions is necessary.

With the discovery that measurement of the glycated proteins could serve as an alternative to repeated glucose measurements, a method free of interference by shortterm fluctuations in glucose concentration was evolved. The concentration of glycated proteins in the patient's blood has been found to provide a reliable estimate of the average glucose concentration over the preceding weeks. In fact, the measurement of one of these glycated proteins, the glycated haemoglobin $\left(\mathrm{HbA}_{1}\right)$, is nowadays commonly used in the monitoring of glycaemic control.

Several years ago, the measurement the glycated serum proteins also became interesting for the glycaemic control in diabetics, particularly with the introduction of the highly practicable "fructosamine assay'. $\mathrm{HbA}_{1}$ and fructosamine measurements were found to be complementary to each other rather than alternatives, a direct consequence of their different half-lives. The fructosamine concentration serves as an indirect estimate of the mean glucose concentration over a preceding period of 1-3 weeks, whereas the $\mathrm{HbA}$ concentration reflects the average glucose level over a period of 6-10 weeks.

The study described in this thesis was designed to evaluate the possibilities and limitations of fructosamine as an estimate of the glycaemic status in various clinical conditions. If appropriate, fructosamine data were compared with $\mathrm{HbA}_{1}$ values.

In chapter 1 a general introduction is given on the importance of glycaemic control and the methods employed for its assessment in both pregnant and non-pregnant subjects.

In chapter 2 the literature on non-enzymatic glycation of proteins is reviewed. In the first part of this chapter some chemical aspects of the non-enzymatic glycation of proteins are described. The second and third parts focus on non-enzymatic glycation of haemoglobin $\left(\mathrm{HbA}_{1}\right)$ and non-enzymatic glycation of serum proteins. With 
respect to the latter, extra emphasis is put upon its measurement by the fructosamine assay. In the last part of this chapter, the non-enzymatic glycation of proteins other than haemoglobin and serum proteins is discussed. It is stressed that enhanced nonenzymatic glycation may interfere with many physiological processes in the body, for instance through the accelerated formation of irreversible glycation end products in vessel walls. This phenomenon may play an important role in the pathogenesis of most long-term diabetic complications.

In chapter 3 the principles and characteristics of the fructosamine assay are evaluated. The intra- and inter-assay variations were very low. The fructosamine concentration of serum that had been stored at $-20^{\circ} \mathrm{C}$ for an extended period appeared to be stable for at least one year and its use as a (secondary) standard with proper matrix is recommended.

In 103 non-diabetic patients the relation between fructosamine and serum proteins was studied. The serum fructosamine concentration correlated with the albumin and total serum protein concentration. A decrease in albumin by $1 \mathrm{~g} / 1$ was parallelled by a fall in the fructosamine concentration by $0.026 \mathrm{mmol} / \mathrm{l}$. Because of the small adjustment (1\% per gram albumin), correction of the fructosamine concentration is only recommended when the serum albumin concentration differs by more than $10 \mathrm{~g} / \mathrm{l}$ from the reference value.

In addition, it was confirmed that the fructosamine concentration does not change in response to short-term glucose fluctuations, such as occur during the OGTT. Blood for fructosamine measurement can therefore be sampled irrespective of the time of previous meals.

For the purpose of evaluating quality of glycaemic control, the value of fructosamine measurement is compared with that of $\mathrm{HbA}_{\|}$in chapter 4 . In 180 elderly non-insulin dependent diabetics (NIDDM) a correlation was found between the glucose concentration 2 hours after breakfast on the one hand, and fructosamine and $\mathrm{HbA}_{1}$ concentrations on the other. In this study, the fructosamine concentration correlated also with the $\mathrm{HbA}_{1}$ concentration. The correlation between fructosamine and thi other two variables did not improve by correcting the fructosamine concentration for the albumin concentration. From these data and those reported. in the literature reviewed it was concluded that in NIDDM subjects fructosamine measurement is an attractive alternative to $\mathrm{HbA}_{1}$ determination, particularly when glucose control is to be evaluated over a preceding period of up to 4 weeks.

In chapter 5 the value of fructosamine and $\mathrm{HbA}_{1}$ measurement as screening and diagnostic tests for impaired glucose tolerance, diabetes mellitus and gestational diabetes is described. Glucose tolerance was tested by $75 \mathrm{~g}$ OGTTs. In a group of 312 non-pregnant patients suspected of diabetes mellitus, the fructosamine and $\mathrm{HbA}_{1}$ concentrations were higher in patients with impaired glucose tolerance or diabetes mellitus than in patients whose glucose tolerance was normal. The value of fructosa- 
mine and $\mathrm{HbA}_{1}$ measurements as screening tests for impaired glucose tolerance and diabetes mellitus could be demonstrated by receiver operating characteristic curves. However, the diagnostic value of these tests for impaired glucose tolerance or diabetes mellitus was disappointing.

In a group of 250 pregnant patients suspected of gestational diabetes, it was demonstrated that both fructosamine and $\mathrm{HbA}$, measurements lacked screening and diagnostic power with respect to gestational diabetes.

The patterns in fructosamine and $\mathrm{HbA}_{1}$ concentrations throughout pregnancy are reported in chapter 6 . In 276 patients with a normal OGTT in pregnancy, a small but significant decrease in fructosamine was observed. This change appeared to be attributable to a concomitant decrease in the albumin concentration. When the fructosamine concentration was corrected for the albumin concentration, the fructosamine concentration varied independently of gestational age. The decrease of the fructosamine concentration during pregnancy was so small that correction for albumin concentration or gestational age in the clinical setting seemed trivial.

In the course of pregnancy the $\mathrm{HbA}_{1}$ concentrations as measured by two different techniques varied independently of the gestational age. Apart from that, the $\mathrm{HbA}$, concentrations measured by the chromatographic column method (Biorad) were sys tematically higher than those measured with the electrophoretic method (Corning). It was demonstrated that glucose tolerance decreased during pregnancy, as indicated by an increase in the area under the OGTT-curve $(+17 \%)$ and in the $2 \mathrm{~h}$ OGTT glucose concentration $(+24 \%)$. On the other hand, the fasting glucose concentration decreased by $10 \%$. Balance between these two features with opposite effects on the concentration of glycated proteins may explain why fructosamine and $\mathrm{HbA}_{1}$ concentrations in normal pregnancy change little.

In chapter 7 the value of fructosamine measurement in pregnancy for the prediction of hyperglycaemia-related adverse neonatal outcome and large-for-gestational-age (LGA) births is described. In 765 consecutive pregnant patients the birth weight ratio (BWR) was higher in the of fspring of patients in whom fructosamine concentrations in pregnancy had been higher than $2.30 \mathrm{mmol} / \mathrm{l}$. In the of tients the incidence of hypoglycaemia, hyperbilirubinaemia and respiratory distress syndrome was not increased.

Although the BWR did vary as a function of the fructosamine concentration, only $1.4 \%$ of the variation in BWR was attributable to variation in the fructosamine concentration; this contribution was clearly lower than that of influences such as smoking $(10 \%)$, and weights of the infant's mother $(6.5 \%)$ and father $(2.8 \%)$. Analysing the results by receiver operating characteristic curves confirmed the limited screening value of fructosamine measurements for identifying patients who were to give birth to an LGA infant. It is concluded that in an unselected population fructosamine measurement is an insensitive method for predicting neonatal complications of maternal hyperglycaemia and LGA births. 
A subpopulation of 175 patients from the original study sample was selected on the basis of clinical risk factors for gestational diabetes. The presence of these risk factors was reason to subject these women to a $75 \mathrm{~g}$ oral glucose tolerance test (OGTT). In this selected population both the fructosamine concentration alone and the combination of fructosamine concentration and OGTT outcome had a poor screening value for patients whose offspring was destined to develop complications such as hypoglycaemia, hyperbilirubinaemia, or respiratory distress syndrome. The higher contribution of the fructosamine concentration to the variation in BWR in this subpopulation $(5.8 \%)$ relative to that in the unselected population (1.4\%) did not raise the independent screening value of the fructosamine measurement with respect to predicting LGA births. However, when fructosamine measurement was used in combination with the outcome of the OGTT, the predicting value for the subsequent birth of an LGA infant definitely increased.

In short, it is concluded that:

1. Fructosamine measurement is comparable to that of $\mathrm{HbA}_{1}$ with respect to monitoring the recent glycaemic status in NIDDM patients.

2. Fructosamine and/or $\mathrm{HbA}_{i}$ measurements have screening potential but no diagnostic value with respect to diabetes mellitus; the tests are insensitive as screening tests for gestational diabetes.

3. The fructosamine concentration increases the value of an OGTT for identifying pregnant patients with a higher likelihood of giving birth to an LGA infant. 


\section{Samenvatting en conclusies}

Diabetes mellitus is een ziekte met als voornaamste kenmerk abnormale glucoseconcentraties in het bloed van de patiënt. Bepaling van de hoogte van de glucoseconcentratie is daarom een belangrijke maatstaf voor de beoordeling van de therapie en het verloop van de ziekte. Bij gezonde personen, maar vooral bij patiënten met diabetes mellitus kan de glucoseconcentratie binnen een kort tijdsbestek (uren) flink schommelen. Deze schommelingen zijn met name gerelateerd aan het tijdstip en de samenstelling van de maaltijden. Het glucosegehalte van het bloed is daarom alleen bruikbaar als parameter bij het beoordelen van behandeling en beloop van de ziekte als de meting ervan onder streng gestandaardiseerde condities plaatsvindt.

Met de ontdekking van de mogelijkheid om het gehalte van niet-enzymatisch geglyceerde eiwitten te gebruiken als maatstaf voor de gemiddelde glucoseconcentratie in de voorafgaande periode (weken), kwam een parameter voor glucoseregulatie ter beschikking die onafhankelijk is van kortdurende schommelingen van het glucosegehalte. Van de bepalingen van geglyceerde eiwitten is die van geglyceerd haemoglobine $\left(\mathrm{HbA}_{1}\right)$ als eerste praktisch toegepast. De $\mathrm{HbA}_{n}$-bepaling wordt tegenwoordig veel gebruikt voor de beoordeling van de glucoseregulering op langere termijn.

Sedert enkele jaren is er ook belangstelling voor de beoordeling van het gemiddelde glucosegehalte met behulp van de concentratie geglyceerde serumeiwitten, chemisch aangeduid als fructosamines. Hiermee kan de glucoseregulering op middellange termijn worden beoordeeld. Deze methode werd des te meer populair toen het mogelijk werd het gehalte te bepalen met de geautomatiseerde, eenvoudige en goedkope "fructosaminetest". Omdat het fructosaminegehalte een maat is voor de gemiddelde glucoseconcentratie van de voorafgaande 1-3 weken en het $\mathrm{HbA}_{1}$-gehalte een maat is voor de gemiddelde glucoseconcentratie van de voorafgaande 6-10 weken, kunnen de tests als complementair worden beschouwd.

Het onderzoek dat in dit proefschrift is beschreven had als doel de mogelijkheden en beperkingen van de fructosaminebepaling, als maat voor het gemiddelde glucosegehalte, te evalueren in verscheidene klinische omstandigheden waar een veranderd glucosemetabolisme een rol speelt, zoals bij diabetes mellitus en bij verminderde glucosetolerantie tijdens de zwangerschap. De resultaten van de fructosaminebepalingen werden meestal vergeleken met die van $\mathrm{HbA}_{1}$-metingen.

In hoofdstuk 1 wordt in een algemene inleiding het belang van glucoseregulering besproken bij zowel zwangeren als niet-zwangeren. Tevens worden de methoden beschreven waarmee de glucoseregulatie geëvalueerd kan worden.

In hoofdstuk 2 wordt een overzicht gegeven van literatuur die betrekking heeft op niet-enzymatische glycering van eiwitten. Na een korte bespreking van enkele chemische aspecten van de reactie tussen suikers en eiwitten wordt met name aandacht besteed aan de niet-enzymatische glycering van haemoglobine en serumeiwitten. 
Meer in het bijzonder wordt de bepaling van geglyceerde serumeiwitten met de fructosaminetest besproken. In het laatste deel wan dit hoofdstuk wordt ingegaan op de niet-enzymatische glycering van andere eiwitten. Uit de literatuur blijkt dat toegenomen niet-enzymatische glycering van eiwitten door verhoogde glucoseconcentraties diverse fysiologische processen in het lichaam nadelig beïnvloedt en dat bijvoorbeeld in de vaatwand de vorming van irreversibele eindproducten van glycatie wordt versneld. Het leidt geen twijfel dat de niet-enzymatische glycatie van eiwitten centraal stat in de pathogenese van de meeste chronische complicaties van diabetes mellitus.

In hoofdstuk 3 worden eigen onderzoekingen met betrekking tot het principe en de kenmerken van de fructosaminetest beschreven. De intra- en interrun variaties waren laag. Tevens bleek dat het fructosaminegehalte van diepgevroren serum gedurende tenminste een jaar stabiel was; bij $-20^{\circ} \mathrm{C}$ bewaard zogenaamd "poolserum" is daarom een goede (secundaire) bepalingsstandaard.

De invloed van het serumeiwitgehalte op de fructosaminevorming werd bij 103 nietdiabetische patiënten onderzocht. Het fructosaminegehalte bleek te correleren met zowel het albumine- als het totale serumeiwitgehalte. Een albumine daling van $1 \mathrm{~g} / 1$ ging gepaard met een daling van het fructosaminegehalte met $0.026 \mathrm{mmol} / \mathrm{l}$. In de praktijk is correctie van de fructosamineconcentratie voor de albumineconcentratie, in verband met de relatief kleine aanpassing ( $1 \%$ per gram albumineverschil) en het ermee invoeren van een nieuwe variabele met een extra bepalingsonnauwkeurigheid (albumine), alleen zinvol wanneer de albumineconcentratie meer dan $10 \mathrm{~g} / \mathrm{l}$ van de referentiewaarde afwijkt.

Voorts werd bevestigd dat het fructosaminegehalte onafhankelijk is van snelle en soms sterke variaties van de glucoseconcentratie zoals die optreden na glucosebelasting bij een orale glucosetolerantie test (OGTT). Bloed voor de fructosaminemeting kan daarom, in tegenstelling tot bloed voor glucosebepaling (en sommige $\mathrm{HbA}_{1}$-bepalingen), onafhankelijk van het tijdstip van de maaltijd worden afgenomen; analyseresultaten worden niet erdoor beïnvloed.

De waarde van de fructosaminemeting alls parameter voor de controle van de glucoseregulering wordt in hoofdstuk 4 vergeleken met die van de $\mathrm{HbA}_{1}$-bepaling. Bij 180 patiënten met niet-insuline-afhankelijke diabetes mellitus werd een goede correlatie gevonden tussen de glucoseconcentratie 2 uur na het ontbijt enerzijds, en het fructosamine- en $\mathrm{HbA}_{1}$-gehalte anderzijds. De fructosamine- en $\mathrm{HbA}_{1}$-gehalten waren ook met elkaar gecorreleerd. De mate van correlatie werd niet versterkt door correctie van het fructosaminegehalte voor de albumineconcentratie. Aan de hand van deze resultaten en gegevens uit de literatuur wordt geconcludeerd dat voor de controle van de glucoseregulering gedurende de aan de bloedafname voorafgaande 4 weken, het fructosaminegehalte een goed alternatief is voor het $\mathrm{HbA}_{\mid}$-gehalte bij patiènten met niet-insuline-afhankelijke diabetes mellitus. 
De waarde van de fructosamine- en $\mathrm{HbA}_{1}$-meting als screenings-en diagnostische test voor verminderde glucosetolerantie, diabetes mellitus en zwangerschapsdiabetes werd onderzocht en beschreven in hoofdstuk 5 . Bij een groep van 312 patiënten, verdacht van diabetes mellitus, werd de $75 \mathrm{~g}$ OGTT (WHO criteria) gebruikt als standaard-test voor de bepaling van de glucosetolerantie. Bij patiënten met verminderde glucosetolerantie of diabetes mellitus werd een significant hoger fructosamine- en $\mathrm{HbA}_{1}$-gehalte gevonden dan bij patiënten met een normale glucosetolerantie. Door analyse van de gegevens met "receiver operating characteristic curves" kon worden aangetoond dat de fructosamine- en $\mathrm{HbA}_{1}$-bepaling een zekere screeningswaarde hebben voor verminderde glucosetolerantie en diabetes mellitus. De tests bleken echter ongeschikt te zijn als diagnostische methoden voor verminderde glucosetolerantie of diabetes mellitus.

Bij een groep van 250 zwangere patiënten bleek noch de fructosamine- noch de $\mathrm{HbA}_{1}$-bepaling van waarde te zijn als screenings- of diagnostische test voor zwangerschapsdiabetes. Bij deze conclusies speelt uiteraard ook de soms niet eenduidige uitslag van de OGTT een rol.

In hoofdstuk 6 wordt de invloed van de zwangerschap op het fructosamine- en $\mathrm{HbA}_{1}$-gehalte beschreven. In een groep van 276 patiënten met een normale OGTT werd in het verloop van de zwangerschap een kleine doch significante daling gevonden van het fructosaminegehalte. Deze verandering kon verklaard worden door de met haemodilutie gepaard gaande daling van het albuminegehalte tijdens de zwangerschap. Na correctie van het fructosaminegehalte voor het albuminegehalte bleek het (gecorrigeerde) fructosaminegehalte niet meer significant te veranderen met de zwangerschapsduur. Overigens was de daling van het fructosaminegehalte tijdens de zwangerschap zo klein, dat correctie voor zwangerschapsduur of albuminegehalte in de dagelijkse praktijk van de klinische geneeskunde overbodig is.

Het $\mathrm{HbA}_{1}$-gehalte, gemeten met twee verschillende methoden, veranderde niet in het verloop van de zwangerschap. Wel waren de $\mathrm{HbA}_{1}$-gehalten die bepaald werden met een chromatografische kolommethode (Biorad) steeds hoger dan clie welke gemeten werden met een electrophoretische methode (Corning).

In het verloop van de zwangerschap bleek er een daling op te treden van de glucosetolerantie, gemeten aan een toename van de oppervlakte onder de OGTT curve met $17 \%$ en een stijging van de 2 -uurs glucosewaarde van de OGTT met $24 \%$. Daarentegen daalde de nuchtere glucosewaarde met $10 \%$. Tijdens de normale zwangerschap zal een evenwicht tussen deze twee mechanismen, die een tegengesteld effect hebben op de gemiddelde glucose concentratie, resulteren in stabiele fructosamine- en $\mathrm{HbA}_{1}$-gehalten.

Voorts werd onderzoek verricht naar de waarde van de fructosaminebepaling in de zwangerschap voor het opsporen van patiënten van wie de pasgeborenen complicaties krijgen die gerelateerd zijn aan verhoogde glucosespiegels bij de moeder. De resultaten zijn vermeld in hoofdstuk 7 . In een populatie van 765 zwangeren bleek de 
"birth weight ratio" (BWR, relatieve geboortegewicht) significant hoger te zijn bij pasgeborenen van patiënten met een fructosaminegehalte in de zwangerschap boven $2.30 \mathrm{mmol} / \mathrm{l}$. De incidentie van hypoglycaemie, hyperbilirubinaemie en het respiratory distress syndroom was bij de pasgeborenen van deze patiënten niet verhoogd. Ondanks het feit dat de BWR varieerde met het fructosaminegehalte, kon slechts $1.4 \%$ van de variatie in BWR verklaard worden door variatie in de fructosamineconcentratie. Veel groter was de invloed van roken door de moeder op de variatie in BWR $(10 \%)$. Ook het gewicht van de moeder $(6.5 \%)$ en vader $(2.8 \%)$ van het kind droegen bij tot de wariatie in BWR. De beperkte waarde van de fructosaminebepaling voor het vroegtijdig opsporen van zwangeren die een kind met een overgewicht zouden krijgen, werd bevestigd door analyse van de gegevens met "receiver operating characteristic curves". Geconcludeerd wordt dat de fructosaminebepaling in een niet-geselecteerde populatie een te ongevoelige methode is om overgewicht en/of complicaties bij de pasgeborene te voorspellen die het gevolg kunnen zijn van vèrhoogde glucosespiegels bij de moeder.

Nader onderzoek werd nog gedaan bij 175 patiënten uit de oorspronkelijke populatie van 765 zwangeren. $\mathrm{Zij}$ werden geselecteerd op basis van klinische risico-factoren voor zwangerschapsdiabetes en bij hen werd een OGTT verricht. In deze geselecteerde populatie bleek het niet mogelijk op basis van het fructosaminegehalte alleen, noch met de combinatie van fructosaminegehalte en resultaat van de OGTT patiënten op te sporen waarvan de pasgeborenen hypoglycaemie, hyperbilirubinaemie of het respiratory distress syndroom ontwikkelden. Ondanks een hogere bijdrage van het fructosaminegehalte tot de variatie in de BWR in deze subpopulatie $(5.8 \%)$ vergeleken met de bijdrage in de oorspronkelijke populatie $(1.4 \%)$, verbeterde de voorspellende waarde van de fructosaminebepaling voor de geboorte van een kind met overgewicht niet. Echter bij combinatie van het fructosaminegehalte met het resultaat van de OGTT bleek de voorspellende waarde voor de latere geboorte van een kind met overgewicht duidelijk toe te nemen.

Samenvattend wordt het volgende geconcludeerd:

1. Voor de controle van de glucoseregulering gedurende de voorafgaande 4 weken bij patiënten met niet-insuline-afhankelijke diabetes mellitus is de waarde van de fructosaminebepaling gelijk aan die van $\mathrm{HbA}_{1}$.

2. De fructosamine-en/of $\mathrm{HbA}_{1}$-bepaling hebben wel screeningswaarde doch geen diagnostische waarde voor diabetes mellitus; de tests hebben geen screeningswaarde voor zwangerschapsdiabetes.

3. Het fructosaminegehalte tijdens de zwangerschap verhoogt de voorspellende waarde van de OGTT met betrekking tot de geboorte van een kind met overgewicht (LGA). 


\section{Curriculum vitae}

De schrijver van dit proefschrift werd op 6 november 1953 in Maastricht geboren. In 1971 behaalde hij het diploma H.B.S.-B aan het Bisschoppelijk College te Roermond. De studie geneeskunde werd gevolgd aan de Katholieke Universiteit Nijmegen en op 6 juli 1979 afgesloten met het artsexamen. Vervolgens vervulde hij de militaire dienstplicht als reserve-luitenant-arts van de Koninklijke Landmacht te Oirschot. $\mathrm{Na}$ een periode van tijdelijke assistentschappen $\mathrm{kwam}$ hij in februari 1984 in opleiding tor gynaecoloog in het De Wever Ziekenhuis te Heerlen (opleider Dr. L.A. Schellekens). Het laatste anderhalf jaar van de opleiding werd gevolgd in het Academisch Ziekenhuis te Maastricht (opleider Prof.Dr. J. de Haan). Op 1 februari 1989 werd hij ingeschreven in het Specialisten Register. Van $\mid$ februari 1989 tot 1 januari 1990 werkte hij als chef de clinique in het St.Gregorius Ziekenhuis te Brunssum en het De Wever Ziekenhuis te Heerlen. Sedert 1 januari 1990 is hij in deze ziekenhuizen werkzaam als gynaecoloog in associatief verband met Dr. J.M.H. Ubachs, Dr. J.E.G.M. Stoot, J.A. Zandwoort, J.E.M. Degen en Dr. M.J. Heineman. Hij is gehuwd en vader van een zoon. 
Met dank aan:

Srichting Dr.Ir.J.H.J. van de Laar Haffmann-La Roche B. $V$.

Organon Nederland B. $V$.

Schering Nederland B.V.

Pie Medical B.V.

Druk: Groenevelt Landgraaf 